University of Louisville

ThinkIR: The University of Louisville's Institutional Repository

$12-2010$

\title{
The effects of collective racial esteem on African American undergraduate male involvement in public four-year institutions of higher education.
}

Michael David Anthony

University of Louisville

Follow this and additional works at: https://ir.library.louisville.edu/etd

Part of the Higher Education Commons, and the Race and Ethnicity Commons

\section{Recommended Citation}

Anthony, Michael David, "The effects of collective racial esteem on African American undergraduate male involvement in public four-year institutions of higher education." (2010). Electronic Theses and Dissertations. Paper 42.

https://doi.org/10.18297/etd/42

This Doctoral Dissertation is brought to you for free and open access by ThinkIR: The University of Louisville's Institutional Repository. It has been accepted for inclusion in Electronic Theses and Dissertations by an authorized administrator of ThinkIR: The University of Louisville's Institutional Repository. This title appears here courtesy of the author, who has retained all other copyrights. For more information, please contact thinkir@louisville.edu. 


\title{
THE EFFECTS OF COLLECTIVE RACIAL ESTEEM ON AFRICAN AMERICAN UNDERGRADUATE MALE INVOLVEMENT IN PUBLIC FOUR-YEAR INSTITUTIONS OF HIGHER EDUCATION
}

\author{
By \\ Michael David Anthony \\ B.S., North Carolina State University, 2003 \\ M.A., University of Louisville, 2005 \\ A Dissertation \\ Submitted to the Faculty of the \\ Graduate School of the University of Louisville \\ in Partial Fulfillment of the Requirements \\ for the Degree of \\ Doctor of Philosophy \\ College of Education and Human Development \\ University of Louisville \\ Louisville, Kentucky
}

December 2010 
(C) Copyright 2010

Michael D. Anthony

All rights reserved 
THE EFFECTS OF COLLECTIVE RACIAL ESTEEM ON AFRICAN AMERICAN UNDERGRADUATE MALE INVOLVEMENT IN PUBLIC FOURYEAR INSTITUTIONS OF HIGHER EDUCATION

By

Michael David Anthony

B.S., North Carolina State University, 2003

M.A., University of Louisville, 2005

A Dissertation Approved on

October 12,2010

by the following Dissertation Committee:

Dissertation Director 


\section{DEDICATION}

The completion of this life's work would not have been possible without the blessings given to me by my savior Jesus Christ. Through Him, all things have been made possible. And He has provided me with the support, love, and discipline to accomplish this and all things.

I primarily dedicate this dissertation to my little girl, Katharine Elizabeth Anthony. She is the representation of all that God has blessed me with throughout my life. She represents my loving wife and better half, Hannah, who I love and appreciate more than she knows. Katharine represents my loving family, my past, and my future. She is my mother's joy, my stepfather's peace, my brother and sisters' humor and love, my in-laws' strengths, and my grandparent's never-ending love. She represents all that is right with my life.

To all of my family (both here and gone), fraternity brothers, friends, and colleagues; from Charlotte, $\mathrm{NC}$, to Raleigh, $\mathrm{NC}$, to Kentucky and everywhere in between; I dedicate this to you. 


\section{ACKNOWLEDGEMENTS}

I first want to acknowledge Dr. Fashaad Crawford and Dr. Joseph Petrosko. These two men served as advisors, mentors, confidants, and role models throughout this process. Their influence extends across my entire post-baccalaureate experience, and I appreciate their leadership and example. Dr. Adams thank you for your constant support both academically and as a professional. Dr. Wilson, thank you for stepping in despite a number of other priorities, and while still acclimating to your role within the University of Louisville. Your insight, challenge, and support have been appreciated. Dr. Rosch, who I admire more and more everyday, thank you for agreeing to share in this experience from Illinois. Your knowledge of the MSL and passion for this work is inspiring and much appreciated. Thank you all!

I want to also acknowledge the following people and groups for your support and encouragement throughout the years: Cultural Center staff and family, Office of Civic Engagement, Leadership, and Service, Housing \& Residence Life, Community Empowerment Center, Division of Student Affairs, College of Education and Human Development, the Alpha Lambda Chapter of Alpha Phi Alpha Fraternity, Inc., Ms. Diane Whitlock, Ms. Jennifer Edwards, Dr. Michael Cuyjet, Dr. John Keedy, Dr. Sam Stringfield, Dr. Craig Hochbein, Dr. Namok Choi, Dr. John Welsh, Dr. Paul Winter, Kelly Ising, Marji Settles, Dr. Mordean Taylor-Archer, Dr. Tom Jackson, and Dr. Michael Mardis. 


\title{
ABSTRACT \\ THE EFFECTS OF COLLECTIVE RACIAL ESTEEM ON AFRICAN AMERICAN UNDERGRADUATE MALE INVOLVEMENT IN PUBLIC FOUR-YEAR INSTITUTIONS OF HIGHER EDUCATION
}

\author{
Michael David Anthony
}

October 12,2010

This dissertation examines the influence of collective racial esteem (CRE) on the quantity and type of involvement for African American male undergraduate students in public four-year institutions of higher education in the U.S. In addition, this relationship is examined to determine if differences exist across gender (male and female), and institutional variables (specifically, public HBCUs vs. public PWIs). The persistence and graduation of African American males at four-year institutions of higher education has increased in past decades, but still remains consistently and significantly lower than that of their non-African American male counterparts (Planty et al., 2009). African American male retention rates are also lower than their female counterparts of the same ethnic background. These data continue to be a reality, despite the extensive literature on African American students in college.

Using multiple regression, hierarchical logistic regression, multivariate analysis of variance (MANOVA) and multivariate analysis of covariance (MANCOVA), this exploratory research design assessed the predictive potential of CRE to certain involvement variables established by the literature on African American male undergraduates. The predictor variables included in the study were the four sub-scales of 
CRE: Private CRE, Public CRE, Identity Salience, and Membership CRE. Independent variables were gender and institutional type. The criterion variables were quantity of campus involvement, decision to join an ethnic/minority organization, and faculty and peer interaction. Dependent variables were the four sub-scales of CRE.

The study found Membership CRE to be a significant predictor of quantity of campus involvement for African American males; Identity Salience to be a significant predictor of decision to join an ethnic/minority organization for African American males; and Private CRE and Membership CRE to be a significant predictor of peer interaction for African American females. Significant differences were found between African American male and female CRE scores, and between students attending HBCUs and those attending PWIs. This study added a significant contribution to the literature for African American students by examining the effects of CRE on college involvement. This study concluded by suggesting that state-level and institutional level decision-makers should work to incorporate CRE into the design, implementation, and assessment of support services for African American students. Resources to support the enhancement of CRE should be adequately staffed and funded in the face of increasing diversity within post-secondary institutions. Individual practitioners and scholars could benefit from an understanding of CRE and its influence on student interactions and involvement, particularly at PWIs. Greater understanding of CRE could lead to more developmentally appropriate support and advising for African American students. 


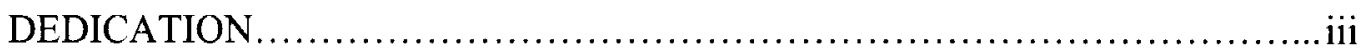

ACKNOWLEDGMENTS .................................................. iv

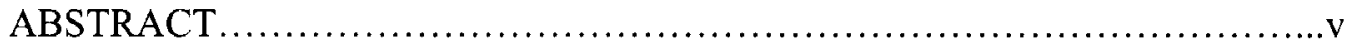

LIST OF TABLES AND FIGURES..........................................

CHAPTER

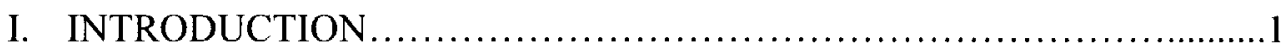

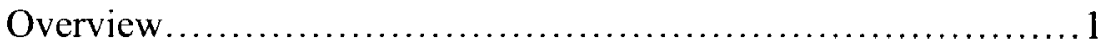

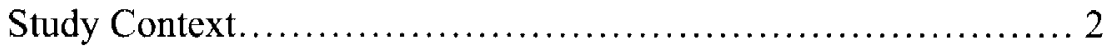

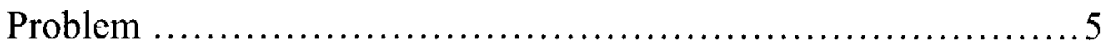

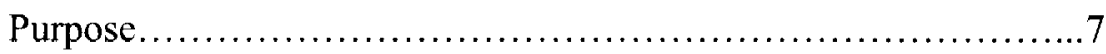

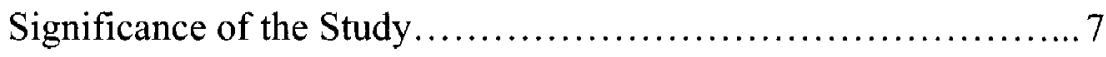

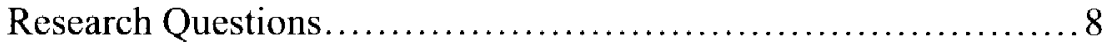

Definition of Terms.............................................. 10

Limitations ............................................... 12

Summary of Chapter I and Overview of Chapters II - V ............ 13

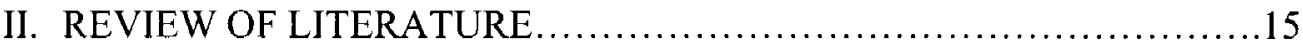

Overview.......................................................

Current Context of American Public Higher Education ............. 15

Involvement and Persistence..................................17

Persistence Frameworks.................................19

African American Involvement............................. 23 
Peer Interaction............................... 24

Faculty Interaction............................. 25

Student Organizations..........................29

Relevant Findings from the MSL ................. 32

Racial Identity Development................................. 33

Racial Identity Models................................34

Impact of Racial Identity Attitudes on African American Students............................................. 37

Involvement.................................. 37

Academic Achievement........................ 38

Critique of Racial ldentity Theories.....................40

Collective Identity and Esteem $\ldots \ldots \ldots \ldots \ldots \ldots \ldots \ldots \ldots \ldots \ldots \ldots \ldots \ldots \ldots \ldots \ldots \ldots$

Collective Self-Esteem................................43

Campus Environment and Climate..........................45

HBCUs and PWIs in Public Higher Education..............49

Predominately White Institutions................5 52

Historically Black Colleges \& Universities..........54

African American Males....................................56

Background......................................... 56

Involvement........................................... 57

Heterogeneity of African American Males.................58

Campus Environment and Climate.................... 59

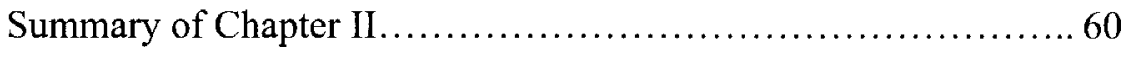

Research Questions.......................................6 63 


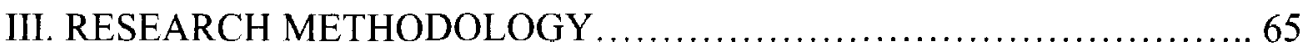

Overview..................................................65

Theoretical Framework....................................65

Research Design...........................................68

Participants...............................................69

Data Collection........................................... 70

Instrument Used in Data Collection............................ 71

Instrument Design.......................................... 72

Instrument Scales and Validity and Reliability ................. 73

Predictor Variables.......................................... 74

Criterion Variables........................................ 75

Data Analysis....................................... 77

Study Delimitations..................................... 81

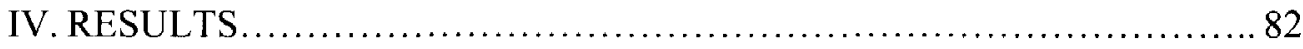

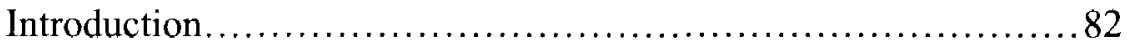

Data Collection........................................... 82

Data Analysis........................................... 83

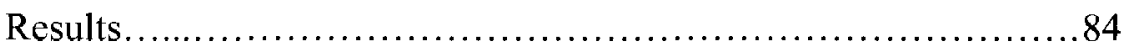

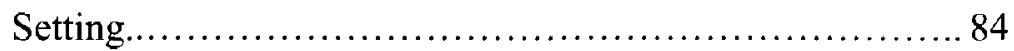

Sample............................................84

General Characteristics of the Sample.............85

African American Male Student Characteristics..... 86

Research Question 1............................... 88

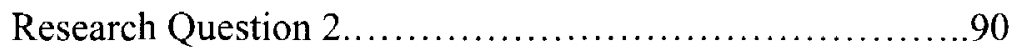

ix 
$2 b$. 92

$2 \mathrm{c}$ 94

Research Question 3................................97

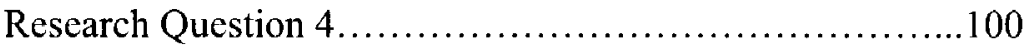

Summary of Chapter IV ...................................... 103

V. DISCUSSION, IMPLICATIONS, AND LIMITATIONS .................107

Introduction....................................................

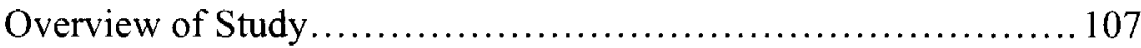

Discussion of Study Findings............................... 109

Sample Findings.....................................109

Involvement and Collective Racial Esteem...................... 110

Faculty and Peer Interaction...............................111

Gender Differences...............................114

Institutional Effects and Differences....................115

Implications for Research.....................................116

Recommendations for State-Level Practice................116

Recommendations for Institutional Practice................ 118

Recommendations for Student Involvement Practice and Research............................................ 119

Study Limitations......................................... 124

Conclusion................................................. 126

REFERENCES............................................... 129

APPENDIX A............................................. 139

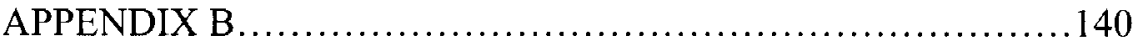

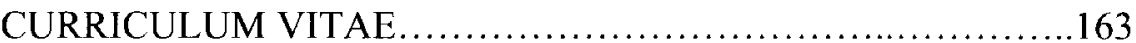




\section{LIST OF TABLES AND FIGURES}

\section{TABLES}

1. Kuh and Love (2000) Propositions vs. Tierney (1997) Five Key Points..........67

2. MSL Items Representing Peer Interaction Variable for Research Question 2c.. 76

3. Comparison of Institutional Characteristics............................. 79

4. Summary of Statistical Tests Used in Study................................. 80

5. Frequency Distributions for Gender and Class Level........................ 85

6. Frequency Distribution of Institutional Characteristics (Size, Carnegie,

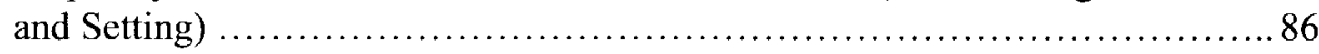

7. Frequency Distribution of African American Males (Enrollment, Class Level,

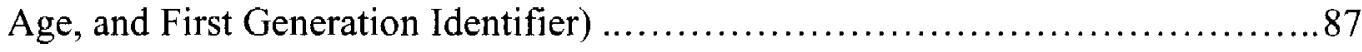

8. Research Question 1: Means and Standard Deviation for Quantity of Involvement and CRE scales for African-American males $(\mathrm{n}=390)$

9. Research Question 1: Multiple Regression Results for Prediction of Quantity of Involvement by CRE scales for African-American males.

10. Research Question 2a: Logistic Regression Results for Prediction of Decision to Join an Ethnic/Minority Organization by CRE scales for AfricanAmerican males

11. Research Question 2b: Logistic Regression Results for Prediction of Faculty Interaction (Faculty Mentor) by CRE scales for African-American males.

12. Research Question 2b: Logistic Regression Results for Prediction of Faculty Interaction (Research with a Faculty Member) by CRE scales for AfricanAmerican Males.

13. Research Question 2c: Logistic Regression Results for Peer Interaction for African American Males.

14. Research Question 2c: Logistic Regression Results for Peer Interaction:

African American Females. 
15. Research Question 3: Means and Standard Deviations for Private CRE, Public CRE, Identity Salience, and Membership CRE by Gender................ 98

16. Between-Subjects Effects of CRE and Gender.......................... 99

17. Research Question 4: Means and Standard Deviations for Private CRE, Public CRE, Identity Salience, and Membership CRE by Institutional Type........ 101

18. Between-Subjects Effects of CRE and Institutional Type...................... 102

19. Summary of Research Questions and Key Results Found for the Overall Study

\section{FIGURES}

1. Revised Input-Environment-Outcomes Model............................... 19

2. Origins of Collective Racial Esteem (CRE) ............................ 73 


\section{CHAPTER I}

\section{INTRODUCTION}

\section{Overview}

This dissertation will examine the influence of collective racial esteem (CRE) on the quantity and type of involvement for African American male undergraduate students in public four-year institutions of higher education in the United States. This dissertation also focuses on the differences in CRE scores for African American males compared to African American females, and African American males attending a predominately White institution (PWI) versus African American males attending a historically Black college and university (HBCU). Understanding and increasing student persistence continues to be a primary concern for institutions of higher education in the U.S., especially as it relates to minority students.

When delimiting the focus to African American students, persistence to degree completion remains markedly lower than their White, Hispanic, and Asian counterparts (Planty et al., 2009). Further, African American males specifically, continue to persist at lower rates than all other ethnic groups, as well as their female counterparts (Planty et al., 2009), particularly at public four-year institutions. The intersections and impact of involvement, racial identity, CRE, and campus environment on African American students will be further explored in this dissertation. What follows in this chapter is: (a) a description of the study's context, (b) statement of the research problem and purpose, (c) significance of the study, (d) research questions, (e) definitions of terms, (f) limitations of 
the study, and $(\mathrm{g})$ summary of the chapter.

\section{Study Context}

The economic impact of higher education for individuals is well documented, and the National Center for Education Statistics (NCES) reported that students with bachelor's degrees earn more than those who have an associate's degree or high school diploma. For instance, 25-34 year olds with a baccalaureate degree earned $29 \%$ more than those with an associate's degree, and 55\% more than those with only a high school diploma (Planty et al., 2009). The increased median income for highly educated individuals has also been found to be consistent across gender and racial categories. It should be noted that these data represent national trends, and that the economic advantages of bachelor degree attainment varies from state-to-state. Despite the economic advantages of attaining a bachelor's degree specifically, only about $58 \%$ of first-time students seeking a bachelor's degree in 2000-2001 completed the degree or its equivalent in six years (Planty et al., 2009).

Several institutional efforts have been undertaken at public and private institutions to increase completion rates. Graduation rates have been found to be higher at private, not-for-profit institutions $(65 \%)$ than at public four-year institutions $(55 \%)$. Between the years 2000 and 2007 undergraduate enrollment increased by $19 \%$ in public institutions of higher education in the U.S. During the same time period, there were greater gains in women enrolling in higher education than their male counterparts ( $20 \%$ vs. $16 \%$, respectively) (Planty et al., 2009). Enrollment is expected to continue to increase, with projections noting 17.5 million students $(26 \%)$ enrolled in public post-secondary institutions by 2018 (Hussar \& Bailey, 2009). This presents a challenge for the public 
sector, as more students enroll at public four-year institutions than private not-for-profit institutions (Planty et al., 2009). Public four-year institutions also tend to be more accessible for underserved populations (i.e., racial minorities, first-generation colleges students, students from low SES backgrounds) than their private counterparts. Therefore, these institutions are expected to be sensitive and responsive to the needs of African American and other underserved students.

According to the 2009 NCES Condition of Education, in $200764 \%$ of college students in the U.S. were White, and the second largest racial/ethnic group represented were African American students at 13\%. African American student make-up 14\% of student enrolled in Public 2-Year institutions, 11\% in Public 4-Year institution, 19\% in Not-for-profit 2-Year institutions, $11 \%$ in Not-for-profit 4 -Year institutions, and $26 \%$ in For-profit institutions (Planty et al., 2009). Unfortunately, African Americans have one of the lowest $(42 \%)$ retention rates of all other racial/ethnic groups, and the gap between White and African American 25- to 29-year-olds that completed bachelor's degree or higher has widened between 1971 and 2008 from $12 \%$ to $17 \%$. When considering institution attended, African Americans overwhelmingly enroll in PWIs as opposed to HBCUs, or institutions that otherwise have an African American population of $50 \%$ or greater (Minor, 2008).

State and local legislatures are increasingly asking public institutions to do more by way of preparing students for the workforce, and successfully bridging the gap between K-12 education and the workforce (Crawford, 2007). This current climate weighs heavy on the public four-year sector of higher education because of large amounts of state and federal tax dollars committed to these institutions. The current economic 
downturn has also created challenges even for those who possess a post-secondary degree. During this time of greater accountability and diminishing resources there has been emerging work targeting African American students' college experience and retention (Flowers, 2004).

In exploring what options will help improve African American student retention, student involvement has been shown to be a variable of focus in the literature. Existing research has clearly linked involvement to persistence, and other psychosocial and cognitive outcomes in college (Astin, 1993; National Survey of Student Engagement, 2009; Pascarella \& Terenzini, 2005). The research is clear: actively involved students in the classroom and out-of-the classroom gain more from college than those who are not involved (Kuh, 1991). Involvement has been shown to significantly correlate to racial identity attitudes among African American students (Taylor \& Howard-Hamilton, 1995). Racial identity represents a sense of group identity, and is based on the belief that one shares a racial heritage with a particular group (Phelps, Taylor, \& Gerard, 2001). Racial identity has been positively linked to higher levels of involvement, self-esteem, selfconcept, and academic outcomes (Awad, 2007; Lockett \& Harrell, 2003; Mitchell \& Dell, 1992).

Little research exists on the relationship between racial identity attitudes, collective self-esteem, and level of involvement in the college environment. Though selfesteem has been shown to mediate the role of racial identity in academic achievement (Lockett \& Harrell, 2003), the literature review for this dissertation yielded little in relation to collective esteem within college impact research (i.e., research on the impact of college on students). Hence, the purpose of this study is to examine the relationship 
between students' quantity and type of involvement and CRE. The data is used to better understand students' self-concept related to racial group membership (Dugan et al., 2009).

\section{Problem}

This study addresses two main issues. First is the continued lack of involvement and low persistence rates of African American males in college. Second is an examination and use of CRE as a construct in college impact research. Persistence and graduation of African American males at public four-year institutions of higher education is consistently, significantly lower than that of their White, Hispanic, and Asian counterparts. African American male retention rates are also lower than those of African American females (Planty et al., 2009). This is despite the extensive literature on African American students in college over the last several decades.

Previous literature has found that integration and involvement in the college environment is positively correlated to persistence and graduation. Involvement in college may take many forms including faculty interaction, peer interaction, and involvement in student organizations (Astin, 1993; Pascarella \& Terenzini, 1991, 2005). Cuyjet (2006) found that African American males who are involved in the college environment are more likely to integrate into the campus community, and thereby persist and eventually graduate. Research has also identified differential experiences, persistence, and graduation rates for students across different institutional types and settings.

There is a paucity of research on CRE in the literature as it relates to college student involvement and persistence. There is an abundance of literature that uses race 
and/or ethnic background as a construct to understand how students are motivated, how they behave, or if they will achieve certain outcomes. However, race/ethnic background as a construct is insufficient as a predictor of campus involvement due to changing demographics, attitudes, and backgrounds of incoming students (Helms, 2007). Helms and Cook (1999) found that racial categories serve as sociopolitical constructions that denote unequal access to resources. This inequality results in certain negative psychological consequences for individuals socialized into particular groups. Dugan, Komives, and Segar (2008) argue that despite this fact, college impact research continues to rely on these limiting dimensions of race, rather than the more complex psychological influences related to identity. One such complex psychological influence that can add much to the existing literature is CRE.

Research centering on racial identity has focused a great deal on the experiences of African American students (Cross, 1991). This line of research has also examined differences across gender within racial groups. There is, however, little research on how CRE is related to the frequency and type of campus involvement of African American students. The trend of poor graduation rates and rates of involvement for African Americans - particularly males - in higher education has persisted at secondary and postsecondary institutions. This trend continues despite numerous institutional efforts, state reform efforts, and federal initiatives to increase retention and graduation for African Americans (Crawford, 2010).

In a climate of diminishing resources and greater calls for public institutional accountability, institutions must work harder to create a climate that better understands and supports African American male experiences and factors that lead to retention. The 
problem this study addresses, therefore, is the lack of theoretical explanations hypothesizing the predictive relationships between CRE and involvement for African American undergraduate students--particularly males—in higher education institutions.

\section{Purpose}

The purpose of this study is to examine the influence of CRE on the quantity and type of involvement for African American male undergraduate students in public fouryear institutions of higher education in the U.S. In addition, this relationship will be examined to determine if differences exist across gender (male and femalc), and institutional variables (specifically, public HBCUs vs. public PWIs). CRE and involvement is measured using responses from the Multi-Institutional Study of Leadership (MSL). The instrument measured the four sub-scales of CRE: private, public, membership, and identity salience. The participants of the study are undergraduate students attending public four-year institutions in the U.S. that participated in the MSL during the Spring 2009 semester. The criterion variables for this study will include several college environmental factors that represent involvement. These factors include interaction with faculty members, interaction with peers, and involvement in student organizations. For purposes of this dissertation, student organizations are defined as extra-curricular, or co-curricular groups or clubs within institutions. Several types of involvement have been linked to persistence for African American students (Astin, 1993; Flowers, 2004; Pascarella \& Terenzini, 2005). These student organizations will be explored further in subsequent chapters.

\section{Significance of the Study}

Four factors define the significance of this study. First, this study adds clarity to 
the myriad factors influencing African American students' motivation, behavior, and involvement. Several factors have been found to contribute to positive African American student academic achievement (Parker \& Flowers, 2003), involvement in organizations (Mitchell \& Dell, 1992), racial identity development (Cross, 1991), and self-esteem (Lockett \& Harrell, 2003). None of these studies, however, have examined the unique contribution of CRE on some of these same variables. Uniquely, this study examines the mediating effect of CRE on involvement in college. Second, this study advances the discussion about African American males as it relates to involvement. The existing literature rarely disaggregates the data for African American men and women (Harper \& Quaye, 2007).

Thirdly, through the examination of CRE and its impact on involvement, this study will connect college impact research with social identity theory in a practical and theoretically appropriate manner. This will allow for more developmental programming interventions for use in and out of class for African American students in post-secondary institutions. Institutional decision-makers can analyze this study's results in order to create developmentally appropriate interventions for students on their campuses, in particular African American males. The use of CRE can provide enhanced understanding of the differences that exists within African American student populations on college campuses.

\section{Research Questions}

The research questions addressed in this study are listed below followed by null hypotheses. Details about the methodology used to test these hypotheses are found in Chapter III: 
1. Do CRE scores for African American undergraduate males significantly predict quantity of campus involvement?

Null Hypothesis 1 (H1): There is no predictive relationship among the CRE scales (membership, private, public, identity) and quantity of campus involvement.

2. Do CRE scores of African American undergraduate male students significantly predict the following:

(a) the decision to join an ethnic/minority organization;

(b) degree of interaction with faculty;

(c) degree of interaction with peers?

Null Hypothesis 2 (H2): There is no predictive relationship among the CRE scales (membership, private, public, identity) and (a) decision to join an ethnic/minority organization, (b) degree of interaction with faculty, or (c) degree of interaction with peers.

3. Research Question 3 (RQ3): Is there a statistically significant difference between African American male and African American female undergraduates' CRE scores?

Null Hypothesis 3 (H3): There is no statistically significant difference between African American male CRE scores and African American female CRE scores.

4. Research Question 4 (RQ4): Is there a statistically significant difference between undergraduate African American students' CRE scores at a PWI compared to a HBCU?

Null Hypothesis 4 (H4): There is no statistically significant difference between undergraduate African American students' CRE scores at a PWI compared to a 
HBCU.

\section{Definition of Terms}

The following definitions apply to this study:

1. Persistence: the matriculation of a student through the educational process (Tinto, 1987).

2. Involvement: the amount of physical and psychological energy that the student devotes to the academic experience (Astin, 1984).

3. Student Organizations: defined as student-led extra-curricular or co-curricular groups or clubs within institutions (Kimbrough \& Sutton, 2007).

4. Quantity of Involvement: the self-reported amount of time a student spends involved in college generally, regardless of specific type of involvement.

5. Campus Environment: the extent to which students believe that their institutions are committed to their success and report that the social and working relationships among different groups on campus are positive (Pike \& Kuh, 2006, p. 432).

6. Collective Racial Esteem (CRE): an individual's sense of self-concept as it relates to racial group membership (i.e., those aspects of the self-concept that relate to race, ethnic background, religion, fcelings of belonging in one's community, and the like). CRE has four scales: (a) membership (how well one believes he or she fits in with their social group); (b) identity (the centrality or salience of one's social group to their identity); (c) private (one's personal assessment and beliefs of the value of their social group); and, (d) public (one's beliefs about how others value their social group) (Dugan et al., 2009; Luhtanen \& Crocker, 1992).

7. Black or African American: a person having origins in any of the Black racial 
groups of Africa (Planty et al., 2009).

8. White: a person having origins in any of the original peoples of Europe, North Africa, or the Middle East (Planty et al., 2009).

9. Four-Year-and-Above Institutions: institutions or branches that offer programs of at least four years' duration or that offer programs at or above the baccalaureate level. These institutions award a four-year degree or higher in one or more programs, or award a post-baccalaureate, post-master's, or post-first-professional certificate. Includes schools that offer post-baccalaureate certificates only or those that offer gradate programs only. This also includes freestanding medical, law, or other first-professional schools (Planty et al., 2009).

10. Historically Black College and University: institutions established prior to 1964 , whose principal mission is the education of Black Americans (Planty et al., 2009).

11. Predominately or Traditionally White Institutions: institutions that have, or have historically or traditionally had, a majority White student population.

12. Public Institutions: institutions whose programs and activities are operated by publicly elected or appointed school officials and which are supported largely by public funds (Planty et al., 2009).

13. Private Not-For-Profit Institutions: institutions in which the individual(s) or agency in control receives no compensation, other than wages, rent, or other expenses for the assumption of risk. These include both independent not-for-profit schools and those affiliated with a religious organization (Planty et al., 2009).

The terms minority students and students of color are used interchangeably throughout this dissertation. The term predominately White institution (PWI) is equivalent to the 
term traditionally White institution (TWI) used elsewhere in the literature.

\section{Limitations}

As with any study, there are several limitations that should be mentioned that are inherent despite the research design employed. This is not a true experimental design as defined by Shadish, Cook, and Campbell (2002) and others. Findings in this study are relational, and causality is not implied. For example, if high scores on a student's public CRE score is positively correlated to a high quantity of involvement, that does not mean that high public CRE causes students to be more involved.

The MSL study used in this dissertation is secondary data. Several limitations of secondary data (e.g., inaccurate data, out of data information, small sample sizes, disreputable company, etc.) were accounted for through the selection of this particular dataset. The MSL contains recently collected data, from a large sample size, using statistically valid and reliable constructs. The use of different definitions of certain variables posed a slight limitation. For example, items used to measure faculty interaction, peer interaction, and quantity of involvement do not include every possible scenario through which students experience these variables. Items used were informed by prior research, though the choices were limited due to the instrument design. Participating institutions self-selected into the MSL study and therefore did not provide a random sample of institutions from across the United Sates. Furthermore, institutions chosen for this study did not represent a random sample of public four-year institutions. This study cannot be generalized to the entire student population of the U.S. Students were randomly selected to take the MSL at each institution; the overall response rate was a modest $30 \%$, and the response rates varied across institutions. Due to the limited number of public 
four-year HBCUs, the study only compared one HBCU and one PWI to address RQ4. Findings cannot be generalized to all PWIs or HBCUs.

Though this study is not about college choice, it is important to note that African American students make-up higher percentages of students attending public and private two-year colleges than public four-year institutions (Aud et al., 2010). This means that the sample of public four-year institutions excludes a large number of the population of African Americans in post-secondary education. A final limitation for this study concerns the definitions used for constructs such as race. Many of the definitions outlined in this dissertation come from the National Center for Education Statistics (2009), and thereby represent one possible definition of many of the terms used in this study. The author recognized the abundance of definitions that exist for many of the constructs used. The author also recognized the exclusion of cases within the data based on definitions listed in this chapter.

\section{Summary of Chapter I and Overview of Chapters II -V}

African American male involvement and persistence in higher education have remained consistently lower than that of other racial/ethnic groups and their female counterparts. This trend holds constant across institutional type. Despite decades of research on the Black college student experience, little has changed by way of the ultimate outcome of higher education: the attainment of a college degree. Though gains have been made within K-12 and post-secondary education as they relate to access and enrollment of minority students, there are opportunities for institutions to better engage and support African American males once they arrive on campus. CRE is a construct found in the social identity literature that has not been extensively examined in the body 
of student development literature. Institutions may find that knowledge of student CRE is useful in designing interventions to assist students in their involvement and matriculation through the college environment.

This study will explore the influence of CRE on involvement in college, and could help account for significant variability in student outcomes across and within racial groups. Attaining a clearer understanding of the relationship between the predictor and criterion variables used in this study, administrators at post-secondary institutions can be better equipped to construct interventions that promote and support African American student achievement. This could include designing mentoring opportunities, livinglearning communities, and in-class and out-of-class support for students based on their CRE.

Having introduced the study in this chapter and providing the context, background, and significance of the study, it is necessary to briefly discuss how the remaining chapters are organized. Chapter II reviews the literature about African American student involvement as it relates to faculty and peer interactions, involvement in cultural/minority student organizations, racial identity development, CRE, and campus environmental factors. African American male undergraduates will be discussed specifically in Chapter II as well. Chapter III discusses the research design, study participant characteristics, instrument design, and procedures used to collect data. Results are presented in Chapter IV with a description of statistical applications employed in the study. Lastly, Chapter V presents conclusions and implications of study. 


\section{CHAPTER II}

\section{REVIEW OF LITERATURE}

\section{Overview}

This dissertation will examine the influence of collective racial esteem (CRE) on the quantity and type of involvement for African American male undergraduate students in public four-year institutions of higher education in the U.S. This study will examine the predictive ability of the four scales that represent CRE on various involvement variables using data from a national study. This review of research is divided into six main sections: (1) the current context of American public higher education, (2) involvement and persistence, (3) racial identity development, (4) collective identity and esteem, (5) campus environment and climate, and (6) the college experience of African American males. The chapter concludes with a summary overview of the chapter and review of research questions examined.

\section{Current Context of American Public Higher Education}

Recent projections estimate $60 \%$ of new jobs created will require some form of post-secondary education (Educating America, 2004). This projection indicates that the necessity for students to stay in the educational pipeline through the post-secondary years has intensified (Crawford, 2010). This dissertation focuses specifically on post-secondary institutions in the public, four-year sector of higher education.

The U.S. has a diverse array of more than 4,300 public and private institutions, both for-profit and not-for-profit. These institutions vary by Carnegie type, control, size, 
and mission. Students attending post-secondary institutions are as diverse as the institutions they attend. There are over 600 public four-year institutions, which many consider to be among our country's most important social establishments (Harper, 2006a).

Duderstadt and Womack (2003) contended that these public institutions have a unique mission to democratize and provide access to higher education for all citizens. Equal opportunity, via access to higher education, is a cherished American ideal that has been passed through generations. The outcomes of a public education not only benefit the individual, but also society as a whole, and therefore a strong social contract exists between public institutions and citizens within the U.S.

Planty et al. (2009) reported that within public four-year institutions, $67 \%$ of the students are White, $11 \%$ are African American, $9 \%$ are Hispanic, $7 \%$ are Asian/Pacific Islander, and 1\% are American Indian/Alaska Native. According to the 2000 U.S. Census (http://censtats.census.gov/cgi-bin/pct/pctProfile.pl), this compares to $75 \%$ White, $12.3 \%$ Blacks, $12.5 \%$ Hispanic, and $3.6 \%$ Asian in the U.S. Approximately $57 \%$ of the students attending public and private institutions of higher education are female. Despite comprising the second largest racial group represented at public four-year institutions the six-year graduation rates for African American students are among the lowest in the country (Planty et al.). This has remained a reality for the last several decades, despite numerous efforts at the institutional, state, and federal level to ameliorate these differences. It has been offered that the social contract between African American students and the nation's public post-secondary institutions has been broken (Harper, 2006a). Furthermore, research suggests that these trends in racial disparity may result in 
destructive consequences for our society (Kelly, 2005). Student enrollment for African Americans is predicted to increase by $26 \%$ by the year 2018 (Hussar \& Bailey, 2009). This projection indicates a need for continuous and research-driven solutions to improve African American persistence and degree completion.

One explanation of the low persistence rates of African American students is their lack of involvement in the campus environment. Research has consistently shown that involvement in college, amongst other variables, is positively correlated to persistence and graduation for students (Astin, 1993; Pascarella \& Terenzini, 1991, 2005; Tinto, 1987). Astin's (1993) input-environment-outcome (I-E-O) model is one of the first and most widely cited theories of student involvement found in this literature review.

\section{Involvement and Persistence}

Astin (1984) defined involvement as "the amount of physical and psychological energy that the student devotes to the academic experience" (p. 518). Involvement in college includes, but is not limited to, faculty interaction, participation in clubs/organizations, time spent using the library and other campus resources, and peer interaction. Astin's (1993) model hypothesizes that students enter the institution with certain inputs (pre-college factors such as family income, high school GPA, attitudes, values), which interact with the college environment (e.g., campus activities, coursework, faculty and peer interaction), and results in a range of student outcomes (e.g., psychosocial, cognitive, etc.). Astin's model assumes that learning and involvement are more a function of what the students does, and less a function of what the institution does.

Pascarella and Terenzini $(1991,2005)$ supported Astin's findings that 
involvement positively affects a range of college outcomes. Pascarella and Terenzini studied the effects of college on students over a 30-year period and measured the impact of college across a number of variables, including cognitive and intellectual skills, psychosocial change, attitudes and values, moral development, and quality of life after college. Furthermore, involvement has been found to positively affect persistence. When it comes to persistence, Tinto (1998) notes, involvement matters. This finding is particularly important to decision makers in post-secondary education, as student involvement is something that administrators can influence through existing systems within the institutions.

CRE is defined as a student's self-concept as it relates to his or her racial group (Dugan et al., 2009), and is what Astin (1993) may describe as an input variable for students entering college. A hypothesis in this dissertation is that CRE serves as both an input (i.e., a factor with which students enter college), and as a mediator for involvement in the campus environment. Figure 1 illustrates a modified version of Astin's model, with CRE added.

In the figure, CRE was labeled an intermediate input variable to set the variable apart from Astin's original model. As indicated by the arrows, CRE has a reciprocal interaction with the environment. This interaction means CRE impacts how students will interact with the college environment, and the environment, in turn, modifies CRE as a student progresses through college. It should be noted that this model does not indicate whether CRE increased or decreased, only that it is modified. Finally, CRE is hypothesized to impact the psychosocial and cognitive outcomes of college as well.

The review of literature for this study yielded few quantitative analyses of the 
effect of students' CRE on involvement in college. Through an examination of CRE, this study seeks to add to the literature regarding factors that facilitate undergraduate African American male involvement and persistence in public post-secondary institutions. The following section discusses persistence frameworks and the specific relationship between involvement and student persistence.

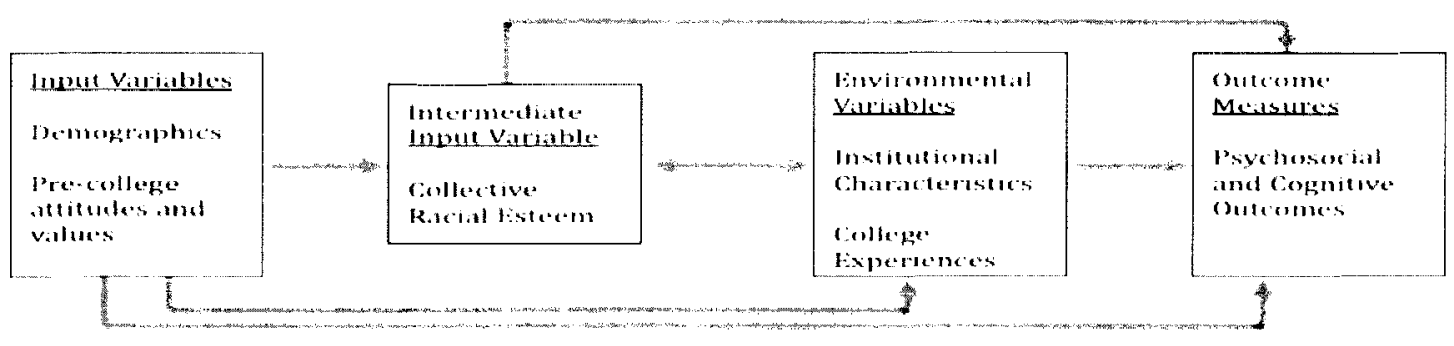

Figure 1. Revised Input-Environment-Outcome (I-E-O) Model

\section{Persistence Frameworks}

Persistence in higher education has consistently been linked to involvement and social and academic integration into the college environment (Astin, 1993; Braxton, Hirschy, \& McClendon, 2004; Pascarella \& Terenzini, 1991, 2005; Tinto, 1975). Tinto’s (1975) theory of student departure is a widely cited theoretical framework for explaining student departure. The theory has its roots in Durkheim's theory of suicide (1961, as cited in Tinto, 1975), which states that suicide is more likely to occur when an individual is not sufficiently integrated into society. Applying this theoretical lens to higher education, students commit the equivalent of academic suicide if they do not sufficiently integrate into the campus environment. Despite its usefulness as a framework, Durkheim's theory has limited applicability to studying student dropout due to the myriad of environmental variables affecting student attrition. Tinto (1975) therefore extended his model to view dropout as "a longitudinal process of interaction between the individual and the academic 
and social systems of the college during which a person's experiences ... continually modify his goal and institutional commitments in ways which lead to persistence" (p. 94). Contrary to Astin's (1993) model, Tinto's model places the onus of persistence on both individual and institutional factors.

According to Tinto (1987) persistence or dropout is attributable to a confluence of factors, including student pre-college variables, academic goals, commitment to goals and to the institution, the degree of involvement with the social and academic environment, and career goals (Flowers, 2004). An assumption of Tinto's (1987) model is that students, who come from cultures incongruent with that of the dominant culture, must detach themselves from their culture of origin. Students must then adopt the norms and values of the dominant culture to be successful in college. From this perspective, Tinto's theory implies that students must assimilate to the dominant culture and thereby become integrated in the environment to achieve positive outcomes. Cabrera, Castañeda, Nora, and Hengstler (1992) affirm the complexity of understanding persistence, stating that persistence is an outcome of good fit between the student and the institution, while others have offered significant critiques of Tinto's propositions.

Tierney (1999) offered a critique of Tinto's $(1975,1987)$ model, stating that it fails to recognize the importance of culture and its effects on minority student integration in higher education. Tierney forwarded that Tinto's model may represent a form of cultural suicide, and that the need to assimilate into the dominant culture places a tremendous burden on students not from the dominant culture (Museus, 2008). Tierney instead posited cultural integrity as an alternative, which emphasizes programs that foster cultural validation through engaging students' backgrounds and the communities around 
them. The concept of cultural integrity is based on the belief that college campuses can shape their dominant cultures to engage diverse pre-college cultures from which students come.

Tierney (1992) also takes issue with many of the assumptions and definitions used by Tinto to discuss student departure, particularly the analogies made to rites of passage rituals within college environments. Tierney holds that the references made to anthropological theories as they relate to rites of passage are inaccurate, largely because rites of passage are intra-cultural and are designed for members of a community to succeed. Therefore, failure or dropout in the case of post-secondary education, is not an option in the anthropological use of the term, and should not be used as a frame by which to discuss integration into the college culture.

Similarly, Kuh and Love (2000) analyzed Tinto's $(1975,1987)$ model of student departure by arguing that it is not empirically proven, is inadequately operationalized, and understates the role of the institution in adapting to student needs. Instead they offer a cultural framework by which to view college student departure decisions. Kuh and Love posited that persistence is inversely related to the distance between a student's native culture and the campus culture. Students can either acclimate to the dominant culture, or seek membership in a campus subculture. The importance of subcultures and their role in student persistence are well documented, and they have been found to be particularly useful vehicles for involving African American students and other ethnic and racial minorities into college settings (Kuh \& Love, 2000; Museus, 2008; Tinto, 1993).

Kuh and Love (2000) went on to add that student departure from college, and other student experiences, is not just a result of individual psychological experiences; 
departure is also shaped by a number of cultural forces linked to racial or ethnic group, family background, social class, and previous family experiences. According to Kuh and Love, colleges and universities develop their own cultures that shape how people think and behave. They further add that culture is a pattern of behaving, believing, and knowing that is collective and mutually shaping. Culture provides a frame of reference by which to interpret the meaning of campus events and actions.

The cultural perspective of student departure parallels much of Tierney's (1992, 1997, 1999) work as it relates to cultural integrity. Along these lines, Nora and Cabrera (1996), when examining African American students at a predominately White institution (PWI) in the Midwest, revealed findings contrary to Tinto's (1975) notion of detachment from one's native culture. Nora and Cabrera found that attachment to significant others, such as parents and other family members, were key for the successful transition of minority students. Furthermore, Guiffrida (2006) concluded that Tinto's (1993) theory should be advanced to include minority students' connection to their heritage, traditions, and home support systems. He also advances the literature on African American persistence through an examination of motivational (intrinsic vs. extrinsic) and cultural (individualistic vs. collectivist) orientations. Finally, Guiffrida provides a more complex and more culturally valid discussion of student departure that sheds light on key developmental factors in African American student persistence.

It is important to note the strong predictive ability of socio-economic status (SES) as it relates to student persistence, particularly as it relates to minority populations (Cabrera, Stampen, \& Hansen, 1990; Crawford, 2007; Tinto, 2007). Though outside of the scope of this literature review, the confluence of race, gender, and SES cannot be 
overstated. As a result, chapter 4 will statistically control for the effects of SES in the analysis of the data, and is discussed more within that chapter. Other key factors found in the review of the literature related to African American involvement and persistence are outlined below.

\section{African American Involvement}

Flowers (2004) studied the extent to which student involvement experiences influenced specified educational outcomes for African American students. Using results from the College Student Experiences Questionnaire (CSEQ), the author examined 7,923 African American students from 192 institutions who participated in the CSEQ between 1990 and 2000 . Of the sample, $18 \%$ attended HBCUs while $82 \%$ attended PWIs.

Represented in the sample are 93 public and 99 private institutions. The study used ordinary least squares regression to examine the relationship between involvement as the independent variable and five academic measures as dependent variables.

African American student involvement was found to be low to moderate on most of the measures for student involvement. This is relevant because it reflects the scarcity of involvement in campus activities by many African American students. It also reflects the scarcity of activities and resources available to African American students, and researchers' ability to access these areas sufficiently. Some measures of involvement in the study negatively impacted academic gains; for instance, following a regular schedule of exercise or attending social events in the student union. These findings contradict a number of previous studies that report the positive outcomes of such activities (Astin, 1993; Pascarella \& Terenzini, 2005; Tinto, 1975). This contradiction could be due to the choice of variables used to measure involvement in the CSEQ instrument. Overall, results 
of this study reinforced the existing research on the positive impact of both in-class and out-of-class involvement on academic and social outcomes. In the review of literature, peer interaction, faculty interaction, and involvement in student organizations frequently appear as positive types of involvement for African American students, as the following sections will discuss. As it relates to student organizations, special attention was given to the positive impact of involvement in ethnic/minority student organizations in this literature review.

Peer interaction. Astin (1993) found that "the single most powerful source of influence on the undergraduate student's academic and personal development is the peer group" (p. 2). His longitudinal study included more than 25,000 students at more than 200 colleges in the U.S. Peer interaction included discussing course content with other students, working on group projects for classes, tutoring other students, participating in intramural sports, being a member of a social fraternity or sorority, participation in campus protests, being elected to a student office, and hours per week spent socializing or participating in student clubs or organizations.

Similarly, Cuyjet (2006) stated that students use peer groups to negotiate their college experience. The peer group is particularly important for African Americans students. The peer group essentially serves as an audience and proving ground where students are supported and able to test integration strategies and plans in a safe environment. Peer group interaction produces student gains across many psychological, psychosocial, and cognitive outcomes (Astin, 1993; Cuyjet, 2006; Pascarella \& Terenzini, 1991, 2005). Related to this dissertation, students' CRE and racial identity appear to play a role in how or if African American students interact positively with 
others in and out of their racial group. The same holds true for students' interactions with institutional faculty.

Faculty interaction. Faculty interaction has been found to play a significant role in the involvement and retention of students (Tinto, 2007). In Astin's (1993) longitudinal study using the Cooperative Institutional Research Program (CIRP) in 1985-1989 referenced earlier, he reported that faculty represents the most important part of a student's development as an undergraduate, second only to the influence of peers. Astin goes on to say that the interaction between students and faculty is positively correlated with every academic outcome, including grade point average (GPA) and degree completion.

Using the third edition of the CSEQ, Kuh and Hu (2001) examined the character and impact of student-faculty interaction on student learning and personal development in the $1990 \mathrm{~s}$. The sample consisted of 5,409 randomly selected students from 126 colleges and universities. The authors used regression analysis to examine general patterns between student-faculty interaction and college outcomes. The results supported existing findings about the importance of student-faculty interactions (i.e., the more faculty contact, the better for the student). A noteworthy finding to this dissertation is that students devote more effort to other educational activities because of their interaction with faculty. This finding illustrates the importance of faculty influence in the involvement and integration process of students.

Also highlighting the importance of faculty interaction, Littleton (2002) reported that the number one factor attributing to the persistence of African American students at a small PWI in the south was approachable and caring faculty. Similarly, Latiker (2006), 
examining African American students at a small HBCU in the south reported faculty being a significant predictor in African American student persistence in college through three roles: "teacher (in-class), mother/father figure (out of class), and mentor/advisor (out of class)" (p. 13). Mentoring is a specific type of faculty-student interaction and is well researched in the literature, particularly as it relates to African American students (Guiffrida, 2005). Himelhoch, Nichols, Ball, and Black (1997) found that faculty mentoring was the sole predictor of African American persistence at PWIs.

Mentoring was described by Strayhorn and Terrell (2007) as the "process by which a student or protégé is positively socialized by a faculty member or mentor into the institution and/or profession" (p. 70). Santos and Reigadas (2005) examined the studentfaculty mentoring process and its effects on at-risk students. Many of the at-risk students in this particular study were African American students and are therefore relevant to this dissertation. Using a Social Network Theory (SNT) perspective, the researchers studied a Faculty Mentor Program (FMP) at a comprehensive public institution located in Los Angeles, California. The FMP was established in 1987 to provide faculty mentors to students who were defined as at-risk. The program was designed to promote students' social and academic integration in college through a mentoring relationship with faculty. Santos and Reigadas proposed a model that students with mentors of the same race yielded greater student-mentor contact. This increased contact would increase student commitment to the university setting. Researchers hypothesized that frequency of student-mentor contact was expected to positively increase perceived mentor supportiveness and positively influence students' attitudinal adjustment to college.

Two hundred participants were used to evaluate the effectiveness of the Faculty 
Mentoring Program (FMP) and the impact of ethnic homogeneity on certain outcomes. Out of the 200 participants, $45 \%$ (90) were matched with mentors of the same ethnic background. Findings indicated that frequency of student-mentor contact had a positive direct effect on FMP satisfaction and GPA. Furthermore, the frequency of student-mentor contact was directly affected by ethnic homogeneity of the student-mentor pair.

Ethnic homogeneity also had an indirect impact on perceived mentor support through frequency of student-mentor contact. In other words, students with the same ethnic mentors yielded better educational outcomes than others in the program who did not have the same ethnicity mentors. This study supported the importance of a diverse faculty at institutions of higher education in order to foster higher satisfaction and success through mentoring of minority and other at-risk students. One of the factors examined through CRE is identity salience, or the centrality of race to one's sense of self. This study also highlighted the importance of racial identity salience in the successful experience of African American students.

Strayhorn and Terrell (2007) examined the extent to which faculty-student mentoring predicts African American students' satisfaction in college. Using data from the CSEQ, fourth edition, researchers sampled 554 Black college students who completed the survey in 2004. The instrument contained 91 items designed to measure the quality and quantity of student involvement in college activities and use of campus facilities. The sample was restricted to unmarried, full-time, residential first and second year students attending four-year institutions. This sampling strategy allowed controls for race, gender, institutional type (two-year vs. four-year), and marital status. Involvement with faculty was measured using six scales of the CSEQ and included the following items that 
reflected involvement with a faculty member: (a) frequency with which students worked on a research project, (b) discussed personal problems, (c) discussed academic program, (d) discussed career goals, (e) socialized outside of class, and (f) asked for criticism about performance. The dependent variable was satisfaction, measured using the college satisfaction index of the CSEQ.

Hierarchical multiple regression analyses were used to examine correlations between satisfaction and two types of faculty involvement: personal- and researchfocused. Consistent with previous research (Guiffrida, 2005), African American students' satisfaction with college improved through a purposeful, research-based mentoring relationship with faculty (Strayhorn \& Terrell, 2007). This finding was not consistent for students who established a personal, informal mentoring relationship with faulty. This study, along with Santos and Reigadas (2005), supported the relationship of formal mentoring programs for African American and other minority students to satisfaction with college and increased academic outcomes.

Similar to these findings, Guiffrida (2005) provided additional insight into the importance of student-faculty interactions for African American students. Particularly at PWIs, African American students were found to expect more intrusive personal, academic, and career advising from faculty and other staff. These students also expected more support and advocacy from their faculty and staff in and out of class. Guiffrida attributed this to the phenomenon of othermothering within the African American community. Othermothering is an "expanded relationship between Black students and Black teachers" (Guiffrida, 2005, p. 715), and leads African American students to have high expectations that mentors will go above and beyond the normal call of duty. 
However, as Guiffrida points out, many times African American students do not receive that level of intense mentoring from White faculty at PWIs. Therefore, several African American students reported that White faculty were not seen as realistic role models or mentors (Guiffrida, 2005). This lack of meaningful mentor relationships with faculty, coupled with a lack of African American faculty role models, can reduce the positive effects of faculty interaction on African American student persistence.

Student organizations. Student organizations have been found to serve as venues for African American student involvement. African Americans, particularly at PWIs, need formal means of involvement (e.g., student organizations), as there are limited opportunities for informal interactions due to small numbers of African American students on campus (Guiffrida, 2003). Sutton and Kimbrough (2001) examined trends in Black student involvement within traditional campus organizations at PWIs (PWIs). The researchers used the Student Involvement and Leadership Scale (Kimbrough, 1995) to measure different types of involvement on and off-campus. A total of 989 surveys were distributed to campuses affiliated with a national student affairs professional organization, and 405 surveys $(41 \%)$ were returned. This study specifically examined the co-curricular experiences of members and non-members of Black Greek-lettered organizations.

Sutton and Kimbrough (2001) distinguished between "traditional" and "multicultural" organizations in this study. Traditional organizations are defined simply as groups that promote student friendships and camaraderie. The authors assert that African American involvement in these organizations at PWIs has remained marginal, despite the growth in ethnically diverse students on campus. On the other hand, 
multicultural organizations are defined as those that are not predominately White, and these organizations continue to positively influence the involvement of African American students. In fact, Sutton and Kimbrough found that multicultural organizations remain the primary venue for involvement among African American students. Participants' involvement in multicultural/ethnic organizations at PWIs was significantly higher than participants at HBCUs. These organizations have been found to provide a venue for African American students to be affirmed, validated, and celebrated. This finding is consistent with the existing literature on the role of ethnic organizations on African American student involvement (Harper, 2006a; Mitchell \& Dell, 1992; Museus, 2008; Taylor \& Howard-Hamilton, 1995).

Museus (2008) sought to increase the understanding of the role of ethnic organizations in fostering minority membership in cultures at a PWI. In the review of literature, this Museus study was the most recent of its kind to examine ethnic/minority group participation exclusively, and the effects of these organizations on student success. The concepts of cultural integrity (Tierney, 1999) and a cultural perspective of student departure (Kuh \& Love, 2000) grounded Museus' study. The study was guided by a phenomenological design and defined involvement as "holding a position of leadership or contributing 10 or more hours per week to an ethnic student organization" (p. 575). The sample examined was composed of 12 African American and 12 Asian American, traditional-aged students. The site was a large PWI in the Mid-Atlantic region of the U.S. that had recently experienced racial/ethnic unrest on campus.

Museus' (2008) study supported findings about the importance of ethnic student organizations in the socialization and support of students of color (Mitchell \& Dell, 1992; 
Harper, 2006a; Harper \& Quaye, 2007; Sutton \& Kimbrough, 2001; Taylor \& HowardHamilton, 1995). The findings also support the important role these organizations have in college student persistence and success (Kuh \& Love, 2000). Ethnic organizations facilitate cultural adjustment by serving as a source for cultural familiarity, vehicles for cultural expression and advocacy, and venues for cultural validation. These findings are supported by an earlier qualitative study conducted by Littleton (2002), wherein participants stated that African American social organizations are not set up to separate them from other students, but rather serve as a means of bringing African American students together. The findings were consistent in Littleton (2002) and Museus (2008) despite the difference in institutional type and a six-year time period between the two. Guiffrida (2003) also adds support to the findings above in his study of 88 African American students at a PWI in the Northeastern U.S. The researcher sought to understand under which conditions involvement facilitates social integration. This study supported prior research on the importance of African American student organizations to the social integration of the campus (Harper \& Quaye, 2007; Tinto, 1993). This study added to the literature by describing the conditions by which integration occurred, and specifically from African American students from predominately Black or White environments. Involvement in African American organizations provided students with a comfortable environment, important professional connections with faculty, an opportunity to give back to their communities, and exposure to Black culture (Guiffrida, 2003). These findings support the review of literature in this dissertation as it relates to peer and faculty interactions, and involvement in student organizations. Finally, this study reinforced the heterogeneity of African American students, and the need for more complex 
understandings of this group of students' behavior. CRE could be a useful variable in college impact research that provides a more complex understanding.

Relevant findings from the multi-institutional study of leadership (MSL). It is important to discuss CRE in the context of the larger MSL, particularly as it related to findings about racial identity and outcomes of this national study. Since 2006 many studies have emerged using MSL data (e.g., Dugan \& Owen, 2007; Haber \& Komives, 2009; Komives, 2007; Martinez, Gehrke, Komives, \& Dugan, 2007). Most of these studies focused on outcomes related to student leadership development, and students' practice of socially responsible leadership as measured through the Social Change Model of Leadership Development (HERI, 2006). A few of these studies highlighted outcome differences across racial groups. For example, Rosch (2007) stated that:

Often those students of color who choose to participate in leadership-oriented groups or initiatives must not only find a way to fit into a group whose members may not share their values, they must also justify their decisions to a peer group who may not support them. (p. 38)

This burden is similar to the burden that African American students face in trying to adapt to majority environments and cultures (Museus, 2008; Ogbu, 2004; Tierney, 1999). Dugan, Komives, and Segar (2008) reported that African American students scored significantly higher than their White peers on group values within the Social Change Model of Leadership Development (e.g., Controversy with Civility and Citizenship), as well as the values of Consciousness of Self and Change. This finding is relevant because it reinforces the importance of groups in the lives and experiences of African American college students (Guiffrida, 2003).

Dugan, Brown, Chavez, Mendoza, \& Rodriguez (2010) examined the influence of CRE on socially responsible leadership, and found that CRE scale within the instrument 
explained $5 \%-7 \%$ of the variance when predicting the dependent variable. This represented a significant increase in the predictive power of CRE over racial group membership in college impact research, and further necessitates the need for research using CRE as a predictor variable for involvement in the college environment.

Clearly, there are several recurring themes of involvement in the literature on African American undergraduate students. Peer interaction, faculty interaction, and involvement in student organizations were the most prevalent found in the review of literature for this study. For African American students, identity development is an important developmental outcome of college (Pascarella \& Terenzini, 2005). Racial identity development uniquely impacts the involvement and persistence of African American students as they progress through higher education.

\section{Racial Identity Development}

A salient factor for many African American students entering higher education is race/ethnicity. Much research has been conducted on the effects of race on African American student success. Racial identity development during college plays a large role in the experiences and outcomes of African American students. Results from studies on the impact of racial identity development are at times contradictory. Racial identity development theories, applications, and findings are discussed in this section.

Race and ethnic background as a construct is increasingly insufficient as a predictor of campus involvement due to changing demographics, attitudes, and backgrounds of incoming students (Helms, 2007). According to Helms (1990), racial identity is a type of collective identity based on the belief or perception that one shares a common racial background with a certain group (Phelps, Taylor, \& Gerard, 2001). Dugan 
et al., (2010) added that racial categories are externally defined visible cues, but do not necessarily indicate how individuals construct their sense of self-concept as it relates to their race. This does not suggest that race is irrelevant or unimportant; rather it suggests that race should be combined with more complex measures of identity. This is particularly true because the research on racial identity theory and involvement shows positive relationships between racial identity attitudes, as defined by Cross (1991), and student involvement and engagement in college (Chavous, 2000; Mitchell \& Dell, 1992; Parker \& Flowers, 2006; Taylor \& Howard-Hamilton, 1995).

Mitchell and Dell (1992) stated at the time of their study that there was not much attention given to how racial identity correlated to student behavior or decision-making. The studies that have been conducted since then generally depict a significant relationship between African American racial identity attitudes and involvement in campus activities and organizations (Harper \& Quaye, 2007; Mitchell \& Dell, 1992; Sutton \& Kimbrough, 2001; Taylor \& Howard-Hamilton, 1995). Where the research is lacking is in an analysis by gender of the impact of racial identity attitudes and involvement.

\section{Racial Identity Models}

Cross' $(1971,1991)$ model of nigrescence is a widely cited racial identity theory within higher education, in particular as it relates to African American students. Nigrescence is literally the process of becoming Black, which makes the model a useful lens through which to examine African American identity development. The model originally proposed in 1971 has been revised and expanded. Worrell, Cross, and Vandiver (2001) provided a useful summary of the changes to the model since its 
inception. The revised model includes four stages: (1) pre-encounter, (2) encounter, (3) immersion-emersion, and (4) internalization. The pre-encounter and internalization stages are the only stages with expanded levels from the earlier model.

Worrell, Vandiver, Schaefer, Cross, and Fhagen-Smith (2006) provided additional commentary on the substantive changes to the stages over time. They stated that the most important change in the model is the change from a developmental stage-based theory to one that focuses on attitudinal factors and social identity. Scales to measure racial identity attitudes have been created and used in several studies. These scales demonstrate relationships between racial identity attitudes and certain college academic and social outcomes. For example, the Black Racial Identity Attitude Scale (RIAS-B) (Parham \& Helms, 1985) has been widely used, followed by the more recent Cross Racial Identity Scale (CRIS) (Vandiver et al., 2001).

Worrell, Cross, and Vandiver (2001) and Vandiver, Fhagen-Smith, Cokley, Cross, and Worrell (2001) examined the CRIS to ensure the instrument had sound psychometric properties, and generalized well across various educational contexts (Worrell, Vandiver, Schafer, Cross, \& Fhagen-Smith, 2006). Since this examination, others (e.g., Awad, 2007) have used the CRIS to examine the relationship between racial identity attitudes and college outcomes. Though Cross' $(1971,1991)$ work is the most widely used, other models have emerged to describe the process of racial identity development for students within post-secondary education.

Helms' (1990) model adapts and extends Cross' (1971) model in describing racial identity development in African Americans, Latinos, Asians, and Native Americans. According to Helms, regardless of race, students go through six different statuses that 
reflect beliefs and behaviors that govern racial reactions (Pascarella \& Terenzini, 2005). The six statuses of the model include (a) conformity, (b) dissonance, (c) immersion, (d) emersion, (e) internalization, and (f) integrated awareness. Helms' model is similar to the other models in this literature review, in that racial identity development is seen as a process of learning about oneself in relationship to others. Individuals ultimately become more conscious of oppression and its effects on self and others.

Somewhat similar to Helms', Phinney's (1996) model describes ethnic identity as a complex construct. Consistent with CRE scales, ethnic identity includes a connection and sense of belonging to one's own ethnic group, positive evaluation of one's own groups, knowledge of the group, and involvement in activities and traditions of the group. Phinney presents a model that differs from other models of racial identity development, in that it is "intended as a guide to considering variation among young adults in their understanding of ethnicity, rather than as a theoretical explanation of the process" (p. 146). The three-stage model includes unexamined ethnic identity; moratorium or exploration; and finally, achieved ethnic identity. At each stage the relationship between one's own group and other groups is impacted, either positively or negatively. In the first stage, depending on the individual, relationship to one's own group and other groups ranges from positive, to negative, to neutral. The second stage is characterized by high involvement in one's own group and increased anti-White behavior or anger. In the final stage, a secure sense of one's own group membership emerges, as well as a realistic appraisal of one's own group. Racial salience may be high or low at this stage. Relationships to others becomes either collaboratively integrated, or can become separated due to beliefs that one's own group is better off by itself. Using these models as 
a lens, the impact of racial identity attitudes on African American students is explored further.

\section{Impact of Racial Identity Attitudes on African American Students}

Involvement. Mitchell and Dell (1992) examined the relationship of student racial identity attitudes and participation in campus organizations using the Racial Identity Attitude Scale (RIAS). The RIAS uses Cross' (1991) model to assess stages of nigrescence. The sample consisted of 55 female and 46 male Black undergraduates enrolled at a large PWI on the West coast. The racial composition of the university was $64.2 \%$ White, $18.8 \%$ Asian, $10.5 \%$ Latino, 5.6\% Black, $1.0 \%$ Native American, and 9.3\% unknown. Using multiple regression analyses, the authors found that the stages within the nigrescence model predicted participation in cultural and non-cultural campus organizations. Students in the earlier stages of racial identity development participated less in cultural organizations than did peers in the latter stages. Though this study is limited in its ability to generalize across campuses, it was useful in understanding how racial attitudes may impact involvement.

In a similar study, Taylor and Howard-Hamilton (1995) used analysis of variance, Pearson correlations, and stepwise regression to study the relationship between rates of student involvement and racial identity attitudes among African American males specifically. The authors surveyed 117 African American male students across 10 large PWIs in the Southeastern U.S. using the Racial Identity Attitudes Scale-B (RIAS-B) (Parham \& Helms, 1985) and the Student Involvement Survey (SIS) (Erwin, 1991). The researchers hypothesized that students reporting higher levels of pre-encounter attitudes were less involved, whereas those reporting higher levels of internalization attitudes were 
more involved. The research confirmed the hypotheses, and supported the role of involvement in contributing to higher stages of racial identity development. The SIS instrument used in the study lacked construct validity, and it is unclear if an adequate sample size was obtained that would allow generalizing the findings to other campuses. However, the findings demonstrate the strong relationship between racial identity and student involvement.

Academic achievement. To fully understand the impact of racial identity development on African American students, it is necessary to review both out-of-class involvement and academic outcomes. Lockett and Harrell (2003) cautioned against overinterpreting relationships between racial identity and academic achievement. Lockett and Harrell hypothesized that self-esteem plays an important role in mediating the relationship between racial identity and academic achievement. Their study examined 128 African American students at a HBCU in the Mid-Atlantic region of the U.S. The sample consisted of a large number of students that grew up in predominately Black neighborhoods $(68 \%)$ and attended predominately Black high schools $(57 \%)$. The Racial Identity Attitude Scale (RIAS) was used to measure racial identity attitudes and the Rosenberg Self-Esteem Scale (RSE) (Rosenberg, 1989) was used as a measure of selfesteem. Simple and multiple regression analyses were used to determine the unique variance in the dependent variable (GPA) predicted by racial identity attitude scores and global self-esteem scores. The researchers found that over half $(52 \%)$ of the variance in GPA, related to racial identity, is predicted by individual self-esteem differences. The single-site, majority female sample limited the study, though it illuminates the important role of esteem in the achievement of academic outcomes for African American students. 
Parker and Flowers (2003) also explored the influence of racial identity on African American students' academic achievement, as well as perceptions of campus connectedness at PWIs. This study examined the unique effects of racial identity on the dependent variables academic achievement and campus connectedness. Gender, year in school, perceptions of campus connectedness, and GPA were used as controls. The study used the RIAS to measure racial identity attitudes, the Campus Connectedness Scale (Lee \& Davis, 2000), and GPA to measure academic achievement. The sample consisted of 118 African American students from a large PWI in the Southeastern U.S.

Using correlation statistics, ordinary least squares regression, and hierarchical regression statistics the researchers found that racial identity attitudes did not have a significant effect on African American GPA, $F(6,111)=.92, p<.01$, after controlling for gender, year in school, and African American students' perception of campus environment. As mentioned earlier, differences across gender were not reported. Racial identity attitudes predicted campus connectedness in the expected theoretical direction (i.e., students reporting lower stages of racial identity were less connected than those reporting higher stages of racial identity). Pre-encounter attitudes of students did not affect campus perceptions, while immersion-emersion attitudes were negatively correlated with campus perceptions. Also, internalization attitudes were positively correlated with campus perceptions. The study demonstrated that racial identity does impact African American students' perception of their institution, but has no affect on GPA after controlling for African American perceptions of campus environments. A limitation to this study occurred in the sampling procedures. The study involved a small convenience sample and the participants were volunteers. 
In a similar study, Awad (2007) sought to assess the roles of racial identity, academic self-concept, and self-esteem in the prediction of both grade point average and verbal standardized test scores. This study used the Cross Racial Identity Scale (CRIS), which demonstrated more sophisticated psychometric properties than the instrument used in the Parker and Flowers (2003) study. The sample consisted of 313 African American students at a HBCU in the Northeastern U.S. This study found that higher racial identity scores were positively correlated to higher academic self-concept and GRE verbal scores. Academic self-concept was positively correlated to GPA. These findings support Parker and Flowers' (2003) assertion that a third variable, in this case academic self-concept, mediates the relationship between racial identity attitudes and GPA. However, a limitation of the study was that the participants were from one institutional type.

In general, the literature reported above provides a snapshot of how racial identity development impacts African American students in college, though it has its limitations as evidenced below. This dissertation seeks to find other cognitive developmental and psychosocial measures that impact African Americans in college.

\section{Critique of Racial Identity Theories}

Not all research supports the utility of psychosocial theories generally, or racial identity theories specifically, in helping students achieve certain outcomes. Cokley (1999) argues that psychosocial developmental theories proposed by Chickering (1969) and Erikson (1968) fall short of paying attention to racial and cultural identity development. Cokley also forwards that the theories do not highlight the value of identity to African Americans and other ethnic minorities. Cokley argues that racial identity models proposed by Cross (1971) and others face problems due to psychometric 
limitations with the most commonly used instrument, the RIAS-B (Parham \& Helms, 1985). Cokley goes on to state that there is a distinction between racial awareness (how much a student values, is aware of, and appreciates his or her race) and racial ideology (how a student believes members of his or her race should act). He asserts that the prevailing theory tends to conceptualize racial identity as hierarchical levels of racial awareness. This conceptualization causes ideology to be confounded with the significance of being Black as judged by a person's self-definition (Sellars, Chavous, \& Cooke, 1998 as cited in Cokley, 1999).

The use of CRE as a variable could bridge the gap between racial awareness and racial ideology as defined by Cokley (1999). Racial identity theory has limitations, and there is vast within-group diversity that exists among African American students as well. Therefore, it is necessary to examine different variables as it relates to the effects of race on individual students. CRE measures esteem as it relates to racial group membership, and may provide more insight into the needs and behavior of African American students in post-secondary institutions.

\section{Collective Identity and Esteem}

Phelps, Taylor, and Gerard (2001) state that self-esteem is highly researched throughout the literature. Within higher education, students that exhibit low self-esteem tend to perform at lower levels than peers who have high self-esteem. Essentially, selfesteem is directly linked to academic performance (Bonner \& Bailey, 2006). Two areas of self-esteem research have emerged over the years: (a) group self-esteem, focusing on how one feels about being a member of a racial, ethnic, or other social group; and (b) personal self-esteem, focusing on personal evaluations and assessments of one's self, 
including feelings of value, competence, and worth (Phelps, Taylor, \& Gerard, 2001).

This dissertation is concerned with the former, specifically racial group membership.

Phinney (1996) says, "Ethnic identity . . . appears to be a characteristic of individuals that can be reliably measured, that shows variation across both individuals and ethnic groups, and that is implicated in psychological well-being" (p. 148).

John Ogbu (2004) asserted that collective identity and cultural frame of reference could more fully explain the variability in minority student performance. Though Ogbu's research was in the secondary education $(\mathrm{K}-12)$ sector, the author contributes important insights into the role of collective identity in the lives of African Americans. Ogbu presented a brief evolution of African American collective identity and discussed the burden of "acting White" in contemporary society. Ogbu had this to say about collective identity:

Collective identity refers to people's sense of who they are, their "we feeling" or "belonging." People express their collective identity with emblems or cultural symbols which reflect their attitudes, beliefs, feelings, behaviors, and language or dialect." (p. 3)

The treatment or mistreatment of African American's and other minorities happens despite individual differences, abilities, aptitudes, or attitudes held by individuals. African Americans cope with the burden of acting White with five strategies as defined by Ogbu (2004): (a) assimilation or emulation of Whites, (b) accommodation without assimilation, (c) ambivalence, (d) resistance or opposition, or (e) encapsulation. Though outside the scope of the current study, these strategies appear to be theoretically similar to stages of ethnic and racial identity development of African American students as developed by Cross (1991) and others (Helms, 1990; Phinney, 1996). 


\section{Collective Self-Esteem}

Collective self-esteem is a self-evaluation of one's social identity. Luhtanen and Crocker (1992) were among the first researchers in the review of literature for this study to create a scale to measure collective self-esteem. According to social identity theory (the term collective identity is used in the U.S.), a social group is simply a group of individuals who claim membership or see themselves as members of a similar social category. The researchers differentiate between personal identity (having to do with personal values, goals, etc.), social identity (having to do with interpersonal aspects of identity) and collective identity (having to do with self-concept relating to membership in a group or community). Individuals vary in how they evaluate their social groups positively.

Luhtanen and Crocker (1992) noted that there were no instruments to measure collective identity, and as such, created an instrument to measure collective self-esteem (Collective Self-Esteem Scales, CSES). The CSES has four subscales: (a) membership, or how well one believes he or she fits in with their social group; (b) identity, or the centrality or salience of one's social group to their identity; (c) private, or one's personal assessment and beliefs of the value of their social group; and (d) public, or one's beliefs about how others value their social group. Researchers found that the CSES had strong construct validity and that it positively correlates, as expected, to personal self-esteem (Luhtanen \& Crocker, 1992). The instrument was designed to measure global collective esteem for social groups ascribed to individuals, though the instrument maintains its psychometric properties when used for a specific social group (e.g., race or gender).

Crocker, Luhtanen, Blaine, and Broadnax (1994) studied the psychological well- 
being of 238 White, Black, and Asian college students in a large Northeastern university in the U.S. They found that two of the scales of the general Collective Self-Esteem Scale (CSES) and the race-specific CSES were positively correlated to psychological wellbeing across all subjects. Researchers used analysis of variance (ANOVA) to examine mean group differences and linear regression to examine relationships between variables. This study validated the efficacy of race-specific CSES and suggested interpreting the four scales separately as opposed to a total CSES score. Valuable between group differences are lost when the scores are summed together. The authors stated that further research on the role of collective identity on college academic and social outcomes is needed.

Cokley (1999) was among the first to use the Multidimensional Inventory of Black Identity (MIBI) to examine the impact of college racial composition on African American students' racial identity at PWIs and HBCUs (Sellers, Rowley, Chavous, Shelton, \& Smith, 1997). The MIBI is a 51 -item survey that measures variables conceptually similar to the CSES instrument developed by Luhtanen and Crocker (1992). The MIBI contains three stable dimensions of racial centrality (comparable to the identity scale in CSES), racial ideology, and racial regard (comparable to the public and private scales in CSES). Cokley found that despite the type of institution students attended, racial centrality had a significant relationship with identity. This is relevant because one of the CRE scales measures racial centrality, and other variables used by Cokley (1999) also had relationships to CRE scales. Furthermore, Cokley found evidence to support findings in the literature that environment has an effect on the psychosocial development of African American college students. The following paragraphs explore the 
effects of environment and campus climate on African Americans in post-secondary education.

\section{Campus Environment and Climate}

Campus climate and environment play a significant role in whether or not students of color will integrate into the campus setting, and thereby receive the full range of outcomes. The review of literature for this study found a plethora of articles related to the role of campus environment on student success. Students attending institutions that demonstrate a commitment to diversity tend to report a higher sense of belonging to the campus, which in turn affects student integration and persistence.

Flowers (2004b) conducted an integrative review of factors that contribute to the retention of African American students in higher education. Using Tinto's (1987) theory of student persistence, the synthesis confirmed findings that student-faculty programs, peer-to-peer interactions, and a strong institutional commitment to diversity matters in retaining African American students. Flowers reiterated the importance of environments free of discrimination and prejudice as critical for African American student success. Research supports this notion that African American students who are comfortable in their ethnic identity are free to focus on issues beyond their race (Vandiver et al., 2001).

Continuing this line of inquiry, research has found that campus environment and climate play a significant role in whether or not African American students successfully integrate into, and persist through, college. Perceptions of differential treatment within campus environments have emerged as one of the possible explanations for the difference in college retention rates between majority and minority students (Nora \& Cabrera, 1996). As such, research examining African American persistence and retention is 
incomplete without an analysis of campus environment. Most frameworks analyzing or explaining persistence, via Tinto (1975), and involvement, via Astin (1993), have excluded environmental factors as central constructs in the persistence process (Museus, Nichols, \& Lambert, 2008).

Pike and Kuh (2006) defined campus environment as how much students believe institutions support, and are committed to, their success. This definition includes how positive the relationships are between different groups on campus. Prior research suggested that campuses free of environmental prejudice or discrimination foster gains in several cognitive, social, and academic outcomes (Astin, 1993; Cabrera, Nora, Terenzini, Pascarella, \& Hagedorn, 1999; Flowers \& Pascarella, 1999; Hagedorn, Siadat, Nora, \& Pascarella, 1997). Pike and Kuh (2006) sought to enhance the understanding of the relationships between structural diversity and campus environment. Structural diversity represents how many students from diverse groups are in the population. The study examined this relationship as mediated by interactional diversity, which represents how much diverse groups interact with one another academically and socially. Using structural equation modeling, the researchers found that a diverse population (structural diversity) is associated with higher levels of interaction among diverse groups of students (interactional diversity). Increased diversity did not, however, increase positive perceptions of the campus environment. In sum, structural diversity is a prerequisite in contributing to positive diversity outcomes, but the nature and quality of student interactions must be strong to attain those outcomes.

As it relates to structural diversity and campus climate, Hurtado, Milem, ClaytonPedersen, and Allen (1998) provided a framework for understanding campus climate 
using two domains: (1) external domains, subdivided into (a) government policy, programs, and initiatives; and (b) socio-historical forces on campus racial climate; and, (2) institutional/internal factors including (a) an institution's historical legacy of inclusion or exclusion of various racial/ethnic groups; (b) its structural diversity in terms of numerical representation of various racial/ethnic groups; (c) the psychological climate of perceptions and attitudes between and among groups; and (d) the behavioral climate dimension, characterized by intergroup relations on campus. This study reinforced the Pike and Kuh (2006) study by asserting that students are less likely to report negative experiences with the campus climate when they feel valued and supported (Hurtado, Milem, Clayton-Pedersen, \& Allen, 1998). Furthermore, both structural diversity (quantity of diverse students and faculty) and institutional commitment (quality of interactions amongst diverse groups) are important.

In addition, Flowers and Pascarella (1999b) examined the cognitive cffects of racial composition on African American students' after three years of college. Even after controlling for a number of confounding variables, attendance at an HBCU significantly enhanced the intellectual growth of African American students. In both the 1999a and 1999b studies by Flowers and Pascarella, many of the findings were conditional, and the results were influenced by different background characteristics or different experiences in college. These within-group differences cannot be ignored, and the literature identifies differences in how certain institutional types acknowledge and support African American student differences better than others (Minor, 2008).

Somewhat dissimilar, Nora and Cabrera (1996) contended that with few exceptions, there exists little evidence to support the predictive ability of students' 
negative perceptions of the campus environment or climate. Thus, they sought to document the role negative perceptions of prejudice and discrimination play among minority and majority students. Using students at a major predominately White commuter institution in the Midwest, Nora and Cabrera found that minority students did perceive more discrimination on campus than did their White peers. These perceptions did not, however, have the overwhelming negative effect on persistence for minority students that it is presumed to exert. This is in large part due to the positive effects of family encouragement and interaction that negates the perceptions of prejudice and discrimination. Both minority and majority students perceived negative campus climates, though the minority students' perceptions were more negative.

Suarez-Balcazar, Orellana-Damacela, Portillo, Rowan, and Andrews-Guillen (2003) advanced the work of Nora and Cabrera (1996) with their discussion of differential treatment of students of color in college. Suarez-Balcazar et al. (2003) randomly sampled 500 White students and 495 students of color enrolled at a private Midwestern urban university. The researchers were interested in the frequency with which students experienced campus-related situations of discrimination, the degree to which these situations were offensive, and the extent to which these situations were attributable to the students' race. Similar to other research findings, Suarez-Balcazar et al. found that African American students, on average, experienced more differential treatment than their Hispanic, Asian, and White classmates. This finding held constant in both in-class and out-of-class experiences.

Along these lines, Flowers (2004) studied the relationships among student background, racial identity, and perceived ethnic fit (PEF) with the college environment 
for African American students at a PWI in the Southeastern U.S. The sample consisted of 146 African American undergraduate students, most of whom were women ( $n=118)$. Multiple regression analyses were used to examine relationships between the variables listed above. Student background was not correlated to perceived ethnic fit, though student background was positively correlated to organizational involvement. Consistent with the literature on racial identity attitudes and African American student involvement in ethnic or cultural organizations, the study found that students participated in fewer cultural/ethnic organizations when they felt less fit due to their ethnicity. Of special note, the researcher used different measures of racial identity than other studies in this review.

Some researchers suggest that homogenous environments negatively impact students' openness to diversity, which is contrary to many missions of public higher education institutions. Flowers and Pascarella (1999a) wanted to study the effects of an institution's racial composition on African American students' openness to diversity. They found little evidence that the homogenous environment of a HBCU had any negative effects on the growth of African American students' openness to racial, cultural, or value diversity. Similar to findings by Flowers (2004), the perceived racial environment was found to negatively affect African American students' openness to diversity, despite the type of institution attended. The following describes African American experiences at PWIs and HBCUs.

\section{HBCUs and PWIs in Public Higher Education}

Researchers have examined differences in the cognitive and psychosocial development and outcomes of African American students based on type of institution (e.g., Carnegie type, size, selectivity, control, and affiliation) (Pascarella \&Terenzini, 
2005). A recent comprehensive study by Pike, Kuh, and Gonyea (2003) found no meaningful links between student learning gains and Carnegie classification of the institution. Pike and Kuh (2006) reported that although students at liberal arts colleges interact informally with diverse others more than at different institutional types, this is not a function of institutional control or size. Differences in outcomes for students attending HBCUs and PWIs are well researched (Allen, 1992; Cokley, 1999; Fleming, 1984; Flowers \& Pascarella, 1999; Outcalt \& Skewes-Cox, 2002), though results of these studies have been mixed.

Over the last several decades, researchers have paid considerable attention to two lines of investigation as it relates to African Americans attending HBCUs in comparison to those attending PWIs. The first line of scholarship concerns the impact of attendance on academic, intellectual, and cognitive outcomes. The other line of research is concerned with the affective and psychosocial outcomes of attendance. Overall, the evidence suggests that African American students make intellectual/cognitive and psychosocial/affective gains at HBCUs that are equal to or greater than the gains made by their counterparts attending PWIs (Flowers \& Pascarella, 1999). African American students at HBCUs also experience less overt racism and isolation, as well as more satisfaction with their educational experience than their PWI counterparts (Outcalt \& Skewes-Cox, 2002). Finally, research has shown that African American students attending HBCUs are more comfortable and more successful in attaining their educational goals than peers at PWIs.

Allen (1992) conducted a quantitative study of the differences in the college experience between Black undergraduates who attend HBCUs and those who attend 
PWIs. Allen sought to understand how campus context and student background influences African American student success in college. In this study, Allen examined three dependent variables: (a) social involvement, (b) academic achievement, and (c) occupational aspirations, and found that Black students attending PWIs reported lower academic achievement than their HBCU counterparts. Allen went on to report that Black students attending PWIs reported lower college grades, higher grades in high school, and less favorable relations with their professors than their HBCU counterparts.

As it relates to involvement for Black students attending PWIs, Allen (1992) also noted that Black students' involvement was most influenced by their White peers, and the belief that they made the right choice to attend their particular college. As mentioned carlier in this review, positive involvement with faculty and a sense of unity among Black students also led to more involvement for Black students. Allen's findings suggested the strong interaction between Black students' positive outcomes in college, and the setting and context in which the student operates. The importance of interpersonal relationships students created with each other was also highlighted. The researcher attributed Black student success at HBCUs to the psychological climate created within these institutions. He also reported that students were allowed to take intellectual risks and, most importantly, felt valued, comfortable, supported, and validated. This validation, in turn, created higher self-esteem, self-confidence, and a sense of empowerment over the student's education.

Museus, Nichols, and Lambert (2008) sought to deepen the understanding of the effects of racial climates on students' persistence decisions. The researchers also sought to expand the findings to a national population, and discover the extent to which those 
effects are applicable across racial minority sub-populations. As scholars have operationalized racial climate a number of ways, Museus et al. defined campus racial climate as attitudes and perceptions about the environment as it relates to race. Their findings supported earlier research that students from different racial groups perceive, experience, and react differently to campus racial climates (Cabrera et al., 1999; Nora \& Cabrera, 1996; Hurtado, Milem, Clayton-Pedersen, \& Allen, 1999). This study also supported findings by Pascarella and Terenzini (2005) that campus racial climate has an indirect effect on persistence and is conditional based on race. African American students in this study were the least satisfied with their campus racial climate. The following examines factors within PWIs and HBCUs separately that are related to African American student persistence and success.

Predominately White institutions. The experiences of Black students at PWIs are varied and diverse. Davis et al. (2004) expand on many of the themes that have emerged in quantitative analyses. They examined university life through the eyes of 11 successful Black undergraduate students at a Southeastern PWI using qualitative analysis. Five themes emerged reflecting the experiences of these students and are summarized as follows:

Unfairness, sabotage, and condescension are everyday occurrences in the white world in which I live at the university. In order to connect with students, faculty, administrators, and others on and around campus, I must be the one to initiate interaction, and I must also prove I am worthy as a student or friend. I am continually made aware of how different I am, especially when I am the only back student in a class. Life is full of opposites: I feel as if I am seen as the same as other blacks by many whites, yet I often feel different from other black students. Perhaps the most common experience I have is one of extremes: Either I am invisible or I am its opposite-I am super-visible. (p. 436)

Several other studies have examined the experiences of African American students at 
PWIs. Since these institutions enroll over $85 \%$ of the African American students in the U.S. (Planty et al., 2009), they are ripe for research on African American student success. Chavous (2000) further goes on to state that research on African American involvement at PWIs begins with the assumption that the African American students do not fit in with the environment. Chavous goes on to state that though research indicates group differences, it does not provide details about individual characteristics within the groups and their interaction with the environment. This information could shed light on the educational experiences and outcomes of African American students.

African Americans are largely under-represented in the mainstream campus life at PWIs and have trouble integrating into the campus environment (Chavous, 2000; Pascarella \& Terenzini, 1991, 2005; Sutton \& Kimbrough, 2001). Sergent and Sedlacek (1990) reported that the low involvement of African Americans at PWIs indicated these students' isolation from the community. Similarly, Sutton and Terrell (1997) reported that few African Americans were involved outside of the classroom, especially at PWIs. Stereotype threat, a type of confirmation bias, and the lack of sufficient numbers of African American role models at PWIs further exacerbates the negative experiences and absence of involved African American students (Cuyjet, 2006; Harper \& Wolley, 2002; Rosch, 2007).

Littleton (2001) conducted a qualitative study of 24 African American students at a small PWI located in the Southeastern U.S. Semi-structured interviews were used as the primary data-collection source. The primary factor attributing to the persistence of African American students at this institution was approachable and caring faculty. Six other themes emerged that reflected students' attitudes towards how the environment did 
or did not support their persistence. These themes ranged from being the Black spokesperson; a lack of African American role models, vis-à-vis African American faculty; stereotypes; and being a minority within a minority.

Littleton (2002) extended his study of African American persistence at small PWIs through qualitative research at four institutions located in small or rural towns in the southern Appalachian region of the U.S. Participants were African American juniors or seniors in good standing with their institutions. Purposeful sampling was used to identity 24 students and five administrators for the study. Semi-structured, open-ended interviews were used to collect data. Again faculty interaction and involvement in student organizations were reported as important factors in determining persistence. Consistent with previous literature, athletics and African American social organizations were seen as important to persistence (Cuyjet, 2006; Harper, 2006; Museus, 2008; Taylor \& HowardHamilton, 1995). Participants noted that activities with little appeal to African American students diminished their experience.

Historically Black colleges and universities. Pascarella and Terenzini (2005) stated that there is fairly extensive evidence to suggest that HBCUs provide a climate that supports African American academic and social adjustment better than PWIs. Pascarella and Terenzini (1991) found that African American students at HBCUs self-reported greater gains in critical thinking and analytical skills than their African American counterparts at PWIs. These findings support existing literature on HBCUs' ability to create a welcoming environment for African American students. Students who feel more welcomed on campus, or have a higher sense of belonging, tended to engage more with the college environment. According to several studies (e.g., Astin, 1984, 1993; Pascarella 
\& Terenzini, 1991, 2005; Tinto, 1975, 1987, 1993), students who engage more persist at higher rates and are more successful in college. This is true despite Allen's (1992) findings that HBCUs enroll students who otherwise might not attend college due to personal, financial, social, or academic barriers.

In a similar study examining HBCUs, Latiker (2006) focused on the positive and negative influences on persistence of African American students attending HBCUs and proposed a model of persistence at private Black colleges in the U.S. The site of the study is a small HBCU located in a Southern city in the U.S. Participants were recommended by faculty/administration and from student observations. Four students were selected for this study and were subjected to formal and informal interviews and observations. Six key factors emerged from this study: (a) physical appearance of the campus, (b) living conditions, (c) student/faculty relationships, (d) school influence/culture, (e) student involvement, and (f) the impracticality of transferring. Despite the small sample size used, the data provided useful insight into the role of private HBCUs in the persistence of African American students.

In summary, the findings at both PWIs and HBCUs demonstrate a need to identify other factors related to African American students that will support their integration and success in higher education. The review of literature up until this point primarily applied to African American students generally. When disaggregated by gender, there are significant differences in the enrollment, involvement, persistence, and graduation rates of African American males and females. African American males lag behind on all of these factors. Despite this reality, there is a paucity of research specifically on African American male success in higher education. 


\section{African American Males}

\section{Background}

Several authors have reported a lack of strategic and purposeful institutional outreach to African American men as a primary problem in higher education (Flowers, 2004; Harper \& Wolley, 2002). In African American Men in College, Bonner and Bailey (2006) identified five critical factors that promote a climate of success for African American men: (1) peer group influence, (2) family influence and support, (3) faculty relationships, (4) identity development and self-perception, and (5) institutional environment. This dissertation examined four of these five critical factors: peer group influence, faculty relationships, identity development and self-perception, and institutional environment. This segment of the dissertation will report findings as they relate to African American men and these factors.

The lack of intentional outreach has been found to lessen the perceived institutional commitment of African American men, which according to some researchers (Tierney, 1999; Tinto, 1987), reduces persistence. African American male persistence and graduation rates at American four-year institutions of higher education are lower than female counterparts and other ethnic groups (Cuyjet, 2006). Cuyjet (1997) examined data from the College Student Experiences Questionnaire (CSEQ) and found that women engaged more in the campus socially (e.g., involvement with clubs and organizations) and in the classroom (e.g., taking detailed notes) than men.

Similarly, Flowers (2004), using the same instrument as Cuyjet (1997), found that African American men consistently reported lower levels of involvement than women along several variables (e.g., looking in the newspaper for notices of events and 
organizations, attending programs, events or meetings of organizations, or working on a committee). For those men that are involved, Harper (2006) contends that the most engaged students find their start in Black student unions, NAACP chapters, historically Black fraternities, and other minority student organizations.

\section{Involvement}

Harper (2005) and Harper and Quaye (2007) provided greater understanding to the African American male experience by examining high-achieving African American men who succeeded as opposed to those who dropped out. The authors examined the effects of active out-of-class engagement on the experiences of 32 high-achieving African American men at six PWIs in the Midwestern region of the U.S. Similar to Museus (2008), a phenomenological design was employed and face-to-face interviews were used to collect data. Findings indicated that participants were heavily involved in African American or other cultural organizations (Harper \& Quaye, 2007). Consistent with previous research (Guiffrida, 2003), the choice to be involved related to advancing the African American community and developing certain skills, such as cross-cultural communication. Care for the African American community motivated many of the participants to take leadership roles in both mainstream and ethnic/minority organizations.

Furthermore, many of the high-achieving African American men in Harper (2005) reported that they chose to be involved because of the influence of older African American students on campus. Harper (2006) found that peer relationships between and among students helps to reinforce a sense of purpose and identity that leads to a more positive educational experience for African American men. Participants also discussed 
the most significant types of involvement for them, which included completing an internship and holding campus leadership positions. Participants reported that they were happy to have an opportunity to select experiences that matched their personal interests, which they attributed to the large number of options presented at their institution.

\section{Heterogeneity of African American Males}

Despite the findings listed above, Harper and Nichols (2008) caution against oversimplifying the African American male experience. The authors found that great heterogeneity exists within the African American male undergraduate population. Harper and Nichols conducted research at three racially diverse private institutions, one small liberal arts college, a midsize religiously affiliated university, and a large research university. The researchers used focus groups to collect data from 39 African American male participants selected with the assistance of administrators in student affairs or African American support services at the three institutions. Findings are categorized by (a) origins and characterizations of within-group heterogeneity, (b) misconceptions about Black male peers because of diversity within the population, and (c) an ethos of competition and social reticence that existed between Black male subgroups.

Harper and Nichols' (2008) research is significant because it reinforces the differences that exists within the African American male population. This necessarily affects the ways in which institutions engage and support African American male students. Given the nature of involvement and persistence, it is important to consider individual experiences, backgrounds, and affiliations when researching African American males. Six distinct subgroups of African American men emerged at the campuses under study: (a) student-athletes, (b) members of predominately Black Greek-letter 
organizations, (c) socially disengaged men, (d) campus leaders and activists, (e) urban males, and (f) men from suburban and predominately White neighborhoods. This diversity of listed male profiles (as well as others that were not listed) presents a useful lens by which to understand the behavior and motivations of African American undergraduate males. It is also important to note that these groups could overlap. This study reinforces the need for more descriptive and developmental understandings of students' behavior and motivations beyond race alone.

\section{Campus Environment and Climate}

As mentioned previously, the environment and climate of institutions have a significant impact on African American student success. The findings up until this point in the literature review reported a welcoming, supportive, and effective picture of HBCUs for African American students. Kimbrough and Harper (2006) presented a less positive analysis of the current climate at these institutions, particularly as it relates to African American males. Using an inductive analytical approach, Kimbrough and Harper (2006) conducted semi-structured interviews that revealed five themes as it relates to the African American male experience at HBCUs: (1) predisposition to college, (2) academic achievement, (3) involvement and leadership development, (4) interpersonal relationships, and (5) perceptions of PWIs.

The findings revealed that the African American males attending HBCUs face academic and social challenges similar to African American males attending PWIs. The African American male participants in this study did not echo some of the findings in the research as it relates to supportive faculty and staff at HBCUs. Though the familial atmosphere of the $\mathrm{HBCU}$ was discussed, the participants attributed this atmosphere to the 
students, not the faculty and staff. These findings also reinforced the influence of the peer group in creating a welcoming and supportive climate conducive to student persistence.

Since the studies of the 1980s and 1990s, HBCUs enrolled significantly fewer students than in the past (Minor, 2008). The National Center for Education Statistics (2009) reported that in 2007 HBCUs enrolled just 13\% of the nation's African American students, compared to over $90 \%$ in 1950 . In addition, challenges for HBCUs include some of the same challenges faced at PWIs. These challenges include significantly lower numbers of African American male students enrolling, persisting, and graduating, than their female counterparts. Degree completion from the associate's degree through the doctoral degree is lower for African American men than women at HBCUs (Planty et al., 2009). Minor (2008) calls for a more contemporary examination of the role of HBCUs considering the current policy decisions, legal climate, and shifting enrollment trends.

\section{Summary of Chapter II}

As outlined in the previous chapter, the U.S. has a diverse array of post-secondary institutional types, and the students enrolled in the U.S. are equally diverse. Public institutions of higher education have a unique role in extending affordable, quality educational opportunities to the citizens of this country. Public four-year institutions also enroll more students than any other institutional type. Some have described higher education as a public good, one that serves a compelling state and national interest. Therefore, the enrollment, persistence, and successful graduation of students remain primary institutional priorities for public institutions across the country. Despite the urgency and importance of higher educational attainment espoused by administrators and decision-makers, large portions of the student population continue to fall incredibly short 
of this goal. African American males in particular have abysmal enrollment and completion rates within higher education.

Harper (2006) produced a report, Black Male Students at Public Flagship Universities in the U.S.: Status, Trends, and Implications for Policy and Practice, wherein he articulated many of the challenges that have continued to plague African American males in higher education. This report is particularly relevant to this dissertation as it analyzed African American male success at public four-year institutions across each state in the U.S. Some of the most startling statistics indicate that nationally, more than two-thirds (67.6\%) of African American men who start college will not finish in six years; at the public flagship universities in 2004, Black men had a six-year graduation rate of $44.3 \%$, which was lower than White men $(61.4 \%)$ and Black women $(53.2 \%)$; at these same institutions, Black males only represented $2.8 \%$ of the undergraduate enrollment, despite representing $7.9 \%$ of $18-24$ year olds in the population; and in 2004,30 of the 50 public flagship universities enrolled less than 500 African American male undergraduates.

Extensive research has explored why students persist or dropout of the postsecondary educational system. Several scholars have offered models to describe and address the phenomena of student departure (Braxton, 2000; Guiffrida, 2006; Kuh \& Love, 2000; Tierney, 1992; Tinto, 1987). Building on this work, Astin (1993) offered one of the first theories of student involvement, articulating the importance of student involvement in the persistence and integration process. Astin's college impact model asserts that students enter with certain inputs that interact with the college environment and produce a range of outcomes. African American students-males in particular--tend 
to demonstrate certain patterns of involvement that lead to their success. Recurrent in the literature as positive influences on African American male student involvement is interaction with faculty, interaction with peers, and involvement in student organizations.

Involvement, patterns of behavior, and motivations of African American male students in higher education is informed by the literature on racial identity development. Students exhibited different behaviors and attitudes at different stages of identity development, as defined by Cross $(1971,1991)$ and Helms (1990), among others. These behaviors and attitudes lead to certain social and academic outcomes that have been observed over the last several decades. Despite the abundance of research on racial identity development, critiques of the theory have emerged in the literature, and scholars have challenged the traditional notions of race, and its efficacy in college impact research.

A potentially useful demographic variable to use in college impact research, above and beyond race, is Collective Racial Esteem (CRE). This variable represents a student's self-concept related to racial group membership (Dugan et al., 2009), and is informed by social identity theory. Ogbu (2004) discusses collective esteem and its utility in describing why some students of color in the secondary school system persist at lower rates than their White counterparts. It appears that Ogbu's research lends some degree of credence to the utility of CRE within post-secondary research. Dugan et al. (2010) also found that CRE explained more of the variance in his study of socially responsible leadership than race alone. Luhtanen and Crocker (1992) developed an instrument that measures CRE, and this scale has been used most recently in a national study known as the Multi-Institutional Study of Leadership (MSL). 
Student involvement, racial identity, and collective racial esteem exist within the context of campus environment. Therefore, any discussion of minority student success would be lacking without an examination of the college environment. Differential treatment within campus environments is increasingly being identified as possible explanations for the differences in minority and majority student success (Nora \& Cabrera, 1996). Structural diversity, which represents the physical aspects of diversity on campus, and campus climate were both discussed in this chapter. Specific attention was paid to the experiences of African American students at PWIs compared to HBCUs.

Due to the paucity of research specifically related to African American male undergraduates, this population was used as a primary focus for this study. This dissertation will advance the literature on African American males through an exploration of CRE and its impact on African American male undergraduates' involvement. Enhanced understanding of CRE's influence on African American males could lead to increased involvement for these students. The increased involvement of these students could result in an array of positive outcomes, including improved integration, persistence, and graduation rates.

\section{Research Questions}

This study seeks to determine if there is a relationship between CRE scores and types of involvement for African American male undergraduates at public four-year institutions in the U.S. This study also seeks to identity the extent to which there may be differences in African American male undergraduate CRE scores and African American female undergraduate CRE scores, and to identity the extent to which there may be differences in African American male undergraduate CRE scores at PWIs compared to 
those attending HBCUs. Four specific questions are addressed through this study:

1. Do CRE scores for African American undergraduate males significantly predict quantity of campus involvement?

2. Do CRE scores of African American undergraduate male students significantly predict the following:

(a) the decision to join an ethnic/minority organization;

(b) degree of interaction with faculty;

(c) degree of interaction with peers.

3. Is there a statistically significant difference between African American male and African American female undergraduates' CRE scores?

4. Is there a statistically significant difference between undergraduate African American students' CRE scores at a PWI compared to a HBCU? 


\section{CHAPTER III}

\section{METHODOLOGY}

\section{Overview}

This dissertation will examine the influence of collective racial esteem (CRE) on the quantity and type of involvement for African American male undergraduate students in public four-year institutions of higher education in the U.S. The site of analysis for the study was 48 public four-year institutions that participated in the 2009 Multi-Institutional Study of Leadership (MSL). The literature review analyzed in Chapter II supported the choice of dependent (criteria) variables, covariates, and independent (predictor) variables of interest. This chapter describes the methodology used to address the research questions listed in Chapter II.

\section{Theoretical Framework}

The framework for this study is undergirded by previous research in the areas of higher education and student affairs. Astin's (1993) College Impact Model (InputsEnvironment-Outcomes) provided the variables under study as it relates to pre-college demographics, involvement in college, faculty, and peer interactions. Tinto's (1987) model of student departure, Tierney's (1999) model of cultural integrity, and Kuh and Love's (2000) cultural perspective of student departure are commonly used frameworks for exploring college student persistence. Each of these persistence frameworks hypothesizes linkages between the following variables: involvement in college, persistence, and interaction between the institutional environment and individual 
students. Each of these frameworks also implicitly demonstrates the dynamic relationship between culture and identity, and how the two can change over time through interaction.

Though all these frameworks are used to understand the factors contributing to student departure, Kuh and Love's (2000) model is particularly relevant to this study. This model accounts for student behavior that results from the interaction of culture as it relates to involvement and belonging. Kuh and Love's (2000) model is built on eight propositions that describe the intersection of cultural factors, environmental factors, and a students' decision to leave college.

Tierney (1997) also discussed a model of education in post-secondary institutions where an individual's identity is "affirmed, honored and incorporated into the organization's culture" (p. 8). His model rests on five key points, and is similar to Kuh and Love's (2000) propositions. At the core of Tierney's view of student departure, is a concentration on individual identity and background as a means of improving academic success. Both Tierney (1997) and Kuh and Love (2000) provide useful frameworks by which to examine African American student persistence and departure. This is due to the importance of culture vis-à-vis race/ethnicity for African American students (Cokley, 1999). Kuh and Love and Tierney's models are shown in their entirety in Table 1. 
Table 1

Kuh and Love (2000) Propositions vs. Tierney's (1997) Five Key Points

\begin{tabular}{|c|c|}
\hline Author / Framework & Propositions / Key Points \\
\hline $\begin{array}{l}\text { Kuh and Love }(2000) \text { - Cultural } \\
\text { Perspective of Student Departure }\end{array}$ & $\begin{array}{l}\text { (1) The college experience, including a } \\
\text { decision to leave college, is mediated through } \\
\text { a student's cultural meaning-making system } \\
\text { (2) one's cultures of origin mediate the } \\
\text { importance attached to attending college and } \\
\text { earning a college degree } \\
\text { (3) knowledge of a student's cultures of origin } \\
\text { and the cultures of immersion is needed to } \\
\text { understand a student's ability to successfully } \\
\text { negotiate the institution's cultural milieu } \\
\text { (4) the probability of persistence is inversely } \\
\text { related to the cultural distance between a } \\
\text { student's culture(s) of origin and the cultures } \\
\text { of immersion } \\
\text { (5) students who traverse a long cultural } \\
\text { distance must become acclimated to dominant } \\
\text { cultures of immersion or join one or more } \\
\text { enclaves } \\
\text { (6) the amount of time a student spends in } \\
\text { one's cultures of origin after matriculating is } \\
\text { positively related to cultural stress and reduces } \\
\text { the chances they will persist } \\
\text { (7) the likelihood a student will persist is } \\
\text { related to the extensity and intensity of one's } \\
\text { socio-cultural connections to the academic } \\
\text { program and to affinity groups } \\
\text { (8) students who belong to one or more } \\
\text { enclaves in the cultures of immersion are more } \\
\text { likely to persist, especially if group members } \\
\text { value achievement and persistence. }\end{array}$ \\
\hline Tierney (1997) - Cultural Integrity & $\begin{array}{l}\text { (1) collaborative relations of power } \\
\text { (2) connections across home, community, and } \\
\text { schooling } \\
\text { (3) local definitions of identity } \\
\text { (4) excellence } \\
\text { (5) academic support }\end{array}$ \\
\hline
\end{tabular}




\section{Research Design}

This research follows a quantitative exploratory design using secondary archival data from the MSL. The survey was designed to measure the impact of various precollege and college environmental factors on student leadership development. The purpose of the MSL is threefold: (a) to explore higher education's role in developing student leadership with a focus on the college environment; (b) to explore leadership capacity across demographic differences and involvement levels; and (c) to enhance the understanding of leadership through new programs and services (http://www.leadershipstudy.net). This predictive study examines the relationship between predictor variables representing CRE: membership, identity, private and public, and students' quantity and type of involvement and interactions in college. For purposes of this dissertation, "quantity" refers to the amount of time a student invests in being involved in general as reported by the student, not necessarily the number or types of activities in which the student participates.

The study gathered data on African American undergraduate students attending 48 public four-year institutions throughout the U.S. that completed the MSL in the Spring 2009 semester. The MSL is comprised of over 400 items assessing various undergraduate student demographic, environment, and outcome variables. The MSL also contains several sub-studies, one of which is CRE, which represents students' self-concept related to racial group membership (Dugan et al., 2009). The MSL predictor variables used in the study for RQ 1 and RQ 2 were Private CRE, Public CRE, Importance to Identity, and Membership CRE. For RQ3 and RQ4, the independent variables were gender and institutional type, respectively. The criterion variables for RQ 1 and RQ 2 were quantity 
of involvement, involvement in identity based organizations, faculty interaction, and peer interaction. For RQ3 and RQ4, the dependent variables were the four sub-scales of CRE.

\section{Participants}

Response rate for the entire $2009 \mathrm{MSL}$ was $34 \%$, representing 118,733 usable cases. Twenty-six percent of the cases were students of color, $65 \%$ were women, and $35 \%$ were men. The sample referred to in this study $(N=1,316)$ consisted of African American undergraduate students attending public four-year institutions and who completed the CRE sub-study within the MSL in the Spring 2009 semester. Three hundred and ninety (29.6\%) participants in the sample were male, and $926(70.4 \%)$ were female. A recommended minimum acceptable sample size for regression analysis when testing each of the individual predictors is $104+k$, where $k$ is the number of predictor variables (Green, 1991, as cited in Field, 2005). For this study, the number of predictor variables was four, therefore $104+4=108$. The sample size of males and females taken together or separately exceeds this number.

The MSL allowed respondents to choose multiple racial/ethnic groups, or choose not to answer. For purposes of this study, African Americans students are those that identified as "Black or African American" exclusively. Those respondents who chose multiple identities or that did not answer were not included in the analysis. Students who identified as "Transgender" or did not answer for their gender were not included in the analysis. International students were also excluded from the analysis.

Ninety-one percent of the sample represented full-time students, and $78.1 \%$ of the sample ranged between the ages of 18-24 years old. Seniors were the most represented in the sample with 433 respondents (32.9\%). Eighty-three percent of the sample had a 
cumulative GPA of 2.5 or higher. Of the sample, $51.1 \%$ attended institutions classified by Carnegie as Masters institutions, followed by $45.8 \%$ of the sample attending Doctoral/Research or Research (Very High) institutions. A majority (56\%) of the students attended large institutions and $68 \%$ of the sample attended institutions located in cities.

\section{Data Collection}

The MSL was administered entirely via the internet. Participants received a series of emails asking them to participate in the study, and the emails were derived from customizable templates used by institutions. Incentives were used at various institutions to increase response rates. Each student received an invitation email and up to three reminder emails until the survey was completed. Students participating in the study were provided a randomly assigned identification number via a secure website. Using this randomly assigned ID number to allow students to take the survey protected confidentiality. Participants were first asked for consent to participate before the survey began (NCLP, 2009).

The Principal Investigator (PI) of the MSL granted access to the national data. The data file was provided by the Center for Student Studies, LLC. The request for data was submitted electronically to the PI and contained the name and contact information of the proposer; program, university, and advisor for the study; a prospectus that contained the study purpose and specific research questions; sample requested; specific variables; and possible publication outlets for the study. Prior to access being granted, the proposer had to obtain IRB approval for the study and sign an agreement to abide by MSL and institutional IRB policies and procedures. 


\section{Instrument Used in Data Collection}

Data collected were part of the MSL, which was constructed to begin benchmarking and quantifying environmental factors in college that have an influence on student leadership development (Dugan, 2005). The MSL examines data at the individual and institutional level, using a national sample of undergraduate students. Since 2006 the MSL has been administered at over 150 campuses across the U.S. and other international locations. For purposes of this study, data were only drawn from U.S. respondents because the construction and definition of race varies greatly in international contexts. The first iteration of the MSL was in 2006 and the second iteration was in the spring of 2009. The National Clearinghouse for Leadership Programs (NCLP), housed at the University of Maryland, College Park, coordinated the national study in collaboration with the Center for Student Studies, LLC. The MSL is administered entirely online, and a version of the MSL is included in Appendix X: MSL 2009 Main Questionnaire.

The MSL is adapted from the Socially Responsible Leadership Scale (SRLS) (Tyree, 1998). The 2006 questionnaire was updated for the 2009 version based on findings from the original study as well as feedback from participating institutions. The MSL has over 400 variables, scales, and composite measures. Sub-studies were included in the instrument, which were sets of questions randomly administered to $50 \%$ of the student sample at each institution (http://leadershipstudy.net).

The Social Change Model (SCM) (HERI, 1996) is the theoretical framework for the MSL. The SCM has eight values within the model, and defines leadership as a valuesladen process that focuses on positive change as the ultimate outcome of leadership (HERI, 1996). Astin's (1993) input-environment-outcomes (I-E-O) model is the 
conceptual framework for the MSL instrument. This model is described in detail in chapter Il. Participating MSL institutions were classified by Carnegie classification, control (private vs. public), size (large or small), affiliation (religious vs. secular), and setting (urban, rural, suburban) (http: leadershipstudy.net). A list of participating institutions can be found in Appendix X: 2009 Participating Schools Profiles.

\section{Instrument Design}

The MSL served as a tool to measure the influence of a student's experiences in college on their development of socially responsible leadership (Dugan, 2005). Using Astin's (1993) model, a student's leadership development can be measured through examining outcomes specific to institutional contexts, while also controlling for personal characteristics (Dugan, 2005). The MSL instrument was over 40 -items and took approximately 20-25 minutes to complete, with built in skip-patterns to accommodate varying degrees of student involvement. Students that were more involved naturally took longer to complete the survey than those students who were not as involved.

The instrument was divided into three parts to represent the three components in Astin's (1993) model. Inputs included demographic information, as well as student perceptions about leadership and his or her development prior to beginning college. Environmental factors included student's on- and off-campus involvement, including membership in student organizations, employment, and volunteer and community service work. Outcomes within this instrument included a scale to measure one's self-reported capacity to lead within the structure of the Social Change Model, and a series of substudy variables including leadership efficacy, spirituality, mentoring, and CRE (Rosch, 2007). 


\section{Instrument Scales and Validity and Reliability}

As previously mentioned, the MSL included more than 400 variables, scales, and composite measures. The Socially Responsible Leadership Scale (SRLS) (Tyree, 1998) comprised the core of the MSL instrument and has undergone significant and extensive psychometric work. Content validity of the original SRLS was established via early pilot studies of the MSL instrument as well as with the 2006 iteration of the study. The scale demonstrated appropriate and consistent relationships amongst outcomes variables and other theoretically supported measures. All eight scales in the original version and subsequent iterations thereafter demonstrated consistent performance levels.

The MSL instrument contained a 16-question sub-study that measured CRE. This variable is derived from social identity theory and represents a students' self-concept related to racial group membership (Dugan et al., 2009). Figure 3 shows a graphic depicting the origins of $\mathrm{CRE}$ and its connection to social identity theory.

\section{Social Identity Theory}

\section{Collective Self-Esteem}

\section{CRE}

Figure 2. Origins of collective racial esteem (CRE)

Helms and Cook (1999) found that racial categories serve as sociopolitical constructions that denote unequal access to resources. This results in certain negative psychological consequences for individuals socialized into particular groups. Despite this 
fact, college impact research continues to rely on these limiting dimensions of race, rather than the more complex psychological influences related to identity (Dugan, Komives, \& Segar, 2008). CRE has four parts: Identity Salience (the degree of centrality of one's racial group membership to their self-concept); Private CRE (personal assessment of the value of one's racial group); Public CRE (personal beliefs regarding how others value one's racial group); and Membership CRE (personal beliefs about how well one functions as a member of their racial group) (Dugan et al., 2009; Luhtanen \& Crocker, 1992;).

The Collective Self-Esteem Scale (CSES) (Luhtanen \& Crocker, 1992) is the instrument from which the CRE scale within the MSL originated. In the Luhtanen and Crocker study, coefficient alphas for the race-specific version of the CSES were .75 for membership CRE, .72 for private CRE, .88 for public CRE, and .84 for identity scales. In the 2009 MSL, coefficient alphas were .71 for membership CRE, .82 for private CRE, .81 for public CRE, and .82 for identity scales (NCLP, 2009). These results represent moderate to high reliability coefficients (Field, 2005).

\section{Predictor Variables}

The predictor variables explored in this study for RQ 1 and RQ 2 included the following continuous variables: membership CRE, private CRE, public CRE, and identity. Each was measured on a 7-point Likert scale ranging from $1=$ Strongly Disagree to $7=$ Strongly Agree. All variable information collected from the MSL was self-reported by participants on the survey. For RQ3, gender is used as the independent variable with two levels: male and female. For RQ4 the independent variable is type of institution, predominately White institutions (PWIs) or historically Black colleges and universities (HBCUs). 


\section{Criterion Variables}

The criterion variables for RQ 1 and RQ 2 were quantity of campus involvement, decision to join an ethnic/minority organization, interaction with faculty, and interaction with peers. CRE scores were used as continuous dependent variables for RQ3 and RQ4. Campus involvement is represented by the item "Have you ever been an involved member in college organizations, " and is measured on a 5-point Likert scale ranging from $1=$ Never to $5=$ Much of the time. Decision to join an ethnic/minority organization is a dichotomous variable measured by "yes" or "no" and recorded 1 or 0 , respectively.

Two dichotomously measured items on the MSL, measured by "yes" or "no" and recorded 1 or 0 , respectively, represented interaction with faculty. The questions asked respondents if they have a mentor relationship with a faculty member and if they have ever participated in research with a faculty member. The peer interaction variable was operationalized using several variables in this study, and are outlined in Table 2. Astin's (1993) delineation of peer involvement served as a foundation for variable choice, and included mentoring other students, participating in intramural sports, being a member of a social fraternity or sorority, elected to a student office, and membership in student clubs or organizations, amongst other activities in college. These variables were all dichotomous, measured by "yes" or "no" and recorded 1 or 0 , respectively. The dependent variables for RQ3 and RQ4 were the four sub-scales of CRE. 
Table 2

MSL Items Representing Peer Interaction Variable for Research Question $2 c$

\begin{tabular}{|c|c|}
\hline MSL Item number & MSL Item Description \\
\hline $16 \mathrm{a}$ & $\begin{array}{l}\text { Academic/Departmental/Professional (ex. } \\
\text { Pre-Law Society, an academic fraternity, } \\
\text { Engineering Club) }\end{array}$ \\
\hline $16 b$ & $\begin{array}{l}\text { Arts/Theater/Music (ex. Theater group, } \\
\text { March Band, Photography Club) }\end{array}$ \\
\hline $16 \mathrm{c}$ & $\begin{array}{l}\text { Campus-Wide Programming (ex. program } \\
\text { board, film series board, multicultural } \\
\text { programming committee) }\end{array}$ \\
\hline $16 \mathrm{~d}$ & $\begin{array}{l}\text { Identity-Based (ex. Black Student Union, } \\
\text { LGBT Allies, Korean Student Association }\end{array}$ \\
\hline $16 \mathrm{e}$ & $\begin{array}{l}\text { International Interest (ex. German Club, } \\
\text { Foreign Language Club) }\end{array}$ \\
\hline $16 \mathrm{f}$ & $\begin{array}{l}\text { Honor Societies (ex. Omicron Delta Kappa } \\
\text { [ODK], Mortar Board, Phi Beta Kappa) }\end{array}$ \\
\hline $16 \mathrm{~g}$ & $\begin{array}{l}\text { Media (ex. Campus Radio, Student } \\
\text { Newspaper) }\end{array}$ \\
\hline $16 \mathrm{~h}$ & Military (ex. ROTC, cadet corps) \\
\hline $16 \mathrm{i}$ & $\begin{array}{l}\text { New Student Transitions (ex. admissions } \\
\text { ambassador, orientation advisor) }\end{array}$ \\
\hline $16 j$ & Resident Assistants \\
\hline $16 \mathrm{k}$ & $\begin{array}{l}\text { Peer Helper (ex. academic tutors, peer } \\
\text { health educators) }\end{array}$ \\
\hline 161 & $\begin{array}{l}\text { Advocacy (ex. Students Against } \\
\text { Sweatshops, Amnesty International) }\end{array}$ \\
\hline $16 \mathrm{~m}$ & $\begin{array}{l}\text { Political (ex. College Democrats, College } \\
\text { Republicans, Libertarians) }\end{array}$ \\
\hline $16 n$ & $\begin{array}{l}\text { Religious (ex. Fellowship of Christian } \\
\text { Athletes, Hillel) }\end{array}$ \\
\hline 160 & $\begin{array}{l}\text { Service (ex. Circle K, Habitat for } \\
\text { Humanity) }\end{array}$ \\
\hline $16 p$ & $\begin{array}{l}\text { Multi-Cultural Fraternities and Sororities } \\
\text { (ex. National Pan-Hellenic Council } \\
\text { [NPHC] groups such as Alpha Phi Alpha } \\
\text { Fraternity Inc., or Latino Greek Council } \\
\text { groups such as Lambda Theta Alpha) }\end{array}$ \\
\hline $16 q$ & $\begin{array}{l}\text { Social Fraternities or Sororities (ex. } \\
\text { Panhellenic or Interfraternity Council } \\
\text { groups such as Sigma Phi Epsilon or Kappa } \\
\text { Kappa Gamma) }\end{array}$ \\
\hline
\end{tabular}




\begin{tabular}{|ll|}
\hline $16 \mathrm{r}$ & $\begin{array}{l}\text { Sports-Intercollegiate or Varsity (ex. } \\
\text { NCAA Hockey, Varsity Soccer) }\end{array}$ \\
\hline $16 \mathrm{~s}$ & $\begin{array}{l}\text { Sports-Club (ex. Club Volleyball, Club } \\
\text { Hockey) }\end{array}$ \\
\hline $16 \mathrm{t}$ & $\begin{array}{l}\text { Sports-Intramural (ex. Intramural flag } \\
\text { football) }\end{array}$ \\
\hline $16 \mathrm{u}$ & $\begin{array}{l}\text { Recreational (ex. Climbing Club, Hiking } \\
\text { Group) }\end{array}$ \\
\hline $16 \mathrm{v}$ & $\begin{array}{l}\text { Social/Special Interest (ex. Gardening } \\
\text { Club, Sign Language Club, Chess Club) }\end{array}$ \\
\hline $16 \mathrm{w}$ & $\begin{array}{l}\text { Student Governance (ex. Student } \\
\text { Government Association, Residence Hall } \\
\text { Association, Interfraternity Council) }\end{array}$ \\
\hline
\end{tabular}

\section{Data Analysis}

This study used archival data collected by the Center for Student Studies, LLC on behalf of the MSL. For human subjects' protection, no individual student identifiers were included in the data. The data analysis for the present study includes both descriptive and inferential statistics. Predictive Analytics Software (PASW) 18.0 was the statistical package used for all procedures. A table at the end of this segment contains a summary of the research questions, statistical test used to investigate the questions, and the independent and dependent variables in the study.

Since RQ1 is concerned with prediction, a regression model was used to determine the predictive ability of the predictor variables (private CRE, public CRE, membership CRE, and identity salience) to the outcome variable (quantity of campus involvement). When using simple ordinary least squares regression or multiple regression, the dependent variable must be continuous, and the predictors can be continuous or dichotomous. RQ2 is also concerned with prediction; however, in cases where the dependent variable is dichotomous and the predictor variables are continuous or dichotomous, logistic regression should be used. 
In logistic regression, instead of predicting the value of $Y$ from a predictor variable $X$ or several predictor variables, we predict the probability of $Y$ occurring given known values of $X$ or multiple $X s$. The resulting equation expresses the linear equation in logarithmic terms. The value from the equation is a probability value that ranges from 0 to 1 . Values close to 0 means that $Y$ is very unlikely to have occurred, and a value close to 1 means that $Y$ is very likely to have occurred. Unlike OLS regression, logistic regression does not assume normal distribution of the predictor variables. Logistic regression also does not assume an equal covariance matrix. Rather this form of regression assumes that "the binomial distribution describes the distribution of the errors that equal the actual $Y$ minus the predicted $Y$. Logistic regression implies that the same probability is maintained across the range of predictor values." (Peng, Lee, \& Ingersoll, 2002, pp. 9-10). This assumption is taken to be robust as long as the sample is random and observations are independent from each other.

RQ3 and RQ4 are concerned with comparing mean CRE scores of two groups of students. Multivariate Analysis of Variance (MANOVA) is used when there are multiple dependent variables and one or more independent variables. Gender and institution type were used as the independent variables in this study. Each have two levels, and the four scales of CRE were used as the continuous dependent variables for this study.

There were only two public four-year HBCUs that participated in the MSL. Other statistical methods (e.g., HLM) would have lacked sufficient power due to the small number of HBCUs; therefore, this single institution-by-institution MANOVA analysis was chosen as the preferred method of analysis. The comparison institutions had similar demographic and institutional characteristics, including Carnegie classification, 
geographic location, campus setting, tuition and financial aid data, and selectivity.

Comparison variables were based on findings in Chapter II of this dissertation as it relates to institutional factors that influence student persistence and success. Comparison data were accessed via the Integrated Postsecondary Education Data System (IPEDS) (http://nces.ed.gov/ipeds/) and the MSL classifications (http://www.leadershipstudy.net). This was done to reduce selection bias based on institutional characteristics. A summary of the institutional profiles used for comparison is listed in Table 3.

Table 3

Comparison of Institutional Characteristics

\begin{tabular}{|lcc|}
\hline \multicolumn{1}{|c}{ Institutional Characteristics } & HBCU & PWI \\
\hline African American Student Enrollment & 6,260 & 3523 \\
\hline Size & Medium & Large \\
\hline Control & Public & Public \\
\hline Carnegie Classification & Research (Very High) & Research (Very High) \\
\hline Selectivity & Competitive & Competitive \\
\hline Affiliation & Secular & Secular \\
\hline Setting/Geographic Region & City / Southeastern U.S. & City / Southeastern U.S. \\
\hline
\end{tabular}

Below is a summary table of the research questions, statistical tests, and independent and dependent variables used in this study. 
Table 4

Summary of Statistical Tests Used in Study

\begin{tabular}{|c|c|c|c|}
\hline $\begin{array}{l}\text { Research } \\
\text { Questions }\end{array}$ & Statistical Tests & $\begin{array}{l}\text { Independent } \\
\text { Variable(s) }\end{array}$ & Dependent Variable(s) \\
\hline 1 & Multiple Regression & $\begin{array}{l}\text { 1. Membership CRE } \\
\text { 2. Private CRE } \\
\text { 3. Public CRE } \\
\text { 4. Identity } \\
\text { (1= Strongly Disagree, } 7= \\
\text { Strongly Agree) }\end{array}$ & $\begin{array}{c}\text { Quantity of Campus } \\
\text { Involvement } \\
(1=\text { Never, } 5=\text { Much of } \\
\text { the time })\end{array}$ \\
\hline $2 a$ & Logistic Regression & $\begin{array}{l}\text { 1. Membership CRE } \\
\text { 2. Private CRE } \\
\text { 3. Public CRE } \\
\text { 4. Identity } \\
\text { (1 = Strongly Disagree, } 7= \\
\text { Strongly Agree) }\end{array}$ & $\begin{array}{c}\text { Decision to Join an } \\
\text { Ethnic/Minority } \\
\text { Organization }\end{array}$ \\
\hline $2 b$ & Logistic Regression & $\begin{array}{l}\text { 1. Membership CRE } \\
\text { 2. Private CRE } \\
\text { 3. Public CRE } \\
\text { 4. Identity } \\
\text { (1 = Strongly Disagree, } 7= \\
\text { Strongly Agree) } \\
\end{array}$ & $\begin{array}{l}\text { Faculty Interaction } \\
\text { (Yes, No) }\end{array}$ \\
\hline $2 c$ & Logistic Regression & $\begin{array}{l}\text { 1. Membership CRE } \\
\text { 2. Private CRE } \\
\text { 3. Public CRE } \\
\text { 4. Identity } \\
\text { (1 = Strongly Disagree, } 7= \\
\text { Strongly Agree) } \\
\end{array}$ & $\begin{array}{l}\text { Peer Interaction } \\
\quad(\text { Yes, No) }\end{array}$ \\
\hline 3 & MANOVA & $\begin{array}{c}\text { Gender } \\
(1=\text { Male, } 2=\text { Female })\end{array}$ & $\begin{array}{l}\text { 1. Membership CRE } \\
\text { 2. Private CRE } \\
\text { 3. Public CRE } \\
\text { 4. Identity } \\
\text { (1 = Strongly Disagree, } 7= \\
\text { Strongly Agree })\end{array}$ \\
\hline 4 & MANOVA & $\begin{array}{c}\text { Institutional Type } \\
\text { Predominately White } \\
\text { Institution vs. } \\
\text { Historically Black } \\
\text { College \& University } \\
\end{array}$ & $\begin{array}{l}\text { 1. Membership CRE } \\
\text { 2. Private CRE } \\
\text { 3. Public CRE } \\
\text { 4. Identity } \\
(1=\text { Strongly Disagree, } 7= \\
\text { Strongly Agree })\end{array}$ \\
\hline
\end{tabular}




\section{Study Delimitations}

Delimitations placed on this research were that the populations for this study were drawn from a national dataset that included institutions that paid for participation in the MSL in the Spring 2009 semester. The participants were only undergraduate students attending public four-year institutions. Additional delimitations included using only one PWI and one HBCU to compare differences in CRE scores for African American students across institutional types. Participants who chose "Black or African American" and another race, were included in the analysis, but those who chose "Multiracial" were not, though they may identify as Black or African American. Participants who chose "Transgender" or did not identify their gender, were not included in the analysis. Finally, students who were classified as "International Students" were not included in the analysis. 


\section{CHAPTER IV}

\section{RESULTS}

\section{Introduction}

This dissertation examines the influence of collective racial esteem (CRE) on the quantity and type of involvement of African American males in public four-year institutions of higher education in the U.S. The participants in this research study were African American undergraduate students attending 48 public four-year institutions throughout the U.S. that completed the Multi-Institutional Study of Leadership (MSL) in the Spring 2009 semester. This chapter explains the participants, data collection methods, and results of the study. The results are further discussed in Chapter V.

\section{Data Collection}

The data for this study were obtained through a secondary data source known as the MSL. This survey instrument was given to students across the U.S. whose institutions participated in the MSL during the Spring 2009 semester. The MSL is comprised of over 400 items assessing various undergraduate student demographic, environmental, and outcome variables. The MSL also contains several sub-studies, one of which is CRE, which represents students' self-concept related to racial group membership (Dugan et al., 2009). The MSL was deemed useful because it is one of the few instruments found in the review of literature for this dissertation that measures CRE and hundreds of other demographic, student involvement, and outcome variables together. 
The four sub-scales of CRE were included as predictor and dependent variables in this study. Institutional type (predominately White institutions vs. historically Black colleges and universities) and gender (male vs. female) were also used as independent variables in this study. The four sub-scales of CRE are: (a) Membership CRE; (b) Private CRE; (c) Public CRE; and (d) Identity Salience. Higher scores for these sub-scales indicate a higher sense of collective racial esteem as it relates to the characteristic described in the sub-scale name. For example, a student that scored 7 for Public CRE has higher public collective racial esteem than a student who scored 4 on the same sub-scale.

The following were dependent variables used in the study: (a) quantity of campus involvement; (b) decision to join an ethnic/minority organization; (c) faculty interaction; and (d) peer interaction. All of the dependent variables were obtained from within the MSL instrument.

\section{Data Analysis}

Data analyses were carried out using the Predictive Analytics Software 18.0 (PASW). Three main statistical procedures were used in this study: multiple regression, hierarchical logistic regression, and multivariate analysis of variance (MANOVA). Multiple regression is a statistical technique that predicts a continuously measured dependent variable from one or more independent variables (Field, 2005). Logistic regression is a form of regression used when predicting a categorical dependent variable (e.g., a binary outcome such as whether something will happen or not) (Peng, Lee, \& Ingersoll, 2002). MANOVA is an inferential statistical technique used to determine if a statistically significant difference exists among the means of three or more groups when there are two or more dependent variables (Field, 2005). The level of significance ( $p$ 
value) for all statistical tests was .05 .

This research study was guided by a total of four research questions discussed in Chapter I. Research question two is composed of three sub-parts. The first two research questions treated the four sub-scales of CRE as the independent variables. The dependent variables for the first two research questions were: (a) quantity of campus involvement; (b) decision to join an ethnic/minority student organization; (c) faculty interaction; and (d) peer interaction. Research question one was examined using multiple regression. Research question two and its sub-parts were examined using logistic regression. Research questions three and four treated the four sub-scales of CRE as the dependent variables. The independent variables for research question three and four were gender and institutional type respectively. Both independent variables had two-levels. Research questions three and four were examined using a MANOVA. Table 3 in Chapter III presented the research questions, variables and statistical procedures used in the study.

\section{Results}

\section{Setting}

The study was conducted using secondary data from 48 public four-year institutions of higher education in the U.S. The MSL collected data on over 118,000 students across the U.S. The entire MSL collected data on over 118,000 students across the country.

\section{Sample}

The data for this study were collected from a sample of respondents of the MSL in the Spring 2009 semester. The sample referred to in this study $(N=1,316)$ consisted of African American undergraduate students attending public four-year institutions and who 
completed the CRE sub-study within the MSL. Three hundred and ninety (29.6\%)

participants in the sample were male, and $926(70.4 \%)$ were female. The study delimited to students who were non-international students, identified as Black or African American, and who identified as male or female. Students who did not answer for race/ethnicity or gender, or those who answered multiracial or transgendered, were excluded from this analysis.

General characteristics of the sample. Descriptive statistics obtained from the MSL were calculated. Table 5 summarizes the results for student gender and class level. As depicted in the top of Table 5 , the majority of the sample was female $(n=926)$. This is consistent with current research statistics that show females outnumber males in postsecondary education (Planty et al., 2009). Also the bottom of the table indicates that seniors were the class level most represented in the sample $(n=433)$.

Table 5

Frequency Distributions for Gender and Class Level

\begin{tabular}{llll}
\hline Factor Name & Level & $N$ & Valid Percent \\
\hline Gender & Male & 390 & 29.6 \\
& Female & 926 & 70.4 \\
Class Level & Freshman/First-year & 235 & 17.9 \\
& Sophomore & 312 & 23.7 \\
& Junior & 336 & 25.5 \\
& $\begin{array}{l}\text { Senior (4 } \\
\text { beyond) }\end{array}$ & 433 & 32.9 \\
Total & & 1316 & 100 \\
\hline
\end{tabular}


Table 6 depicts institutional characteristics of the sample of African American males and females. Institutional characteristics include size, Carnegie classification, and setting. As show in the table, a majority of the students attended large institutions $(n=$ 746), just over $40 \%$ of the sample attended Research (Very High) institutions ( $n=531$ ), and a majority of the institutions attended institutions located in a city $(n=899)$.

Table 6

Frequency Distribution of Institutional Characteristics (Size, Carnegie, and Setting)

\begin{tabular}{|c|c|c|c|}
\hline Factor Name & Level & $N$ & Valid Percent \\
\hline \multirow[t]{3}{*}{ Size } & Small & 14 & 1.1 \\
\hline & Medium & 556 & 42.2 \\
\hline & Large & 746 & 56.7 \\
\hline \multirow[t]{4}{*}{ Carnegie } & Baccalaureate & 40 & 3.0 \\
\hline & Masters & 673 & 51.1 \\
\hline & Doctoral / Research & 72 & 5.5 \\
\hline & $\begin{array}{l}\text { Research (Very } \\
\text { High) }\end{array}$ & 531 & 40.3 \\
\hline \multirow[t]{4}{*}{ Setting } & Rural & 46 & 3.5 \\
\hline & Town & 155 & 11.8 \\
\hline & Suburb & 216 & 16.4 \\
\hline & City & 899 & 68.3 \\
\hline Total & & 1316 & 100 \\
\hline
\end{tabular}

African American male student characteristics. A major focus of this research is the involvement of African American male students specifically. Therefore, additional 
descriptive statistics were analyzed for these students, shown in Table 7 below. The total number of African American males $(n)$ in the sample was 390. Most all of the students were full-time $(n=362)$ and "traditional-aged" being between $18-24$ years old $(n=$ 314). Most of the males were non-first generation students $(n=271)$ and consistent with the sample of all males and females, seniors were the largest class level represented $(n=$ 135).

Table 7

Frequency Distribution of African American Males (Enrollment, Class Level, Age, and First Generation Identifier)

\begin{tabular}{|c|c|c|c|}
\hline Factor Name & Level & $N$ & Cumulative Percen \\
\hline \multirow[t]{2}{*}{ Enrollment Status } & Full-time & 362 & 92.8 \\
\hline & Part-time & 28 & 7.2 \\
\hline \multirow[t]{4}{*}{ Class Level } & Freshman/First-year & 74 & 19 \\
\hline & Sophomore & 95 & 24.4 \\
\hline & Junior & 86 & 22.1 \\
\hline & $\begin{array}{l}\text { Senior }\left(4^{\text {th }} \text { year and }\right. \\
\text { beyond }\end{array}$ & 135 & 34.6 \\
\hline \multirow[t]{3}{*}{ Age } & $18-24$ & 314 & 80.7 \\
\hline & $25-30$ & 30 & 7.7 \\
\hline & $>30$ or $\mathrm{N} / \mathrm{A}$ & 46 & 11.6 \\
\hline \multirow{3}{*}{$\begin{array}{l}\text { First Generation } \\
\text { Identifier }\end{array}$} & First Generation & 112 & 29.2 \\
\hline & $\begin{array}{l}\text { Non-First } \\
\text { Generation }\end{array}$ & 271 & 69.5 \\
\hline & $\mathrm{N} / \mathrm{A}$ & 7 & 1.8 \\
\hline Total & & 390 & 100 \\
\hline
\end{tabular}




\section{Research Question 1}

Do CRE scores for African American undergraduate males significantly predict quantity of campus involvement?

To address research question one, a multiple regression analysis was conducted with the four sub-scales of CRE as the four independent variables. Each was measured on a 7-point Likert scale ranging from $1=$ Strongly Disagree to $7=$ Strongly Agree. The dependent variable was quantity of campus involvement, and is represented by the item: "Since starting college, how often have you been involved in college organizations?" This item was measured on a 5-point Likert scale, $1=$ Never to $5=$ Much of the time. Means and standard deviations are shown in Table 8.

Table 8

Research Question 1: Means and Standard Deviation for Quantity of Involvement and CRE scales for African-American males $(n=390)$

\begin{tabular}{lrr}
\hline Variable & \multicolumn{2}{c}{$\begin{array}{c}\text { Std. } \\
\text { Deviation }\end{array}$} \\
\hline Since starting college, & 3.04 & 1.49 \\
how often have you: & & \\
Been an involved & & \\
member in college & & \\
organizations? & & \\
CRE: Private & 5.87 & 1.14 \\
CRE: Public & 4.08 & 1.22 \\
CRE: Identity Salience & 4.46 & 1.28 \\
CRE: Membership & 5.56 & 1.15 \\
& & \\
\hline
\end{tabular}

African American males reported higher mean scores on Private CRE than on any other scale $(M=5.87)$, while Public CRE represented the lowest mean scores $(M=4.08)$. Private CRE represents one's personal assessment and beliefs of the value of their social 
group, and Public CRE represents ones beliefs about how others value their social group (Dugan et al., 2009). Mean scores for the dependent variable was 3.04. For the multiple regression analysis, all four sub-scale variables of CRE were entered simultaneously into the equation. As shown in Table 9, one sub-scale (Membership CRE, $t=2.396, p<.05$ ) was a statistically significant predictor of quantity of campus involvement. Membership CRE was positively correlated to quantity of campus involvement. The higher a participant scored on Membership CRE, the higher that participant rated his or her quantity of involvement. $R^{2}$ for this model was .040 , which means that $4 \%$ of the variance in quantity of involvement was accounted for by Membership CRE. This represents a small effect size.

Table 9

Research Question 1: Multiple Regression Results for Prediction of Quantity of Involvement by CRE scales for African-American males

\begin{tabular}{|c|c|c|c|c|c|}
\hline \multirow[t]{2}{*}{ Variables } & \multicolumn{5}{|c|}{ Standardized } \\
\hline & $\mathrm{B}$ & Std. Error & Beta & $\mathrm{t}$ & Sig. \\
\hline (Constant) & 1.715 & .460 & & 3.726 & .000 \\
\hline Private CRE & -.025 & .100 & -.020 & -.255 & .799 \\
\hline Public CRE & -.033 & .062 & -.027 & -.525 & .600 \\
\hline Identity Salience CRE & .058 & .065 & .050 & .885 & .377 \\
\hline Membership CRE & .243 & .101 & .187 & 2.396 & $.017^{*}$ \\
\hline
\end{tabular}

In summary, a multiple regression analysis was conducted to examine the relationship between the four sub-scales of CRE and quantity of campus involvement for African American males. A statistically significant positive relationship was found between Membership CRE and quantity of campus involvement, which indicates a positive predictive relationship between these two variables. 


\section{Research Question 2}

Do CRE scores of African American undergraduate male students significantly predict the following: (a) the decision to join an ethnic/minority organization; (b) degree of interaction with faculty; and (c) degree of interaction with peers.

A hierarchical logistic regression was performed to address research question two, which has three sub-parts. Each sub-part of the research question will be designated with a letter (i.e., a, b, c) to differentiate the parts. Logistic regression was used because the dependent variable was dichotomous. The four sub-scales of CRE were entered in the equation simultaneously in one block as the independent variables. Simultaneous entry was chosen because other stepwise techniques are often influenced by random variation, and thus, rarely give results that are replicable even within the same sample. Furthermore, there is no theoretically sound reason to choose which sub-scale of CRE should be entered in a particular order, therefore they should be entered simultaneously.

2a. Decision to join an ethnic/minority organization was the dependent variable for research question $2 \mathrm{a}$, coded as $1=$ Yes and $0=$ No. Statistical significance was based on an alpha level of .05. The dependent variable categories demonstrated that 250 students were not a member of an ethnic or minority group (coded 0), and 140 were (coded 1). The results of the logistic regression are depicted in Table 10 . The $\beta$ coefficients specify the amount of change expected in the log odds when there is one unit change in the predictor, while holding constant the remaining predictors.

Statistical tests for $\beta$ were determined by the Wald chi-square. The $p$ values signify whether or not a predictor was statistically significant, while controlling for the remaining predictors. The column of values for $\operatorname{Exp}(B)$ represent the odds ratios. The 
odds ratios indicate change in odds of joining an ethnic or minority organization based on the changes in the sub-scales of CRE.

Table 10

Research Question 2a: Logistic Regression Results for Prediction of Decision to Join an Ethnic/Minority Organization by CRE scales for African-American males

\begin{tabular}{llllll}
\hline Variable & B & S.E. & Wald & $p$ & $\operatorname{Exp}(B)$ \\
\hline Private CRE & -.011 & .152 & .006 & .940 & .989 \\
Public CRE & -.003 & .091 & .001 & .970 & .997 \\
$\begin{array}{l}\text { Identity } \\
\begin{array}{l}\text { Salience } \\
\text { Membership }\end{array}\end{array}$ & .275 & .098 & 7.846 & $.005^{* *}$ & 1.317 \\
$\begin{array}{l}\text { CRE } \\
\text { Constant }\end{array}$ & -3.261 & .158 & 2.902 & .088 & 1.308 \\
\hline$* p<.05$ & $* * p<.01$ & .715 & 20.798 & .000 & .038 \\
\hline
\end{tabular}

As show in Table 10, Identity Salience $(p<.05)$ was found to have a statistically significant relationship in predicting decision to join an ethnic/minority organization. This finding indicated that students with high Identity Salience as it relates to racial group membership were over 1.3 times more likely to join a ethnic/minority organization than students with low Identity Salience. It should be noted that a significance test for the entire logistic regression equation revealed that the full equation was statistically significant, $\chi^{2}(4 d f)=24.561, p=.000$.

In summary, a hierarchical logistic regression was conducted because the predictor variables were continuous and the dependent variable was dichotomous in this analysis. The variables were entered simultaneously in one block, and Identity Salience was found to have a statistically significant predictive relationship with decision to join an ethnic/minority organization. The proportion of variance in the dependent variable 
accounted for by the predictor variables was estimated between .06 (Cox and Snell R squared) and .08 (Nagelkerke R squared).

2b. Faculty interaction was the dependent variable for research question $2 b$, coded as $1-Y e s$ and $0=$ No. Two items on the MSL were used to determine faculty interaction. The first asked if the student had ever had a faculty member as a mentor, and the other asked if the student had ever conducted research with a faculty member. Both will be reported below in Table 11 and Table 12 respectively. Statistical significance was based on an alpha level of .05 . The dependent variable categories demonstrated that 153 students did not have a faculty mentor (coded 0$)$, and 237 did (coded 1$)$. The results of the logistic regression are depicted in Table 11. The residual chi-square statistic, labeled overall statistics indicates whether or not the coefficients for the variables not in the model are statistically significant from zero. A $p$ value greater than .05 means that adding the variables into the equation will not significantly affect its predictive power. Therefore, the four sub-scales of CRE were not significant predictors of whether or not a student has a faculty mentor. 
Table 11

Research Question 2b: Logistic Regression Results for Prediction of Faculty Interaction (Faculty Mentor) by CRE scales for African-American males

\begin{tabular}{lccc}
\hline Variable & Score & $\mathrm{df}$ & Sig. \\
\hline Private CRE & .230 & 1 & .631 \\
Public CRE & .017 & 1 & .896 \\
$\begin{array}{l}\text { Identity } \\
\text { Salience }\end{array}$ & .118 & 1 & .731 \\
CRE & & & \\
Membership & .263 & 1 & .608 \\
CRE & & & \\
Overall & .340 & 4 & .987 \\
Statistics & & & \\
\hline
\end{tabular}

For research with a faculty member, the dependent variable categories demonstrated that 327 students did not conduct research with a faculty member (coded 0 ), and 61 did (coded 1). The results of the logistic regression are depicted in Table 12 . The residual chi-square statistic, labeled overall statistics indicates whether or not the coefficients for the variables not in the model are statistically significant from zero. A $p$ value greater than .05 means that adding the variables into the equation will not significantly affect its predictive power. Therefore, the four sub-scales of CRE were not significant predictors of whether or not a student conducted research with a faculty member. 
Table 12

Research Question 2b: Logistic Regression Results for Prediction of Faculty Interaction (Research with a Faculty Member) by CRE scales for African-American males

\begin{tabular}{llll}
\hline Variable & Score & Df & Sig. \\
\hline Private CRE & .103 & 1 & .748 \\
Public CRE & .736 & 1 & .391 \\
$\begin{array}{l}\text { Identity } \\
\text { Salience }\end{array}$ & .330 & 1 & .566 \\
$\begin{array}{l}\text { Membership } \\
\text { CRE }\end{array}$ & .558 & 1 & .455 \\
$\begin{array}{l}\text { Overall } \\
\text { Statistics }\end{array}$ & 2.628 & 4 & .622 \\
\hline
\end{tabular}

In summary, a hierarchical logistic regression was conducted because the predictor variables were continuous and the dependent variable was dichotomous in this analysis. The variables were entered simultaneously in one block for both measures of faculty interaction. No statistically significant predictive relationship was found between student CRE scores and faculty interaction as measured by faculty mentoring or research with a faculty member. It should be noted that a significance test for the entire logistic regression equations revealed that both equations were not statistically significant, $\chi^{2}$ (4 $d f)=.340, p=.987$ and $\chi^{2}(4 d f)=2.698, p=.610$.

2c. Peer interaction was the dependent variable for research question $2 \mathrm{c}$. A new variable was created using the 23 items found in Chapter III, Table 2. The new variable was named InterSumBinary and was an index that represented peer interaction for this study. If a student participated one or more of the 23 items that measured peer interaction (e.g., participation in intramural athletics), they were coded as $1=$ Yes, and if they did not 
they were coded $0=$ No. The new variable had an acceptable Cronbach alpha reliability coefficient of $\alpha=.79$. Statistical significance for the regression was an alpha level of .05 . The dependent variable categories demonstrated that 52 students were not involved in any of the organizations/activities (coded 0$)$, and 338 were (coded 1). The results of the logistic regression are depicted in Table 13.

The residual chi-square statistic, labeled overall statistics indicates whether or not the coefficients for the variables not in the model are statistically significant from zero. A $p$ value greater than .05 means that adding the variables into the equation will not significantly affect its predictive power. Therefore, the four sub-scales of CRE were not significant predictors of whether or not a student interacted with his peers. A significance test for the entire logistic regression equation revealed that the full equation was not statistically significant, $\chi^{2}(4 d f)=3.209, p=.523$.

Table 13

Research Question 2c: Logistic Regression Results for Peer Interaction for African American Males

\begin{tabular}{llll}
\hline Variable & Score & Df & Sig. \\
\hline Private CRE & 2.171 & 1 & .141 \\
Public CRE & .796 & 1 & .372 \\
$\begin{array}{l}\text { Identity } \\
\text { Salience }\end{array}$ & .740 & 1 & .390 \\
$\begin{array}{l}\text { Membership } \\
\text { CRE }\end{array}$ & 2.593 & 1 & .107 \\
$\begin{array}{l}\text { Overall } \\
\text { Statistics }\end{array}$ & 3.246 & 4 & .517
\end{tabular}

Due to the strong influence of peer interaction reported in the revicw of the 
literature for this dissertation, the researcher decided to probe this variable in greater depth. Consequently, another logistic regression analysis was conducted for African American females. The dependent variable categories demonstrated that 213 students were not involved in any of the organizations/activities (coded 0$)$, and 713 were (coded 1). The results of the logistic regression are depicted in Table 14.

The $\beta$ coefficients specify the amount of change expected in the log odds when there is one unit change in the predictor, while holding constant the remaining predictors. Statistical tests for $\beta$ were determined by the Wald chi-square. The $p$ values signify whether or not a predictor was statistically significant, while controlling for the remaining predictors. The column of values for $\operatorname{Exp}(B)$ represents the odds ratios. The odds ratios indicate change in odds of interacting with peers based on the changes in the sub-scales of CRE.

Table 14

Research Question 2c: Logistic Regression Results for Peer Interaction: African American Females

\begin{tabular}{llllll}
\hline Variable & $\beta$ & $S . E$ & Wald & $P$ & $\operatorname{Exp}(B)$ \\
\hline Private CRE & -.441 & .117 & 14.204 & $.000^{* *}$ & .643 \\
Public CRE & .026 & .066 & .159 & .690 & 1.027 \\
$\begin{array}{l}\text { Identity } \\
\text { Salience }\end{array}$ & .030 & .069 & .185 & .667 & 1.030 \\
$\begin{array}{l}\text { Membership } \\
\text { CRE }\end{array}$ & .525 & .115 & 20.789 & $.000^{* *}$ & 1.690 \\
Constant & .650 & .547 & & & \\
\hline$* p<.05$ & $* * p<.01$ & & & & \\
\end{tabular}

As shown in Table 14, Private CRE $(p<.05)$ was found to have a statistically 
significant negative relationship in predicting peer interaction among African American females. This finding indicated that students with a high sense of Private CRE were less likely to interact with their peers. Membership CRE $(p<.05)$ was found to have a statistically significant positive relationship in predicting peer interaction among African American females. Students with a high sense of Membership CRE were over 1.6 times more likely to interact with her peers than students with low Membership CRE. It should be noted that a significance test for the entire logistic regression equation revealed that the full equation was statistically significant, $\chi^{2}(4 d f)=24.642, p=.000$.

In summary, a hierarchical logistic regression was conducted because the predictor variables were continuous and the dependent variable was dichotomous in this analysis. The variables were entered simultaneously in one block, first for African American males and then for African American females. No statistically significant predictive relationship was found between CRE and peer interaction for males. For females, Private CRE was found to have a statistically significant negative predictive relationship with peer interaction, and Membership CRE was found to have a statistically significant positive predictive relationship with peer interaction. The proportion of variance in the dependent variable accounted for by the predictor variables was estimated between .026 (Cox and Snell R squared) and .04 (Nagelkerke R squared).

\section{Research Question 3}

Is there a statistically significant difference between African American male and African American female undergraduates' CRE scores?

To address research question three, a MANOVA was conducted to compare the means among the independent variable gender, with two levels (male and female), on the 
dependent variables, represented by the four sub-scales of CRE: Private CRE, Public CRE, Identity Salience, and Membership CRE. A MANOVA was used because the analysis contained multiple dependent variables. Table 15 describes the CRE means and standard deviations for the sample.

Table 15

Research Question 3: Means and Standard Deviations for Private CRE, Public CRE, Identity Salience, and Membership CRE by Gender

\begin{tabular}{llrrr}
\hline Dependent Variable & Gender & Mean & \multicolumn{1}{c}{ Std. Deviation } & \multicolumn{1}{l}{ N } \\
\hline Private CRE & Male & 5.87 & 1.14 & 390 \\
& Female & 6.11 & 1.01 & 926 \\
& Total & 6.04 & 1.05 & 1316 \\
Public CRE & Male & 4.08 & 1.22 & 390 \\
& Female & 3.97 & 1.23 & 926 \\
Identity Salience & Total & 4.00 & 1.23 & 1316 \\
& Male & 4.46 & 1.28 & 390 \\
& Female & 4.68 & 1.30 & 926 \\
Membership CRE & Total & 4.61 & 1.30 & 1316 \\
& Male & 5.56 & 1.15 & 390 \\
& Female & 5.81 & 1.00 & 926 \\
& Total & 5.74 & 1.05 & 1316
\end{tabular}

Female students had a higher mean score for Private CRE $(M=6.11)$, Identity Salience $(M=4.68)$, and Membership CRE $(M=5.81)$. The Hotelling's Trace for the MANOVA was converted to $F(4,1311)=5.799, \mathrm{p}=.000$, indicating a significant multivariate effect. Follow-up ANOVAs were conducted for each of the dependent variables and found that Private CRE, Identity Salience, and Membership CRE were statistically significant. The between-subjects effects and partial eta-squared for each dependent variable are shown in Table 16. Effect sizes were very small-to-small for each of the significant dependent variables $(.006-.012)$

Table 16 
Between-Subjects Effects of CRE and Gender

\begin{tabular}{lll}
\hline Dependent Variable & Sig. & Partial Eta-Squared \\
\hline Private CRE & $.000^{* *}$ & .011 \\
Public CRE & .137 & .002 \\
Identity Salience & $.005^{* *}$ & .006 \\
Membership CRE & $.000^{* *}$ & .012 \\
$* p<.05 \quad * * p<.01$ & &
\end{tabular}

Due to the strong association between socio-economic status (SES) and minority student persistence found in the review of literature for this study (Cabrera, Stampen, \& Hansen, 1990; Crawford, 2007; Tinto, 2007), a multivariate analysis of covariance (MANCOVA) was conducted for both research question three and four. MANCOVA is used to control for the effects of one or more independent variables. For this study, student self-reported SES was used as the covariate, and was measured using the student estimate of parental income. For research question three, 1006 of 1316 students $(76 \%)$ provided parental income.

The MANCOVA indicated almost identical results to the MANOVA. Multivariate effects were statistically significant, with the Hotelling's Trace statistic converted to $F(4,1000)=3.19, \mathrm{p}=.000$, indicating a significant multivariate effect. Follow-up ANCOVAs were significant for Private CRE $(F(1,1003)=7.94, \mathrm{p}<.01)$, Identity Salience CRE $(F(1,1003)=5.82, \mathrm{p}<.05)$, and Membership CRE $(F(1,1003)=$ $9.72, \mathrm{p}<.01)$. As with the ANOVA results, female students had significantly higher mean scores than males for Private CRE, Identity Salience CRE, and Membership CRE. In addition, effect sizes for the MANCOVA were also very small-to-small. These 
findings indicated that SES was not a factor in explaining the differences between the genders.

In summary, a MANOVA as well as follow-up ANOVAs were conducted to compare means of males and females on the four sub-scales of CRE. Statistical significance was found for Private CRE, Identity Salience, and Membership CRE. African American female undergraduates, on average, had higher Private CRE, Identity Salience, and Membership CRE than their African American male counterparts. The mean scores were statistically significant at the .05 alpha level, and at the Bonferroni adjusted alpha level of .0125 . Though males reported having higher Public CRE than their female counterparts, this finding was not statistically significant. A MANCOVA was conducted using SES as a covariate. Findings were consistent with the MANOVA results.

\section{Research Question 4}

Is there a statistically significant difference between undergraduate African American students' CRE scores at a PWI compared to a HBCU?

To address research question four, a MANOVA was conducted to compare the means among the independent variable institutional type, with two levels (predominately White institution and Historically Black College and University), on the dependent variables, represented by the four sub-scales of CRE: Private CRE, Public CRE, Identity Salience, and Membership CRE. A description of institutional characteristics can be found in Chapter III, Table 3. A MANOVA was used because the analysis contained multiple dependent variables. Table 17 describes the CRE means and standard deviations for the sample. 
Table 17

Research Question 4: Means and Standard Deviations for Private CRE, Public CRE, Identity Salience, and Membership CRE by Institutional Type

\begin{tabular}{llrrr}
\hline Dependent Variable & Gender & \multicolumn{1}{c}{ Mean } & \multicolumn{1}{c}{ Std. Deviation } & \multicolumn{1}{c}{ N } \\
\hline Private CRE & PWI & 5.91 & 1.03 & 92 \\
& HBCU & 6.35 & .95 & 76 \\
Public CRE & Total & 6.11 & 1.02 & 168 \\
& PWI & 3.93 & 1.07 & 92 \\
& HBCU & 4.33 & 1.17 & 76 \\
Identity Salience & Total & 4.11 & 1.13 & 168 \\
& PWI & 4.67 & 1.22 & 92 \\
& HBCU & 4.86 & 1.30 & 76 \\
Membership CRE & Total & 4.76 & 1.26 & 168 \\
& PWI & 5.74 & 1.05 & 92 \\
& HBCU & 5.98 & .95 & 76 \\
& Total & 5.85 & 1.01 & 168
\end{tabular}

Note $. \mathrm{PWI}=$ predominately White institution, $\mathrm{HBCU}=$ historically Black college/university.

HBCU students had a higher mean score for each of the four CRE sub-scales. The Hotelling's Trace for the MANOVA converted to $F(4,163)=3.492, \mathrm{p}=.009$, indicating a significant multivariate effect. Follow-up ANOVAs were conducted for each of the dependent variables and found that Private CRE and Public CRE were statistically significant. The between-subjects effects and partial eta-squared for each dependent are shown in Table 18. Effect sizes were small to moderate for each of the significant dependent variables (partial eta square statistics ranged between $.005-.047$ )

Table 18 
Between-Subjects Effects of CRE and Institutional Type

\begin{tabular}{lll}
\hline Dependent Variable & Sig. & Partial Eta-Squared \\
\hline Private CRE & $.005^{* *}$ & .047 \\
Public CRE & $.020^{*}$ & .032 \\
Identity Salience & .344 & .005 \\
Membership CRE & .126 & .014 \\
${ }^{*} p<.05 \quad{ }^{* *} p<.01$ & &
\end{tabular}

As in research question three, due to the strong association between socioeconomic status (SES) and minority student persistence found in the review of literature for this study, a MANCOVA was conducted using student self-reported SES as a covariate. For research question four 123 of 168 students (73\%), provided parental income.

The MANCOVA and subsequent follow-up of ANCOVA were similar to the MANOVA results. Using $p=.06$, multivariate effects were statistically significant, with the Hotelling's Trace statistic converted to $F(4,117)=2.41, \mathrm{p}=.053$. Follow-up ANCOVAs were significant for Private CRE $(F(1,120)=4.88, \mathrm{p}<.03)$, and Public $\operatorname{CRE}(F(1,120)=4.18, \mathrm{p}<.05)$. As with the ANOVA results, HBCU students had significantly higher mean scores than PWI students for Private CRE and Public CRE. In addition, effect sizes were also small to moderate. These findings indicated that SES was not a factor in explaining the differences between the two universities that were compared.

In summary, a MANOVA as well as follow-up ANOVAs were conducted to compare means of students attending PWIs and HBCUs on the four sub-scales of CRE. 
Statistical significance was found for Private CRE and Public CRE. African American students attending HBCUs, on average, had higher Private CRE and Public CRE than their African American counterparts attending PWIs. The mean scores were statistically significant at the .05 alpha level. Although those attending HBCUs had higher Identity Salience and Membership CRE than their PWI counterparts, follow-up analysis showed that this finding was not statistically significant. A MANCOVA was conducted using SES as a covariate. Findings were consistent with the MANOVA results.

\section{Summary of Chapter IV}

The main purpose of this chapter was to outline the results for this study in the form of descriptive and inferential statistics and to answer the four research questions. In this study, data were gathered using the Multi-Institutional Study of Leadership (MSL) survey instrument administered in the Spring 2009 semester. A total of 48 public, fouryear institutions were included in this study. Within those 48 institutions, only noninternational, African American males and females were included for analysis. As for the sample, approximately $70 \%$ of the sample was female and $30 \%$ was male. Most of the sample members were classified as seniors ( $4^{\text {th }}$ year and beyond), and most were traditional-aged students $(18-24$ year olds $)$.

Each research question examined in this study related to a students collective racial esteem (CRE), defined as a student's sense of self-concept as it relates to his or her racial group membership. The purpose of research question one was to determine which CRE sub-scales predicted quantity of campus involvement for African American males. The objective of research question two was to determine which CRE sub-scales predicted a students' decision to join an ethnic/minority organization, faculty interaction, and peer 
interaction. The purpose of research question three was to examine mean differences in CRE scores between African American males and females. The fourth and final research question analyzed the mean differences between CRE scores for African American students attending PWIs versus those attending HBCUs.

The first two research questions treated the four sub-scales of CRE as independent variables, predicting a range of dependent variables. Multiple regression was conducted for research question one, and Membership CRE was a statistically significant predictor of quantity of campus involvement. Using hierarchical logistic regression, research question two examined the predictive relationships among Private CRE, Public CRE, Identity Salience, and Membership CRE on the dependent variables decision to join an ethnic/minority organization, faculty interaction, and peer interaction. The logistic regression analyses showed that Identity Salience $(p<.05)$ was a significant predictor of a student's decision to join an ethnic/minority organization. The analyses also showed that for African American females, Private CRE and Membership CRE are both significant predictors of peer interaction. None of the four sub-scales were significant predictors of faculty interaction or peer interaction for African American males.

Research questions three and four used MANOVA and MANCOVA analyses, as well as follow-up ANOVAs to examine mean differences in CRE scores for gender and institutional type. The MANOVA/MANCOVA analysis for research question three showed that women had significantly higher scores on Private CRE, Identity Salience, and Membership CRE. For research question four, the MANOVA/MANCOVA analyses showed that students attending HBCUs had statistically higher scores on both Private CRE and Public CRE. Table 19 provides an overview of the research questions, and what 
significant relationships were found. This concludes Chapter IV. Next, Chapter V provides further discussion on the findings and results of this research as well as limitations and implications of this study. 
Table 19

Summary of Research Questions and Key Results Found for the Overall Study

\begin{tabular}{|c|c|}
\hline Research Question & Summary of Key Results \\
\hline $\begin{array}{l}\text { 1. Do CRE scores for African American } \\
\text { undergraduate males significantly predict } \\
\text { quantity of campus involvement? }\end{array}$ & $\begin{array}{l}\text { Yes, one found: Membership CRE had a } \\
\text { statistically significant positive relationship } \\
\text { in predicting the dependent variable. }\end{array}$ \\
\hline $\begin{array}{l}\text { 2a. Do CRE scores of African American } \\
\text { undergraduate male students significantly } \\
\text { predict a students' decision to join an } \\
\text { ethnic/minority organization? }\end{array}$ & $\begin{array}{l}\text { Yes, one found: Identity Salience had a } \\
\text { statistically significant positive relationship } \\
\text { in predicting the dependent variable. }\end{array}$ \\
\hline $\begin{array}{l}\text { 2b. Do CRE scores of African American } \\
\text { undergraduate male students significantly } \\
\text { predict degree of interaction with faculty? }\end{array}$ & None Found \\
\hline $\begin{array}{l}\text { 2c. Do CRE scores of African American } \\
\text { undergraduate male students significantly } \\
\text { predict degree of interaction with peers? }\end{array}$ & $\begin{array}{l}\text { None Found for African American Males. } \\
\text { Yes, two statistically significant } \\
\text { relationships were found for African } \\
\text { American Females: Private CRE had a } \\
\text { negative relationship and Membership } \\
\text { CRE had a positive relationship in } \\
\text { predicting the dependent variable. }\end{array}$ \\
\hline $\begin{array}{l}\text { 3. Is there a statistically significant } \\
\text { difference between A frican American male } \\
\text { and African American female } \\
\text { undergraduates' CRE scores? }\end{array}$ & $\begin{array}{l}\text { Yes, significant MANOVA and three } \\
\text { follow-up ANOVAs found: A frican } \\
\text { American females had significantly higher } \\
\text { scores than their male counterparts on } \\
\text { Private CRE, Identity Salience, and } \\
\text { Membership CRE. Results were the same } \\
\text { when SES (estimate of parental income) } \\
\text { was controlled. }\end{array}$ \\
\hline $\begin{array}{l}\text { 4. Is there a statistically significant } \\
\text { difference between undergraduate African } \\
\text { American students' CRE scores at a PWI } \\
\text { compared to a HBCU? }\end{array}$ & $\begin{array}{l}\text { Yes, significant MANOVA and two } \\
\text { follow-up ANOVAs found: African } \\
\text { American students attending HBCUs had } \\
\text { significantly higher scores than their PWI } \\
\text { counterparts on Private CRE and Public } \\
\text { CRE. Results were the same when SES } \\
\text { (estimate of parental income) was } \\
\text { controlled. }\end{array}$ \\
\hline
\end{tabular}




\section{CHAPTER V}

\section{DISCUSSION, IMPLICATIONS, AND LIMITATIONS}

\section{Introduction}

This dissertation examined the influence of Collective Racial Esteem (CRE) on the quantity and type of involvement for African American male undergraduates in public four-year institutions of higher education in the U.S. This chapter discusses the results of the study collected through quantitative analyses of the Multi-Institutional Study of Leadership (MSL). Four research questions guided this study, which were presented in Chapter I and illustrated in Table 4 and 19. This chapter is structured to discuss conclusions based on the study's findings presented in Chapter IV. A discussion of the study's research questions, findings, limitations, and implications for future research concerning the use of the MSL and CRE variables are also discussed in this chapter. Implications will be discussed at the state level, institutional level, and individual scholar/practitioner level.

\section{Overview of Study}

The persistence and graduation of African American males at four-year institutions of higher education has increased in past decades, but still remains consistently and significantly lower than that of their non-A frican American male counterparts (Planty et al., 2009). African American male retention rates are also lower than their female counterparts of the same ethnic background. These data continue to be a reality, despite the extensive literature on African American students in college. 
Integration and involvement has been found to positively correlate to persistence and graduation (Astin, 1993; Pascarella \& Terenzini, 1991, 2005; Tinto, 1987). Involvement in college may include faculty interaction, peer interaction, and involvement in student organizations, and has been linked to gains in several cognitive and psychosocial outcomes (Astin, 1993; Pascarella \& Terenzini, 1991, 2005). These developmental gains are consistent across gender and racial/ethnic groups. Specifically for African Amcrican students, existing research has also found that involvement is correlated with increased persistence and gradation (Harper, 2006b).

This sample examined in this study attended 48 public four-year institutions within the U.S. These students all completed the MSL during the Spring 2009 semester. Of special interest to this study were African American males. In the review of literature for this study, African American males were found to be involved in the campus environment at lower rates than their female counterparts (Cuyjet, 1997). Having the lowest persistence, graduation, and involvement rates, there is much yet to be understood about the African American male experience in colleges and universities.

As seen in Tables 4 and 19, research questions one and two used hierarchical logistic regression analyses to test whether a statistically significant relationship existed between the predictor variables (Membership CRE, Private CRE, Public CRE, and Identity Salience) and the dependent variable, quantity of campus involvement, decision to join an ethnic/minority organization, faculty interaction, and peer interaction. Statistically significant relationships were found for Membership CRE, Identity Salience, and Private CRE on the dependent variables.

In research questions three and four MANOVA and MANCOVA analyses were 
used to examine differences between males and females, and students attending historically Black colleges and universities (HBCUs) and students attending predominately White institutions (PWIs) with respect to the four sub-scales of CRE. Female students had higher means scores on all but one of the dependent variables (Public CRE), while students attending HBCUs had higher means scores on all of the dependent variables. Statistically significant differences were found in research question three on Membership CRE, Private CRE, and Identity Salience scores. Research question four yielded statistically significant differences on Private CRE and Public CRE scores.

\section{Discussion of Study Findings}

This study provided a snapshot of undergraduate African American students attending public four-year institutions in the U.S. in the Spring 2009 semester. Historically, African American males have been found to persist, graduate, and get involved in the campus environment at lower rates than their female and other ethnic group peers (Cuyjet, 1997, 2006; Flowers, 2004a; Guiffrida, 2003; Sutton \& Kimbrough, 2001). In this study, African American males had lower mean scores than their female counterparts on all but one of the CRE sub-scales. All of these differences were found to be statistically significant.

\section{Sample Findings}

The sample in this study was similar to a few other studies conducted using the MSL data in 2006 and 2009 (Dugan, Brown, Chavez, Mendoza, \& Rodriguez, 2010; Dugan et al., 2009; Dugan, Komives, \& Segar, 2008; Rosch, 2007). Similar to these studies, all of the participants were undergraduates, attending medium to large public institutions, and most of the sample was traditionally aged (i.e., $18-24)$. The relatively 
small number of males in the study $(n=390)$ was similar to other quantitative studies examining African American men (Cuyjet, 1997; Strayhorn \& Terrell, 2007; Sutton \& Kimbrough, 2001). The sample was also consistent with similar samples found in previous studies (Flowers, 2004a; Museus, 2008; Taylor \& Howard-Hamilton, 1995) in which female students were the largest gender enrolled at the institution under study. As it relates to female students, this study's sample and findings reflect the current (Planty et al., 2009) and future (Hussar \& Bailey, 2009) projections of African American females outnumbering African American males enrolled in public four-year institutions.

\section{Involvement and Collective Racial Esteem}

In analyzing involvement and CRE for the 390 undergraduate African American males who took the MSL in Spring 2009, Membership CRE significantly predicted quantity of campus involvement. This finding means that, for African American male students in the sample, the more a student "fits in" as an African American, the more likely he is to be an involved member in college organizations. This finding is important, because not all African American students feel comfortable being African American. Similar to findings by Harper and Nichols (2008), great heterogeneity exists within the African American male undergraduate population, which includes students who do not necessarily embrace their racial group membership.

The average score for quantity of involvement for African American males in the sample on a scale of 1 (Never) to 5 (Much of the time) was '3.' This means that half of the students in the sample were involved in campus organizations frequently, while half were not. This finding supports the literature (Flowers, 2004a) that suggests African American men are not as involved as their female counterparts. Due to lower numbers of 
African American males on college campuses than African American females or other ethnic groups, when half of the population is not involved at a high level it is noticed. The absence of those male students can be obvious, particularly amongst peers and administrators who work with these students on a daily basis.

A statistically significant relationship was found between African American male Identity Salience and the decision to join an ethnic/minority organization. This implies that for this sample the more central, or salient, a students' race is to his identity, the more likely he is to join an ethnic/minority organization. This supports Sutton and Kimbrough's (2001) finding that multicultural organizations remain the primary venue for involvement among African American students. This finding also implies that not all African Amcrican males will seek membership in an ethnic/minority student organization just because they are African American. Rather the decision to join is dependent on the centrality of one's racial identity. Mitchell and Dell (1992), Museus (2008), and Taylor and Howard-Hamilton (1995) all report the significance of identity-based or cultural organizations as important venues for positive identity development and involvement for African American students.

\section{Faculty and Peer Interaction}

Findings of this study found no significant predictive relationship between African American male students' CRE and faculty interaction. These results indicate that as it relates to this sample, a students' sense of self-concept as it relates to his racial group membership does not predict whether or not he will be mentored by, or conduct research with, a faculty member. These findings are dissimilar from Strayhorn and Terrell (2007) and Guiffrida (2005), who reported the positive effects of faculty mentoring for African 
American students, and specifically highlighted the positive effects of same-race mentoring relationships.

This disconnect between the findings and the literature for this sample is unclear, as several studies overwhelmingly report the positive effects of faculty interaction on persistence, satisfaction, and graduation (Astin, 1993; Himelhoch, Nichols, \& Ball, 1997; Kuh \& Hu, 2001; Littleton, 2002; Santos \& Reigadas; Tinto, 2007). Perhaps the small number of African American males who conducted research with a faculty member $(n=$ 61) was insufficient to detect significance. Another possibility for the lack of significance is the definition of the construct "mentor" in the survey instrument. Finally, Guiffrida (2005) reported, that at PWIs, several A frican American students reported that White faculty were not seen as realistic role models or mentors. Due to the large number of PWIs used in the sample, there may not be a large number of African American faculty that can serve as mentors. Therefore, collective racial esteem as a construct had no significant bearing on faculty interaction for this sample.

When examining the 23 items representing peer interaction, see Table 2, only $13 \%$ of African American males reported no involvement in any of the activities. Similar to findings by Cuyjet (2006) and Harper (2006a), African American males were heavily involved in intramural athletics. Despite $87 \%$ of the sample reporting being involved with one or more of the activities, none of the four sub-scales of CRE were significant predictors of peer interaction. Due to the strong influence of peer interaction reported in the review of the literature (e.g., Astin, 1984, 1993; Pascarella \& Terenzini, 1991, 2005; Tinto, 1975), another logistic regression analysis was conducted for African American females. Seventy-seven percent of the African American females sampled participated in 
at least one activity listed in Table 2 .

Two statistically significant relationships were found for African American females. The higher a student scored on Private CRE the less likely a student was to interact with her peers as measured by involvement in one or more of the activities listed in Table 2. The higher a student scored on Membership CRE, the more likely a student was to be involved in one ore more of the activities listed. These findings indicate that African American females who have a higher personal assessment of being African American will have less interaction with her peers via these activities. Those females who feel that they fit in with other African Americans are predicted to be involved with their pecrs. Again, as in research question one, Membership CRE positively predicted involvement in some way for African American students.

This finding related to Membership CRE is similar to Flowers (2004b) and Vandiver et al. (2001) who suggested that African American students who are comfortable in their ethnic identity are free to focus on issues beyond their race. These "issues" can very well include interaction with peers and faculty and involvement in clubs and organizations. The finding related to Private CRE did not seem to follow findings in previous studies found in the review of literature. Private CRE is highly correlated to personal self-esteem (Luhtanen \& Crocker, 1992); and as such, should theoretically be positively related to college outcomes in the same way that personal selfesteem is positively correlated.

Following this reasoning, students who score higher on Private CRE are expected to do better academically, and also be more engaged outside of the classroom. However, dissimilar to findings by Parkers and Flowers (2003) and Awad (2007), this was not the 
case. A possible explanation for this is that these authors were examining the effects of racial identity development on certain outcomes, and CRE is similar but distinctly different from racial identity development. As reported below, African American females score significantly higher than African American males on both Private CRE and Membership CRE. The higher scores could be a possible reason for significant findings for African American females.

\section{Gender Differences}

African American females had significantly higher means scores than African American males on Private CRE, Membership CRE, and Identity Salience. This implies that females in this sample had a higher personal assessment of their race, felt that they fit in more with their race, and considered their race more central to their identity than their male counterparts. As African American female students tend to persist, graduate, and get involved at higher rates than their African American male counterparts, it can be assumed that CRE plays some role in the differences between the genders. Further analysis is needed to verify this assumption, and is discussed later in this chapter.

A larger sample of African American males in comparison to African American females may be more adequate in understanding the differences in mean scores. The small number of African American males in this sample illustrates the low number of African American males that attend public four-year universities (Davis, 1994; Harper, 2006a). Clearly, more research is needed to further investigate this finding, particularly in light of African American female college students outpacing African American males in many sectors of the workforce and education (Planty et al., 2009). Due to the strong association between socio-cconomic status (SES) and minority student persistence, a 
follow-up analysis was conducted to examine the effect of SES on these findings. SES was not a factor in explaining the differences between the genders.

\section{Institutional Effects and Differences}

African American males in the sample reported a higher mean score on Private CRE than any other sub-scale. This indicates that the males in this study have a high personal assessment of the value of being African American. Conversely, the males in this study reported the lowest mean scores on Public CRE, indicating that these students held lower beliefs about how others value their racial group. This is not to say that the students' Public CRE was low, per se, however, it was lower in comparison to the other sub-scales.

Important to note is that 46 of the 48 institutions in this study were PWIs. This finding, therefore, is somewhat similar to Allen's (1992) findings that students attending HBCUs felt more valued, comfortable, supported, and validated than their counterparts attending PWIs. This may explain why Public CRE was the lowest mean score of all measures of CRE. African Americans attending PWIs in other national studies (Museus, Nichols, \& Lambert, 2008) reported being least satisfied with their campus racial climate in comparison to other racial/ethnic groups.

African American students attending the HBCU in this sample reported higher mean scores than African American students attending the PWI. Statistically significant differences were found with respect to Private CRE and Public CRE. In other words, African American students attending HBCUs held higher personal beliefs about their racial group and felt that others valued their racial group more than their PWI counterparts. This is not to say that students at the PWI did not feel valued, rather, that 
those attending the HBCU reported that they felt move valued. This finding is similar to findings by several researchers (e.g., Allen, 1992; Flowers \& Pascarella, 1999b; Latiker, 2006; Minor, 2008; Outcalt \& Skewes-Cox, 2002) that report on the positive affective and psychosocial outcomes of African American students attending HBCUs. This finding is also consistent with Kimbrough and Harper (2006) who discussed the familiar atmosphere felt by students attending HBCUs.

As in research question three, a follow-up analysis was conducted to examine the effect of SES on these findings. Students that attend HBCUs tend to come from lower income households (Minor, 2008); therefore SES could potentially impact the results. However, dissimilar to Nora, Barlow, and Crisp (2006), SES was not a factor in explaining the differences between students attending an HBCU and a PWI.

\section{Implications for Research}

The importance of involvement in the college environment is well researched, as is the link between involvement and persistence through college. In light of this fact, public four-year institutions of higher education can and must do a better job of engaging and retaining students to graduation, particularly those who have been historically underrepresented in higher education (Crawford, 2010). Future research must continue to explore reasons why some students persist and graduate, while others consistently lag behind. Implications are discussed in this section and pertain to state-level, institutional, and practice recommendations for future research focusing on student involvement for African American students in public four-year colleges and universities.

\section{Recommendations for State-Level Practice}

This study contained variables pertinent to all institutional types, and across the 
U.S. State policy-makers, despite the geographic region, tend to exert a large amount of control over the resources and priorities of public four-year institutions. Within the state of Kentucky, for instance, major educational reform was passed to improve the secondary and post-secondary education system (Crawford, 2007; Kentucky Council on Postsecondary Education, 2001b). These reforms included creating a more seamless transition between P-12 schools and higher education institutions.

As Ogbu (2004) asserted, collective identity and cultural frame of reference could more fully explain the variability in minority student performance in K-12 schools. Improving the racial esteem of African American students prior to entering postsecondary institutions could have a positive impact on the student's experience entering college. In particular, helping African American students increase how well they fit in with their racial group (Membership CRE), and increasing how they and others value their racial group (Private CRE and Public CRE), could increase the involvement of those students who attend public four-year institutions. TRIO programs or other college bridge programs are possible examples of initiatives designed to do what is suggested above.

Helms and Cook (1999) found that racial categories serve as sociopolitical constructions that denote unequal access to resources. Dugan et al., (2010) asserts that racial categories are externally defined visible cues, but do not necessarily indicate how individuals construct their sense of self-concept as it relates to their race. In a time of changing race codes and definitions (U.S. Census, 2010), state decision makers should encourage campuses to find more creative and developmentally appropriate ways of engaging students of color, and assessing the impact of programs and services for these students. CRE can be a useful tool for institutions to do just that. 
Finally, state-level decision makers and policies can compel campuses to develop and support academic programs, identity based groups, centers, and institutes that allow African American and other students to enhance their CRE; particularly as discrimination continues to be a reality for many African Americans (Banks, 2010). State-level educators and elected leadership should also strongly consider the employment patterns within public institutions. Though CRE did not predict faculty interaction in this study, faculty interaction still remains a strong predictor of African American success in college. African American faculty are needed to serve as adequate role models for African American students (Guiffrida, 2005). These approaches are what Tierney (1999) calls for in his cultural integrity approach to student persistence. Institutions should modify the campus environment in a way that affirms and validates the various subcultures within them.

\section{Recommendations for Institutional Practice}

The implications for institutional practice are many. Public four-year institutions should consider using CRE as a tool to assess and better discern the needs and differences of student sub-populations on campus. Oftentimes institutions view sub-populations as monolithic groups, all having the same needs, goals, assumptions, and values. As it relates to African American males, Harper and Nichols (2008) discuss the many differences between these same-race males, and cautions against oversimplifying their experience. CRE can be assessed within particular initiatives for African American males, and other groups, or during orientation when students are taking other assessment and evaluation instruments.

Institutions can support the success of African American students by creating a 
menu of organizational options in which students can participate. Though ethnic or minority organizations are oftentimes the primary venue for involvement for African American students (Sutton \& Kimbrough, 2001), not all African American students necessarily gravitate to such organizations. The findings of this study suggest that students for whom being African American is central to their identity will likely join one of these organizations. Other students may be interested in other organizations depending on their past experience or particular stage of racial identity (Cross, 1991; Taylor \& Howard-Hamilton, 1995). Therefore it is important to market all opportunities equally and uniformly across the institution.

Institutions can better engage their African American students through fostering a healthy sense of racial esteem within its student population. The research states that higher levels of collective racial esteem, like higher personal self-esteem, is positively correlated to psychological well being across various racial and ethnic groups (Crocker, Luhtanen, Blaine, \& Broadnax, 1994). Institutions should develop and adequately fund resources on campus to enhance the CRE of its students. For instance, since the 1960's Black culture centers and other culturally based support centers are one way that campuses provide a supportive climate for African American and other students of color (Patton, 2006). Faculty and staff will need to be continuously trained and re-trained on how to engage diverse student populations as the landscape of higher education enrollment continues to change.

\section{Recommendations for Student Involvement Practice and Research}

In regards to future practice and research related to involvement and collective racial esteem, Crocker, Luhtanen, Blaine, and Broadnax (1994) recommended that further 
research on the role of collective identity on college academic and social outcomes is needed. It is hypothesized that CRE can be modified by environmental interventions and factors within the institution. As detailed in Astin's (1993) I-E-O college impact model, the environment can interact with certain student inputs to yield a range of positive student outcomes.

A consistent finding in the literature review for this study was that males, particularly African American males, were less involved or engaged on college campuses than their female counterparts (Cuyjet, 1997). What was less clear was if the percentages of males involved were less than percentages of females. More females are enrolled in public four-year institutions, as well as other institutional types (Planty et al., 2009); therefore, there may appear to be more females involved because there are greater numbers of females on campus. Practitioners and researchers alike can benefit from an examination of the percentage of involvement disaggregated by race, rather than raw numbers or involvement data available via traditional methods (c.g., anecdote, student surveys, head count).

Practitioners and scholars must not assume that all students of color interpret their racial group membership the same way. This study found that African American students, male and female, have varying degrees of collective esteem as it relates to their racial group membership. The findings suggest that some African American students are predicted to be involved in some activities based on levels of their racial esteem. Student affairs and student services practitioners, as well as academic advisors and faculty, would benefit by understanding student CRE as they work to teach and support students.

Perceptions of differential treatment and discrimination within campus 
environments have emerged as one of the possible explanations for the difference in retention rates between majority and minority students (Nora \& Cabrera, 1996). African American males, according to Banks (2010), report significantly more discrimination than African American females. Further research is needed to understand how specific aspects of the college environment (e.g., number of faculty of color, number of minority students, curricular and co-curricular programs and courses, campus climate, etc.) affect CRE. The current study examined specific types of involvement as a way to understand the predictive relationship between CRE and involvement. However, there are more variables within the college environment that can be studied to ascertain a relationship. Understanding CRE within the campus environment may also help assess and improve issues surrounding campus climate.

This study used quantitative methodology to explore the relationships between CRE and quantity and type of involvement. Much of the research on African American students found in the literature review for this study utilized qualitative methods to understand student experiences (e.g., Harper, 2005, 2006b; Latiker, 2006; Littleton, 2002; Museus, 2008; Sutton \& Kimbrough, 2001). Qualitative research provides texture, nuance, and context to research (Rossman \& Rallis, 2003). What qualitative research lacks in generalizability, it makes up in depth and breadth of understanding of phenomena. Along with qualitative research, quantitative research can be used to further explore explanations and implications to improve the plight of African American male involvement and subsequent completion. Based on the review of literature for this study, quantitative analysis of CRE is limited. Qualitative analysis is even scarcer.

Qualitative methodologies should be utilized to understand why the findings in 
this study are significant. This includes understanding why females score higher than males, why students attending HBCUs score higher than students attending PWIs, and what specifically leads African American males who have high identity salience to join an ethnic/minority organization. Qualitative research can also help make sense of the cultural differences between African American males and the public four-year institutions in which they attend. Bridging the gap between the college culture and the native culture of the students within the campus environment can improve the persistence of minority students (Kuh \& Love, 2000).

Crocker, Luhtanen, Blaine, and Broadnax (1994) found that levels of CRE positively correlated to psychological well being in African Americans, Whites, and Asian students. CRE's influence on involvement and persistence variables should be replicated with other racial/ethnic identity groups, as well as with women. Luhtanen and Crocker (1992) found that the psychometric properties of the collective self-esteem scale are maintained despite the group membership. Therefore, examining collective esteem as it relates to gender can be very informative. Torres, Jones, and Renn (2009) said it best:

The more practitioners understand how students make meaning of their identities, the better they are able to assist in promoting student learning and development in higher education institutions (p. 578).

CRE is concerned with how students make meaning of their racial identity, thus it is possible that trends in CRE and involvement may exist within minority student groups. Understanding these trends can improve the development and assessment of institutional interventions and advising for these students.

Academic self-concept and other measures of self-esteem have been found to mediate the effect of racial identity on academic outcomes (Lockett \& Harrell, 2003; 
Parker \& Flowers, 2003). The effect of CRE on academic outcomes such as GPA and standardized test scores should be conducted to examine any direct relationships. CRE may be a more useful predictor of academic performance than self-esteem or racial identity development, and can increase understanding of the impact of race on academic outcomes.

This study examined the predictive relationship of CRE to faculty interaction and found no significant relationships. Given the strong relationship between faculty interaction and African American student outcomes (Guiffrida, 2005; Himelhoch, Nichols, Ball, and Black, 1997; Littleton, 2002; Strayhorn \& Terrell, 2007), more analyses needs to be conducted using a larger sample size, or perhaps disaggregating by institutional type (PWI vs. HBCU).

Similar to Vuong, Brown-Welty, and Tracz (2010), this study used MANOVA analysis to examine differences between institutional types. African American students attending HBCUs scored higher than African American students attending PWIs on all CRE sub-scales. Statistical significance was found with two of the four sub-scales. These results were expected based on the research on African Americans attending HBCUs (Allen, 1992; Minor, 2008), however, this study should be replicated using a larger sample of both PWIs and HBCUs. An institution-by-institution sample is not sufficient to generalize across all public four-year institutions within the U.S.

Also, as suggested by Vuong et al. (2010), CRE should be examined and compared across institutions of different sizes to determine if there are any significant differences. As African American students make-up higher percentages of students attending public and private two-year colleges than public four-year institutions (Aud et 
al., 2010), it would be important to examine CRE at these institutions. Though outside of the scope of this study, the findings could be helpful in understanding college choice and eventual transfer decisions.

Finally, CRE allows for a more evolved and sophisticated understanding of race and its impact on student involvement and other outcomes. As research on identity development moves from stage-based models to a more critical perspective of identity, it is important to examine CRE through the lens of critical race theory (CRT). The use of critical race theory acknowledges the centrality of race in a student's experiences, and draws attention "to the critical role of social status of different identity groups in the construction of identities" (Torres, Jones, \& Renn, 2009, p. 584). The exploration of CRE in relation to the other multiple identities within students will be an important next step in identity development research.

\section{Study Limitations}

This study had five main limitations. The first limitation is associated with the low number of African American male students included in the study. This study, and others using CRE, should be replicated using larger sample sizes to attain a clearer understanding of the public four-year college experience for African American males. The second limitation relates to homogeneity of the students selected. The participants were undergraduate students attending public four-year institutions. Research question four utilized only one PWI and one HBCU to compare differences in CRE scores for African American students across institutional types.

In addition, students who were classified as "Multiracial," "Transgendered," or "International Students" were not included in this analysis. As mentioned earlier in this 
study, African American students make-up higher percentages of students attending public and private two-year colleges than public four-year institutions (Aud et al., 2010). This means that the sample of public four-year institutions excludes a large number of the population of African Americans in post-secondary education.

The third limitation of this study was that the MSL study used in this dissertation is secondary data. Secondary data has its advantages, but can pose several limitations as well. Advantages included significant cost and time savings since the data were already collected. Also this dataset included the specific variables of interest for this research problem. Limitations included a non-randomized selection of institutions that participated in the MSL. Participating institutions self-selected into the MSL study and therefore did not provide a random sample of public four-year institutions from across the U.S. These institutions paid for participation in the MSL in the Spring 2009 semester, which could indicate that institutions with the adequate financial resources participated. The type of students attending these institutions may not be representative of all students in the country.

A fourth limitation is related to the research design employed. This is not a true experimental design as defined by Shadish, Cook, and Campbell (2002) and others. Findings in this study are relational, and causality is not implied. For example, based on this study's findings, African American males who have high scores on identity salience are predicted to join an ethnic/minority organization. This does not mean that high identity salience causes African American males to join ethnic/minority organizations. Future research should attempt to use qualitative methodologies to further understand these relationships. 
A final limitation for this study concerns construct definitions. These include definitions used for race, faculty interaction, peer interaction, and quantity of involvement. Though grounded in a review of the literature (Astin, 1984, 1993; Planty et al., 2009; Tinto, 1987) the definitions and variable constructions represent one of many possible definitions. For example, items used to measure peer interaction do not include every possible scenario through which students interact with peers. Rather, a variable was constructed that could represent peer interaction in a statistically valid way using the MSL instrument. Future research should attempt to examine the relationship of CRE to these variables using different items or construct definitions within the MSL and other instruments.

\section{Conclusion}

This dissertation focused on examining the predictive relationship between collective racial esteem and quantity and type of involvement for African American males attending public four-year institutions in the U.S. This study also examined differences in CRE scores between males and females and students attending HBCUs and PWIs. This study was in many ways a persistence study, as involvement in the college environment is so strongly linked to persistence and graduation (Astin, 1993; Pascarella \& Terenzini, 1991, 2005; Tinto, 1975). Public four-year institutions will continue to be expected to serve the states in which they reside by supporting bachelor degree attainment for the citizens of the state.

The conceptual frameworks used to examine involvement and persistence in this study were mainly drawn from the following theoretical models: Astin's (1993) inputsenvironment-outcomes college impact model, Tinto's (1975, 1987) model of student 
departure, Tierney's (1999) model of cultural integrity, and Kuh and Love's (2000) cultural perspective of student departure. This dissertation adds to the existing involvement and persistence literature by examining the effects of collective racial esteem on different types of involvement. This study also contributes to the racial identity literature by attempting to introduce CRE as a more developmentally sophisticated understanding of racial identity and how it impacts college outcomes (Dugan, Brown, Chavez, Mendoza, \& Rodriguez, 2010; Helms \& Cook, 1999).

Levels of CRE in this study were found to be significant predictors of quantity of campus involvement, decision to join an ethnic/minority organization, and peer interaction for African American students. Future research needs to explore the unique contribution of $\mathrm{CRE}$ on other college outcomes, including leadership development, satisfaction with college, and degree completion. The current and future MSL instrument is ripe for examining CRE with an array of outcomes and environmental factors at a diverse number of institutions across the country. Furthermore, longitudinal analyses should be conducted to determine if specific institutional decisions enhance CRE over time.

The findings of this study contribute to the literature concerning differences between African American males and females. Significant differences in CRE were found between African American males and females on three of the four sub-scales of CRE. Similar to national trends within higher education and elsewhere, females within this sample tended to have a higher overall sense of self-concept as it relates to their racial group membership. This is an encouraging finding, as CRE can be enhanced in male students through intentional research and good practice. 
The findings of this study affirm findings in the literature related to African American students attending HBCUs (Allen, 1992; Guiffrida, 2005; Kimbrough \& Harper, 2006; Minor, 2008). Across all levels of CRE, African American students attending the HBCU scored higher than those attending the PWI. Though only two levels were significantly different (Private CRE and Public CRE), future research should focus on a larger sample of HBCUs to determine if these differences are consistent, or if perhaps more significant differences are found.

In conclusion, the study significantly predicted a number of dependent variables related to involvement in the college environment for both males and females. None of the levels of CRE significantly predicted faculty interaction in this sample. Significant difference was observed between African American males and females on three of the four levels of CRE. Similarly, significant difference was observed between African American students attending an HBCU and those attending a PWI.

There is no doubt that more research is needed on the effects of CRE within college impact research. Additionally, research at all levels (state, institutional, and practitioner/scholar) must continue in order to identity strategies to retain African American students in public four-year institutions. As was a primary focus of this study, special attention should be paid to African American males in higher education. This group of students has consistently lagged behind other ethnic/racial groups, as well as behind females. Research should be disaggregated by gender to ensure due attention is paid to this group of students. The improvement of persistence and graduation rates of African American males will yield benefits for individual institutions as well as our society as a whole. 


\section{REFERENCES}

Allen, W. R. (1992). The color of success: African American college student outcomes at predominantly white and historically black public colleges and universities. Harvard Educational Review, 62(1), 26-44.

Allen, W. R., Edgar, G.E., \& Nesha, Z.H. (Eds.) (1991). College in Black and White: African American students in predominantly White and in historically Black public universities (SUNY series, Frontiers in Education). New York: State University of New York Press.

Astin, A. W. (1984). Student involvement: A developmental theory for higher education. Journal of College Student Personnel, 25(4), 297-308.

Astin, A. W. (1993). What matters in college. Liberal Education, 79(4), 4-15.

Aud, S., Hussar, W., Planty, M., Snyder, T., Bianco, K., Fox, M., Frohlich, L., Kemp, J., Drake, L. (2010). The Condition of Education 2010 (NCES 2010-028). National Center for Education Statistics, Institute of Education Sciences, U.S. Department of Education. Washington, DC.

Awad, G. H. (2007). The role of racial identity, academic self-concept, and self-esteem in the prediction of academic outcomes for African American students. Journal of Black Psychology, 33(2), 188-207.

Banks, K. H. (2010). African American college students' experience of racial discrimination and the role of college hassles. Journal of College Student Development, 51(1), 23-33.

Bonner, II, F. A. \& Bailey, K. W. (2006). Enhancing the academic climate for African American men. In M. Cuyjet (Ed.), African American Men in College (pp. 24-46). San Francisco, CA: Jossey-Bass.

Braxton, J. M. (2000). Reworking the student departure puzzle. Nashville: Vanderbilt University Press

Braxton, J., Hirschy, A., \& McClendon, S. (2004). Understanding and reducing college student departure. ASHE-ERIC Higher Education Report, 30(3).

Cabrera, A. F., Castenada, M.B., Amaury, N., \& Hengstler, D. (1992). The convergence between two theories of college persistence. Journal of Higher Education, 63(2), 143-164. 
Cabrera, A. F., Nora, A., Terenzini, P. T., Pascarella, E., \& Hagedorn, L. S. (1999). Campus racial climate and the adjustment of students to college: A comparison between White students and African American students. Journal of Higher Education, 70(2), 134-160.

Cabrera, A. F., Stampen, J. O., \& Hansen, W. L. (1990). Exploring the effects of ability to pay on persistence in college. Review of Higher Education, 13, 303-356.

Chavous, T. M. (2000). The relationships among racial identity, perceived ethnic fit, and organizational involvement for African American students at a predominantly White university. Journal of Black Psychology, 26(1), 79-100.

Chickering, A. W. (1969): Education and identity. San Francisco: Jossey-Bass.

Cokley, K. (1999). Reconceptualizing the impact of college racial composition on African American students' racial identity. Journal of College Student Development, 40(3), 235-246.

Crawford, F. (2007). The impact of income and minority status in the prediction of college student persistence and graduation in a reform context. Retrieved from ProQuest Digital Dissertations. (AAT 3293535).

Crawford, F. (March, 2010). Black male degree completion in a reform context. Kentucky Council on Postsecondary Education Research Roundtable. Paper presentation. Lexington, $\mathrm{KY}$.

Crocker, J., Luhtanen, R., Blaine, B., \& Broadnax, S. (1994). Collective self-esteem and psychological well-being among White, Black, and Asian college students. Personality and Psychology Bulletin, 20, 503-513.

Cross, W. E., Jr. (1971). The Negro-to-Black conversion experience. Black World.

Cross, W. E. (1991). Shades of Black: Diversity in African American identity. Philadelphia, PA: Temple University.

Cuyjet, M. J. (Ed.) (1997). African American men on college campuses: Their needs and their perceptions. New Directions for Student Services, 80, 5-16.

Cuyjet, M. J. (2006). African American men in college. San Francisco: Jossey-Bass.

Davis, J. (1994). College in black and white: Campus environment and academic achievement of African American males. Journal of Negro Education, 63, 620633. 
Davis, M., Dias-Bowie, Y., Greenberg, K., Klukken, G., Pollio, H. R., Thomas, S. P., \& Thompson, C.L. (2004). "A fly in the buttermilk": Descriptions of university life by successful Black undergraduate students at a predominately White southeastern university. Journal of Higher Education, 75(4), 420.

Duderstadt, J.J., \& Womack, F.W. (2003). The future of the public university in America: Beyond the crossroads. Baltimore: Johns Hopkins University Press.

Dugan, J. P. (2005). Multi-Institutional Study of Leadership: Participating School Guidebook, Part II. (Available from the National Clearinghouse for Leadership Programs, University of Maryland.)

Dugan, J. P., Brown, R., Chavez, D., Mendoza, A., \& Rodriguez, W. (2010). Race and leadership: Movement towards complex conceptualizations [PowerPoint slides].

Dugan. J. P., Christensen, C., Kryder, K., Roll, L., Chavez, D., Beazley, M., \& Lithgow, J. (2009). Collective racial esteem (CRE): Exploring alternatives for racial categories in research. [PowerPoint slides].

Dugan, J. P., Komives, S. R., \& Segar, T. C. (2008). College student capacity for socially responsible leadership: Understanding norms and influences of race, gender, and sexual orientation. NASPA Journal, 45(4), 475-500.

Dugan, J. P., Jacoby, B., Gasiorski, A., Jones, J.R., \& Kim, J. C. (2007). Examining race and leadership: Emerging themes. Concepts and Connections, 15(2), 13-15.

Dugan, J. P., \& Owen, J. E. (2007). Practicing what we preach: An institutional approach to student leadership development. The Leadership Exchange, 5(2), 20-23.

Erikson, E. (1968). Identity: youth and crisis. New York: Norton.

Field, A. (2005). Discovering statistics using SPSS ( $2^{\text {nd }}$ ed.). Thousand Oaks, CA: SAGE.

Flowers, L. A. (2004a). Examining the effects of student involvement on African American college student development. Journal of College Student Development, 45(6), 633-654.

Flowers, L. A. (2004b). Retaining African American students in higher education: An integrative review. Journal of College Student Retention Research Theory and Practice, 6(1), 23-35.

Flowers, L. A., \& Pascarella, E. T. (1999a). Cognitive effects of college racial composition on African American students after 3 years of college. Journal of College Student Development, 40(6), 669-677. 
Flowers, L. A., and Pascarella, E. T. (1999b). Does college racial composition influence the openness to diversity of African American students. Journal of College Student Development, 40(4), 405-417.

Green, S. B. (1991). How many subjects does it take to do a regression analysis? Multivariate Behavioural Research, 26, 499-510.

Guiffrida, D. A. (2003). African American student organizations as agents of social integration. Journal of College Student Development, 44, 304-319.

Guiffrida, D. A. (2005). Othermothering as a framework for understanding African American students' definitions of student-centered faculty. The Journal of Higher Education, 76(6), 701-723.

Guiffrida, D. A. (2006). Toward ad cultural advancement of Tinto's theory. Review of Higher Education, 29(4), 451-472.

Haber, P., \& Komives, S. R., (2009). Predicting the individual values of the social change model of leadership development: The role of college students' leadership and involvement experiences. Journal of Leadership Educators, 7(3), 133-166.

Harper, S. R. (2005). Leading the way: Inside the experiences of high-achieving AfricanAmerican male students. About Campus, 10(1), 8-15.

Harper, S.R. (2006a). Black male students at public flagship universities in the U.S.: Status, trends, and implications for policy and practice. Washington, DC: The Joint Center for Political and Economic Studies Health Policy Institute.

Harper, S. R. (2006b). Enhancing African American male student outcomes through leadership and active involvement. In M. Cuyjet (Ed.), African American Men in College (pp. 68-94). San Francisco, CA: Jossey-Bass.

Harper, S. R., \& Nichols, A. H. (2008). Are they not all the same? Racial heterogeneity among Black male undergraduates. Journal of College Student Development, 49(3), 199-214.

Harper, S. R., \& Quaye, S. J. (2007). Student organizations as venues for Black identity expression and development among African American male student leaders. Journal of College Student Development, 48(2), 127-144.

Harper, S. R., \& Wolley, M. A. (2002). Becoming an "involving college" for African American undergraduate men: Strategies for increasing African American male participation in campus activities. Bulletin, 70(3), 16-24.

Helms, J., \& American Psychological Association, W. (2007). Some Better Practices for Measuring Racial and Ethnic Identity Constructs. Journal of Counseling Psychology, 54(3), 235-246. 
Helms, J. E. (Ed.). (1990). Black and White racial identity: Theory, research, and practice. Westport, CT: Greenwood Press.

Helms, J. E., \& Cook, D. A. (1999). Using race and culture in counseling and psychotherapy: Theory and process. Boston: Allyn \& Bacon.

Hurtado, S., Milem, J. F., Clayton-Pedersen, A. R., \& Allen, W. R. (1998). enhancing campus climates for racial/ethnic diversity: Educational policy and practice. Review of Higher Education, 21(3), 279-302.

Hussar, W.J., \& Bailey, T.M. (2009). Projections of education statistics to 2018 (NCES 2009-062). National Center for Education Statistics, Institute of Education Sciences, U.S. Department of Education. Washington, DC.

Kelly, P. J. (2005). As America becomes more diverse: The impact of state higher education inequality. Boulder, CO: National Center for Higher Education Management Systems.

Kentucky Council on Postsecondary Education. (2001). Retrieved from http://cpe.ky.gov/.

Kimbrough, W. M., \& Harper, S. R. (2006). African American men at historically Black colleges and universities: Different environments, similar challenges. In M. Cuyjet (Ed.), African American Men in College (pp. 189-209). San Francisco, CA: Jossey-Bass.

Komives, S. R. (2007). The social change model: A decade of practice and progress. NASPA Leadership Exchange, 5(2), 23.

Kuh, G. D., \& Hu, S. (2001). The effects of student-faculty interaction in the 1990s. Review of Higher Education, 24(3), 309-332.

Kuh, G. D. \& Love, P. G. (2000). A cultural perspective on student departure. In J. Braxton (Ed.), Reworking the Student Departure Puzzle (pp. 198-212). Nashville, TN: Vanderbilt University Press.

Latiker, T. T. (2006). A qualitative study of African American student persistence in a private Black college. In T. Manson (Ed.), Twenty issues in teaching African American pupils: A collective experience of what works. Lewiston: Edwin Mellen Press.

Lee, R. M., \& Davis, C. (2000). Cultural orientation, past multicultural experience, and a sense of belonging on campus for Asian American college students. Journal of College Student Development, 41, 110-115.

Littleton, R. A. (2001). Proceedings from the $26^{\text {th }}$ Annual Meeting of the Association for the Study of Higher Education. Richmond, VA. 
Littleton, R. A. (2002). Campus involvement among African American students at small, predominantly White colleges. College Student Affairs Journal, 21(2), 53-67.

Lockett, C. T., \& Harrell, J. P. (2003). Racial identity, self-esteem, and academic achievement: Too much interpretation, too little supporting data. Journal of Black Psychology, 29(3), 325-336.

Luhtanen R., \& Crocker, J. (1992). A collective self-esteem scale: Self-evaluation of one's social identity. Personality and Social Psychology Bulletin, 18, 302-318.

Martinez, M. T., Gehrke, S. J., Komives, S. R., \& Dugan, J. P. (2007). Student programmers and leadership development: Select findings from the multiinstitutional study of leadership. NACA Campus Activities Programming, 40(1), 46-49.

Minor, J. T. (2008). Contemporary HBCUs: Considering institutional capacity and state priorities. A research report. Michigan State University, College of Education, Department of Educational Administration. East Lansing, MI.

Mitchell, S. L., \& Dell, D. M. (1992). The relationship between Black students racial identity attitude and participation in campus organizations. Journal of College Student Development, 33(1), 39-43.

Museus, S. D. (2008). The role of ethnic student organizations in fostering African American and Asian American students' cultural adjustment and membership at predominantly White institutions. Journal of College Student Development, 49(6), $568-586$.

Museus, S. D., Nichols, A. H., \& Lambert, A. (2008). Racial differences in the effects of campus racial climate on degree completion: A structural model. The Review of Higher Education, 32(1), 107-134.

National Clearinghouse for Leadership Programs (NCLP) and Center for Student Studies. (2009). MSL school report: University of Louisville. College Park, MD.

National Survey of Student Engagement. (2009). Assessment for improvement: Tracking student engagement over time-Annual results 2009. Bloomington, IN: Indiana University Center for Postsecondary Research.

Nora, A., Barlow, E., \& Crisp, G. (2006). Examining the tangible and psychosocial benefits of financial aid with student access, engagement, and degree attainment. The American Behavioral Scientist, 49(12), 1636-1651.

Nora, A., \& Cabrera, A. F. (1996). The role of perceptions in prejudice and discrimination and the adjustment of minority students to college. Journal of Higher Education, 67(2), 119-148. 
Ogbu, J. U. (2004). Collective identity and the burden of "acting White" in Black history, community, and education. Urban Review: Issues and Ideas in Public Education, $36(1), 1-35$.

Outcalt, C. L., \& Skewes-Cox, T. E. (2002). Involvement, interaction, and satisfaction: The human environment at HBCUs. Review of Higher Education, 25(3), 331-347.

Parham, T. A., \& Helms, J. E. (1985). Attitudes of racial identity and self-esteem of Black students: An exploratory investigation. Journal of College Student Personnel, 26(2), 143-147.

Parker, M., \& Flowers, L. A. (2003). The effects of racial identity on academic achievement and perceptions of campus connectedness on African American students at predominately White institutions. College Student Affairs Journal, 22(2), 180-194.

Pascarella, E. T., \& Terenzini, P. T. (1991). How college affects students: Findings and insights from twenty years of research. San Francisco: Jossey-Bass.

Pascarella, E. T., \& Terenzini, P. T. (2005). How College Affects Students: A Third Decade of Research (Vol. 2). San Francisco: Jossey-Bass.

Patton, L. D. (2006). Black culture centers: Still central to student learning. About Campus, $11(2), 2-8$.

Patton, L. D. (2006). The voice of reason: A qualitative examination of Black student perceptions of Black culture centers. Journal of College Student Development, 47 , 628-646.

Peng, C. J., Lee, K. L., \& Ingersoll, G. M. (2002). An introduction to logistic regression analysis and reporting. Journal of Educational Research, 96(1), 3-14.

Phelps, R. E., Taylor, J. D., \& Gerard, P. A. (2001). Cultural mistrust, ethnic identity, racial identity, and self-esteem among ethnically diverse Black university students. Journal of Counseling \& Development, 79(2), 209-216.

Phinney, J. S. (1996). Understanding ethnic diversity: The role of ethnic identity. American Behavioral Scientist, 40(2), 143-152.

Pike, G. R., \& Kuh, G. D. (2006). Relationships among structural diversity, informal peer interactions, and perceptions of the campus environment. The Review of Higher Education, 29(4), 425-450.

Pike, G. R., Kuh, G. D., \& Gonyea, R. M. (2003). The relationship between institutional mission and students' involvement and educational outcomes. Research in Higher Education, 44(2), 241-261. 
Planty, M., Hussar, W., Snyder, T., Kena, G., Kewal Ramani, A., Kemp, J., Bianco, K., Dinkes, R. (2009). The condition of education 2009 (NCES 2009-81). National Center for Education Statistics, Institute of Education Sciences, U.S. Department of Education. Washington, DC.

Rosenberg, Morris. (1989). Society and the adolescent self-image ( $2^{\text {nd }}$ ed.). Middletown, CT: Wesleyan University Press.

Rosch, D. (2007). Relation of campus involvement to self-reported capacities for socially responsible leadership. Retrieved from ProQuest Digital Dissertations. (AAT 3325603).

Rossman, G. B., \& Rallis, S. F. (2003). Learning in the field: An introduction to qualitative research ( 2 nd cd.). Thousand Oaks: Sage.

Santos, S. J., \& Reigadas, E. T. (2005). Understanding the student-faculty mentoring process: Its effects on at-risk university students. Journal of College Student Retention Research Theory and Practice, 6(3), 337-357.

Sellers, R. M., Rowley, S. A., Chavous, T. M., Shelton, J. N., \& Smith, M. A. (1997). Multidimensional inventory of Black identity: a preliminary investigation of reliability and construct validity. Journal of Personality and Social Psychology, $73,805-815$.

Sergent, M. T., \& Sedlacek, W. E. (1990). Volunteer motivations across student organizations: A test of person-environment fit theory. Journal of College Student Development, 31(3), 255-261.

Shadish, W. R., Cook, T. D., \& Campbell, D. T. (2002). Experimental and quasiexperimental designs for generalized causal inference. Boston: Houghton Mifflin.

Strayhorn, T. L., \& Terrell, M. C. (2007). Mentoring and satisfaction with college for Black students. The Negro Educational Review, 58, 69-83.

Suarez-Balcazar, Y., Orellana-Damacela, L., Portillo, N., Rowan, J. M., \& AndrewsGuillen, C. (2003). Experiences of differential treatment among college students of color. Journal of Higher Education, 74(4), 428-444.

Sutton, E. M., \& Kimbrough, W. M. (2001). Trends in Black student involvement. NASPA Journal, 39(1), 30-40.

Sutton, E. M., \& Terrell, M. C. (1997). Identifying and developing leadership opportunities for African American men. In M. J. Cuyjet (Ed.), Helping African American men succeed in college. New Directions for Student Services (No. 80, pp. 55-64). San Francisco: Jossey-Bass. 
Taylor, C. M., \& Howard-Hamilton, M. F. (1995). Student involvement and racial identity attitudes among African American males. Journal of College Student Development, 36(4), 330-336.

Tierney, W. (1992). An anthropological analysis of student participation in college. Journal of Higher Education, 63, 603-618.

Tierney, W. G. (1997). Power, identity and the dilemma of college student departure. A research report. University of Southern California, Center for Higher Education Policy Analysis. Los Angeles, CA.

Tierney, W. G. (1999). Models of minority college-going and retention: Cultural integrity versus cultural suicide. Journal of Negro Education, 68(1), 80-91.

Tinto, V. (1975). Dropout from higher education: A theoretical synthesis of recent research. Review of Educational Research, 45(1), 89-125.

Tinto, V. (1987). Leaving college: Rethinking the causes and cures of student attrition. Chicago: University of Chicago Press.

Tinto, V. (1993). Leaving College: Rethinking the Causes and Cures of Student Attrition ( $2^{\text {nd }}$ ed.). Chicago: University of Chicago Press.

Tinto, V. (1998). Colleges as communities: Taking research on student persistence seriously. Review of Higher Education, 21(2), 167-177.

Tinto, V. (2007). Research and practice of student retention: What next? Journal of College Student Retention: Research, Theory \& Practice, 8(1), 1-19.

Torres, V., Jones, S. R., Renn, K. A. (2009). Identity development theories in student affairs: Origins, current status, and new approaches. Journal of College Student Development, 50(6), 577-96.

Tyree, T.M. (1998). Designing an Instrument to Measure Socially Responsible Leadership Using the Social Change Model of Leadership Development. Doctoral Dissertation; University of Maryland, College Park.

United States Census Data (2010). Population reference bureau. Retrieved from http:/www.prb.org/Articles/2009/questionnaire.aspx.

Vandiver, B. J., Fhagen-Smith, P. E., Cokley, K. O., Cross, W. E., Jr., \& Worrell, F. C. (2001). Cross's nigrescence model: From theory to scale to theory. Journal of Multicultural Counseling and Development, 29(3), 174-200.

Vuong, M., Brown-Welty, S., \& Tracz, S. (2010). The effects of self-efficacy on academic success of first-generation college sophomore students. Journal of College Student Development, 51(1), 50-64. 
Worrell, F. C., Cross, W. E., Jr., \& Vandiver, B. J. (2001). Nigrescence theory: Current status and challenges for the future. Journal of Multicultural Counseling and Development, 29(3), 201-213.

Worrell, F. C., Vandiver, B. J., Schaefer, B. A., Cross, W. E., Jr., \& Fhagen-Smith, P. E. (2006). Generalizing nigrescence profiles: Cluster analyses of cross racial identity scale (CRIS) scores in three independent samples. Counseling Psychologist, 34(4), 519-547. 
1. Samford University

2. University of Arizona

3. California Lutheran

4. California State University, Sacramento

5. University of California, Berkeley

6. Loyola Marymount University

7. University of San Diego

8. University of San Francisco

9. Sonoma State University

10. University of Colorado at Boulder

11. Colorado State University-Ft. Collins

12. Metro State College Denver

13. Regis University

14. Gallaudet University

15. University of Central Florida

16. Rollins College

17. University of South Florida

18. University of Tampa

19. Berry College

20. Georgia Southern University

21. University of Chicago

22. DePaul University

23. Elmhurst College

24. University of Illinois, Urbana-Champaign

25. Loyola University Chicago

26. Milikin University

27. Northwestern University

28. Northeastern Illinois University

29. Indiana University-Bloomington

30. Cornell College

31. Drake University

32. University of Iowa

33. Wartburg College

34. University of Kansas

35. Kansas State University

36. University of Louisville

37. University of Maryland, College Park

38. University of Maryland, Eastern Shore

39. Montgomery College, Maryland

40. Bridgewater State College

41. Harvard

42. University of Massachusetts, Lowell 


\section{Multi-Institutional Study of Leadership \\ Final Codebook}

Version 2.7.09

\section{Red Font $=$ Negative Response Item \\ Blue Font $=$ Skip Pattern \\ Green Shading = Sub-Study}

Purple Shading $=$ Variable Included in Reports Section for Inputs

Peach Shading $=$ Variable Included in Reports Section for Environments 


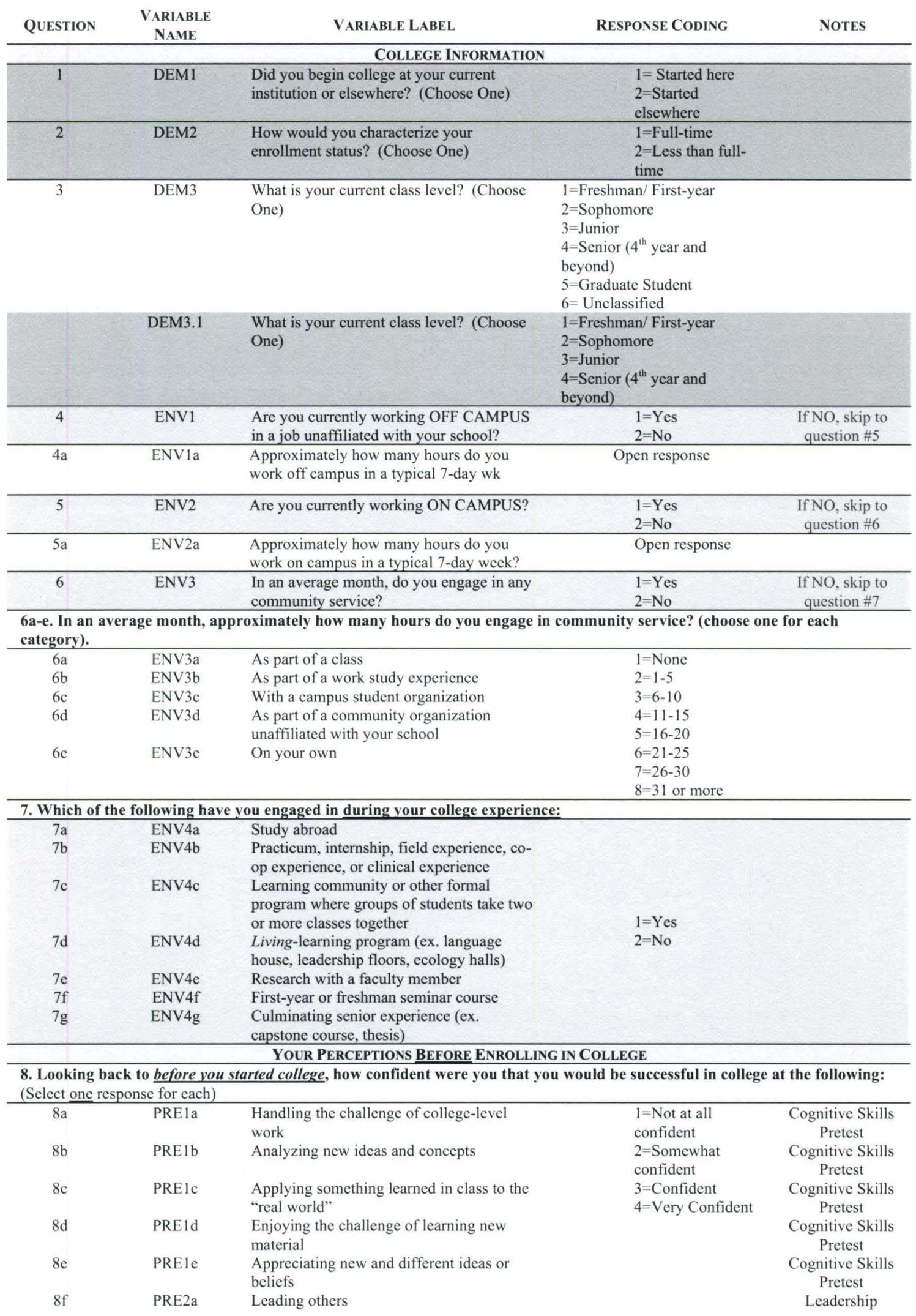




$\begin{array}{lll}8 \mathrm{~g} & \text { PRE2 } \mathrm{b} & \begin{array}{l}\text { Organizing a group's tasks to accomplish a } \\ \text { goal }\end{array} \\ 8 \mathrm{~h} & \text { PRE2c } & \begin{array}{l}\text { Taking initiative to improve something } \\ 8 \mathrm{i}\end{array} \\ \text { PRE2d } & \text { Working with a team on a group project }\end{array}$

9. Looking back to when vou were in high school, how often did you engage in the following activities: (Select one response for each)

\begin{tabular}{|c|c|c|c|}
\hline $9 \mathrm{a}$ & PRE3a & Student council or student government & \\
\hline $9 \mathrm{~b}$ & PRE3b & $\begin{array}{l}\text { Pep Club, School Spirit Club, or } \\
\text { Cheerleading }\end{array}$ & \\
\hline $9 \mathrm{c}$ & PRE3c & $\begin{array}{l}\text { Performing arts (ex. band, orchestra, dance, } \\
\text { drama, art) }\end{array}$ & \\
\hline $9 \mathrm{~d}$ & PRE3d & $\begin{array}{l}\text { Academic clubs (ex. science fair, math } \\
\text { club, debate club, foreign language club, } \\
\text { chess club, literary magazine) }\end{array}$ & \\
\hline $9 \mathrm{e}$ & PRE3e & Organized sports (ex. Varsity, club sports) & $\begin{array}{l}1=\text { Never } \\
2=\text { Sometimes } \\
3=\text { Often } \\
4=\text { Very Often }\end{array}$ \\
\hline 9f & PRE3f & $\begin{array}{l}\text { Leadership positions in student clubs, } \\
\text { groups, sports (ex. officer in a club or } \\
\text { organization, captain of athletic team, first } \\
\text { chair in musical group, section editor of } \\
\text { newspaper) }\end{array}$ & \\
\hline
\end{tabular}

10. Looking back to before you started college, how often did you engage in the following activities: (Select one response for each)

$\begin{array}{lll}10 \mathrm{a} & \text { PRE4a } & \text { Performed community service } \\ 10 \mathrm{~b} & \text { PRE4b } & \text { Reflected on the meaning of life }\end{array}$

Spirituality

Search for

Meaning Pretest

\begin{tabular}{|c|c|c|c|c|}
\hline $10 \mathrm{c}$ & PRE4c & $\begin{array}{l}\text { Participated in community organizations } \\
\text { (ex. church group, scouts) }\end{array}$ & & \\
\hline $10 \mathrm{~d}$ & PRE4d & $\begin{array}{l}\text { Took leadership positions in community } \\
\text { organizations }\end{array}$ & & \\
\hline $10 \mathrm{e}$ & PRE4e & $\begin{array}{l}\text { Considered my evolving sense of purpose } \\
\text { in life }\end{array}$ & $\begin{array}{l}1=\text { Never } \\
2=\text { Sometimes } \\
3=\text { Often } \\
4=\text { Very Often }\end{array}$ & $\begin{array}{c}\text { Spirituality: } \\
\text { Search for } \\
\text { Meaning Pretest }\end{array}$ \\
\hline $10 \mathrm{f}$ & PRE4f & $\begin{array}{l}\text { Worked with others for change to address } \\
\text { societal problems (ex. rally, protest, } \\
\text { community organizing) }\end{array}$ & & \\
\hline $10 \mathrm{~g}$ & PRE4g & $\begin{array}{l}\text { Participated in training or education that } \\
\text { developed your leadership skills }\end{array}$ & & \\
\hline $10 \mathrm{~h}$ & PRE4h & Found meaning in times of hardship & & $\begin{array}{l}\text { Spirituality: } \\
\text { Search for } \\
\text { Meaning Pretest }\end{array}$ \\
\hline
\end{tabular}

11. Looking back to before you started college, please indicate your level of agreement with the following items: 


\begin{tabular}{|c|c|c|c|c|}
\hline $11 \mathrm{a}$ & PRE5a & \multicolumn{2}{|l|}{$\begin{array}{l}\text { Hearing differences in opinions enriched } \\
\text { my thinking }\end{array}$} & $\begin{array}{c}\text { Controversy with } \\
\text { Civility Pretest }\end{array}$ \\
\hline $11 b$ & PRE5b & \multicolumn{2}{|l|}{ I had low self esteem } & $\begin{array}{l}\text { Consciousness of } \\
\text { Self Pretest }\end{array}$ \\
\hline $11 \mathrm{c}$ & PRE5c & I worked well in changing environments & $\begin{array}{l}1=\text { Strongly } \\
\text { Disagree } \\
2=\text { Disagree }\end{array}$ & Change Pretest \\
\hline $11 \mathrm{~d}$ & PRE5d & $\begin{array}{l}\text { I enjoyed working with others toward } \\
\text { common goals }\end{array}$ & $\begin{array}{l}3=\text { Neutral } \\
4=\text { Agree }\end{array}$ & $\begin{array}{l}\text { Collaboration } \\
\text { Pretest }\end{array}$ \\
\hline $11 \mathrm{e}$ & PRE5e & $\begin{array}{l}\text { I held myself accountable for } \\
\text { responsibilities I agreed to }\end{array}$ & $5=$ Strongly Agree & $\begin{array}{l}\text { Commitment } \\
\text { Pretest }\end{array}$ \\
\hline $11 \mathrm{f}$ & PRE5f & $\begin{array}{l}\text { I worked well when I knew the collective } \\
\text { values of a group }\end{array}$ & & $\begin{array}{c}\text { Common } \\
\text { Purpose Pretest }\end{array}$ \\
\hline $11 \mathrm{~g}$ & PRE5g & My behaviors reflected my beliefs & & $\begin{array}{l}\text { Congruence } \\
\text { Pretest }\end{array}$ \\
\hline $11 \mathrm{~h}$ & PRE5h & $\begin{array}{l}\text { I valued the opportunities that allowed me } \\
\text { to contribute to my community }\end{array}$ & & $\begin{array}{l}\text { Citizenship } \\
\text { Pretest }\end{array}$ \\
\hline \multicolumn{5}{|c|}{ 12. Please indicate how well the following statements describe how you were prior to college. } \\
\hline $12 \mathrm{a}$ & PRE6a & $\begin{array}{l}\text { I attempted to carefully consider the } \\
\text { perspectives of those with whom I } \\
\text { disagreed. }\end{array}$ & 1=Does Not Describe Me & $\begin{array}{c}\text { Social } \\
\text { Perspective } \\
\text { Taking Pretest }\end{array}$ \\
\hline $12 b$ & PRE6b & $\begin{array}{l}\text { I regularly thought about how different } \\
\text { people might view situations differently. }\end{array}$ & $\begin{array}{l}\text { Well } \\
2 \\
3\end{array}$ & $\begin{array}{l}\text { Social } \\
\text { Perspective }\end{array}$ \\
\hline $12 \mathrm{c}$ & PRE6c & $\begin{array}{l}\text { Before criticizing someone, I tried to } \\
\text { imagine what it would be like to be in their } \\
\text { position. }\end{array}$ & $\begin{array}{l}4 \\
5=\text { Describes Me Very Well }\end{array}$ & $\begin{array}{l}\text { Taking Pretest } \\
\text { Social } \\
\text { Perspective } \\
\text { Taking Pretest }\end{array}$ \\
\hline \multicolumn{5}{|c|}{$\begin{array}{l}\text { 13. We would like you to consider your BROAD racial group membership (ex. White, Middle Eastern, Native American, } \\
\text { African American/ Black, Asian American/ Pacific Islander, Latino/ Hispanic, Multiracial) in responding to the following } \\
\text { statements. Please indicate what your perceptions were prior to college. }\end{array}$} \\
\hline $13 \mathrm{a}$ & PRE7a & $\begin{array}{l}\text { My racial group membership was important } \\
\text { to my sense of identity. }\end{array}$ & $\begin{array}{l}1=\text { Strongly } \\
\text { Disagree }\end{array}$ & $\begin{array}{l}\text { Collective Racial } \\
\text { Efficacy Pretest }\end{array}$ \\
\hline $13 b$ & PRE7b & $\begin{array}{l}\text { I was generally happy to be a member of } \\
\text { my racial group. }\end{array}$ & $\begin{array}{l}2=\text { Disagree } \\
3=\text { Disagree }\end{array}$ & $\begin{array}{l}\text { Collective Racial } \\
\text { Efficacy Pretest }\end{array}$ \\
\hline $13 \mathrm{c}$ & PRE7c & $\begin{array}{l}1 \text { did not feel a strong affiliation to my } \\
\text { racial group. }\end{array}$ & $\begin{array}{c}\text { Somewhat } \\
4=\text { Neutral } \\
5=\text { Agree } \\
\text { Somewhat } \\
6=\text { Agree } \\
7=\text { Strongly Agree }\end{array}$ & $\begin{array}{l}\text { Collective Racial } \\
\text { Efficacy Pretest }\end{array}$ \\
\hline \multicolumn{5}{|c|}{ YOUR EXPERIENCES IN COLLEGE } \\
\hline \multicolumn{5}{|c|}{ 14. How often have you engaged in the following activities during your college experience: } \\
\hline $14 \mathrm{a}$ & ENV5c & Performed community service & \multirow{10}{*}{$\begin{aligned} 1=\text { Never } & \\
2 & =\text { Once } \\
3 & =\text { Sometimes } \\
4 & =\text { Often }\end{aligned}$} & \multirow{10}{*}{$\begin{array}{l}\text { Social Change } \\
\text { Behaviors Scale }\end{array}$} \\
\hline $14 \mathrm{~b}$ & ENV5d & $\begin{array}{l}\text { Acted to benefit the common good or } \\
\text { protect the environment }\end{array}$ & & \\
\hline $14 \mathrm{c}$ & ENV5e & $\begin{array}{l}\text { Been actively involved with an } \\
\text { organization that addresses a social or } \\
\text { environmental problem }\end{array}$ & & \\
\hline $14 d$ & ENV5f & $\begin{array}{l}\text { Been actively involved with an } \\
\text { organization that addresses the concerns of } \\
\text { a specific community (ex. academic } \\
\text { council, neighborhood association) }\end{array}$ & & \\
\hline $14 \mathrm{e}$ & ENV5g & $\begin{array}{l}\text { Communicated with campus or community } \\
\text { leaders about a pressing concern }\end{array}$ & & \\
\hline $14 \mathrm{f}$ & ENV5h & $\begin{array}{l}\text { Took action in the community to try to } \\
\text { address a social or environmental problem }\end{array}$ & & \\
\hline $14 \mathrm{~g}$ & ENV5i & $\begin{array}{l}\text { Worked with others to make the campus or } \\
\text { community a better place }\end{array}$ & & \\
\hline $14 \mathrm{~h}$ & ENV5j & $\begin{array}{l}\text { Acted to raise awareness about a campus, } \\
\text { community, or global problem }\end{array}$ & & \\
\hline $14 \mathrm{i}$ & ENV5n & $\begin{array}{l}\text { Took part in a protest, rally, march, or } \\
\text { demonstration }\end{array}$ & & \\
\hline $14 \mathrm{j}$ & ENV5o & $\begin{array}{l}\text { Worked with others to address social } \\
\text { inequality }\end{array}$ & & \\
\hline
\end{tabular}




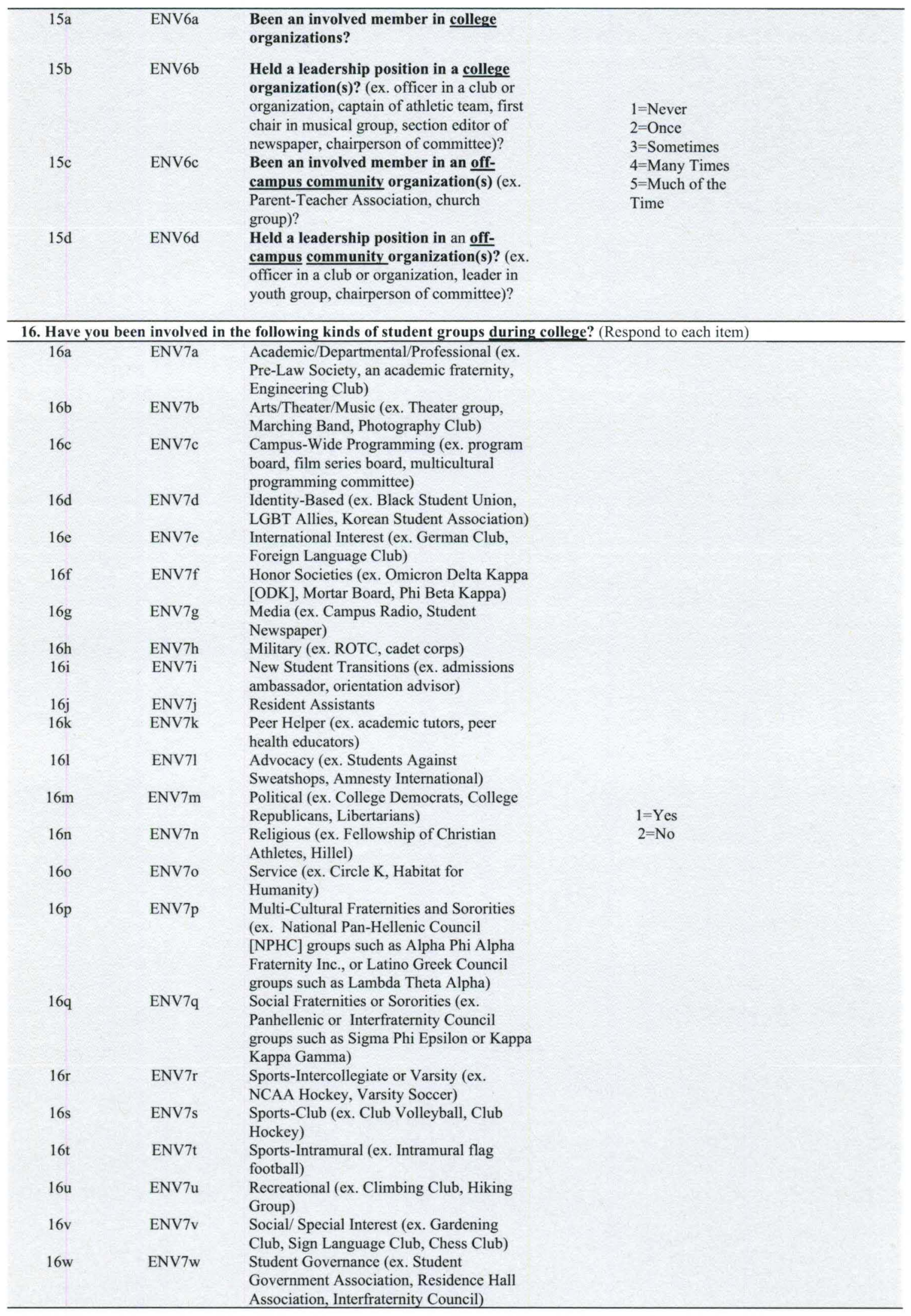




\begin{tabular}{|c|c|c|c|c|}
\hline \multicolumn{5}{|c|}{$\begin{array}{l}\text { 17a. A mentor is defined as a person who intentionally assists your growth or connects you to opportunities for career or } \\
\text { personal development. Since you started at your current college/university, have you been mentored by the following types of } \\
\text { people: }\end{array}$} \\
\hline $17 \mathrm{a} 1$ & ENV8al & Faculty/Instructor & \multirow{6}{*}{$\begin{array}{l}1=\mathrm{Yes} \\
2=\mathrm{No}\end{array}$} & If $\mathrm{NO}$ for $\mathrm{ALL}$ \\
\hline $17 \mathrm{a} 2$ & ENV8a2 & $\begin{array}{l}\text { Student Affairs Professional Staff (ex. } \\
\text { student organization advisor, career } \\
\text { counselor, Dean of Students, residence hall } \\
\text { coordinator) }\end{array}$ & & $\begin{array}{l}\text { items, skip to } \\
\text { question \#18. } \\
\text { For EACH }\end{array}$ \\
\hline $17 \mathrm{a} 3$ & ENV8a3 & Employer & & question with a \\
\hline $17 \mathrm{a} 4$ & ENV8a4 & Community member (not your employer) & & response other \\
\hline $17 \mathrm{a} 5$ & ENV8a5 & Parent/Guardian & & than NO, provide \\
\hline $17 \mathrm{a} 6$ & ENV8a6 & Other Student & & $\begin{array}{l}\text { the } \\
\text { corresponding } \\
\text { variable name } \\
\text { from the next } \\
\text { question. }\end{array}$ \\
\hline
\end{tabular}

17b. A mentor is defined as a person who intentionally assists your growth or connects you to opportunities for career or personal development.

Since you started at your current college/university, how often have the following types of mentors assisted you in your growth or development?

$\begin{array}{llll}17 \mathrm{~b} 1 & \text { ENV8b1 } & \begin{array}{l}\text { Faculty/Instructor } \\ \text { Student Affairs Professional Staff (ex. } \\ \text { student organization advisor, career } \\ \text { counselor, Dean of Students, residence hall }\end{array} & \begin{array}{l}\text { 1=Never } \\ \text { coordinator) }\end{array} \\ \begin{array}{lll}\text { ENV8b2 } \\ 17 \mathrm{~b} 3\end{array} & \text { ENV8b3 } & \text { Employer } & 3=\text { Sometimes } \\ 17 \mathrm{~b} 4 & \text { ENV8b4 } & \text { Community member (not your employer) } & 4=\text { Often } \\ 17 \mathrm{~b} 5 & \text { ENV8b5 } & \text { Parent/Guardian } & \\ 17 \mathrm{~b} 6 & \text { ENV8b6 } & \text { Other Student } & \end{array}$

17c. When thinking of your most significant mentor at this college/university, what was this person's role?

ENV8c1 Faculty/Instructor

ENV8c2 Student Affairs Professional Staff (ex.

student organization advisor, career

Select one response from the

counselor, Dean of Students, residence hall list of participant provided

coordinator) options, but do not include

ENV8c3 Employer options not listed to the left.

\begin{tabular}{|c|c|c|c|c|}
\hline & $\begin{array}{l}\text { ENV8c3 } \\
\text { ENV8c6 }\end{array}$ & $\begin{array}{l}\text { coordinator) } \\
\text { Employer } \\
\text { Other Student }\end{array}$ & options not listed to the left. & \\
\hline $17 \mathrm{~d}$ & ENV8c_2 & $\begin{array}{l}\text { When thinking of your most significant } \\
\text { mentor at this college/university, what was } \\
\text { this person's gender? }\end{array}$ & $\begin{array}{l}1=\text { Female } \\
2=\text { Male } \\
3=\text { Transgender }\end{array}$ & \\
\hline \multirow[t]{10}{*}{$17 \mathrm{e}$} & ENV8d & $\begin{array}{l}\text { When thinking of your most significant } \\
\text { mentor at this college/university, what was } \\
\text { this person's broad racial group } \\
\text { membership? }\end{array}$ & $\begin{array}{l}\text { 1=White/ Caucasian } \\
2=\text { Middle Eastern } \\
3=\text { African American/ Black } \\
\text { 4=Native American } \\
5=\text { Asian American/ Pacific } \\
\text { Islander } \\
6=\text { Latino/ Hispanic } \\
7=\text { Multiracial } \\
8=\text { Unsure } \\
9=\text { Race/ethnicity not indicated } \\
\text { above }\end{array}$ & \\
\hline & ENV8D.1 & White/Caucasian & & Note these \\
\hline & ENV8D.2 & Middle Eastern & & variables are \\
\hline & ENV8D.3 & African American/ Black & & permutations of \\
\hline & ENV8D.4 & Native American & & the above \\
\hline & ENV8D.5 & Asian American/ Pacific Islander & & question that \\
\hline & ENV8D.6 & Latino/ Hispanic & & allow for the \\
\hline & ENV8D.7 & Multiracial & & identification of \\
\hline & ENV8D.8 & Unsure & & each unique \\
\hline & ENV8D.9 & Race/ethnicity not indicated above & & $\begin{array}{c}\text { racial group } \\
\text { identified above. }\end{array}$ \\
\hline
\end{tabular}

17f. When thinking of your most significant mentor at this college/university, indicate your level of agreement or disagreement with the following: This mentor helped me to ...

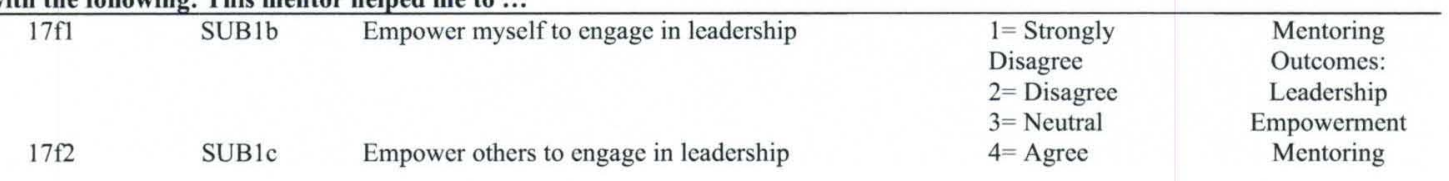


Mentor others
Outcomes:

Leadership

Empowerment

Mentoring

Outcomes:

Leadership

Empowerment

Mentoring

Outcomes:

Personal

Development

Mentoring

Outcomes:

Personal

Development

Mentoring

Outcomes:

Personal

Development

Mentoring

Outcomes:

Personal

Development

Mentoring

Outcomes:

Personal

Development

Mentoring

Outcomes:

Personal

Development

Mentoring

Outcomes:

Personal

Development

18. During interactions with other students outside of class, how often have you done each of the following in an average school year? (Select one for each)

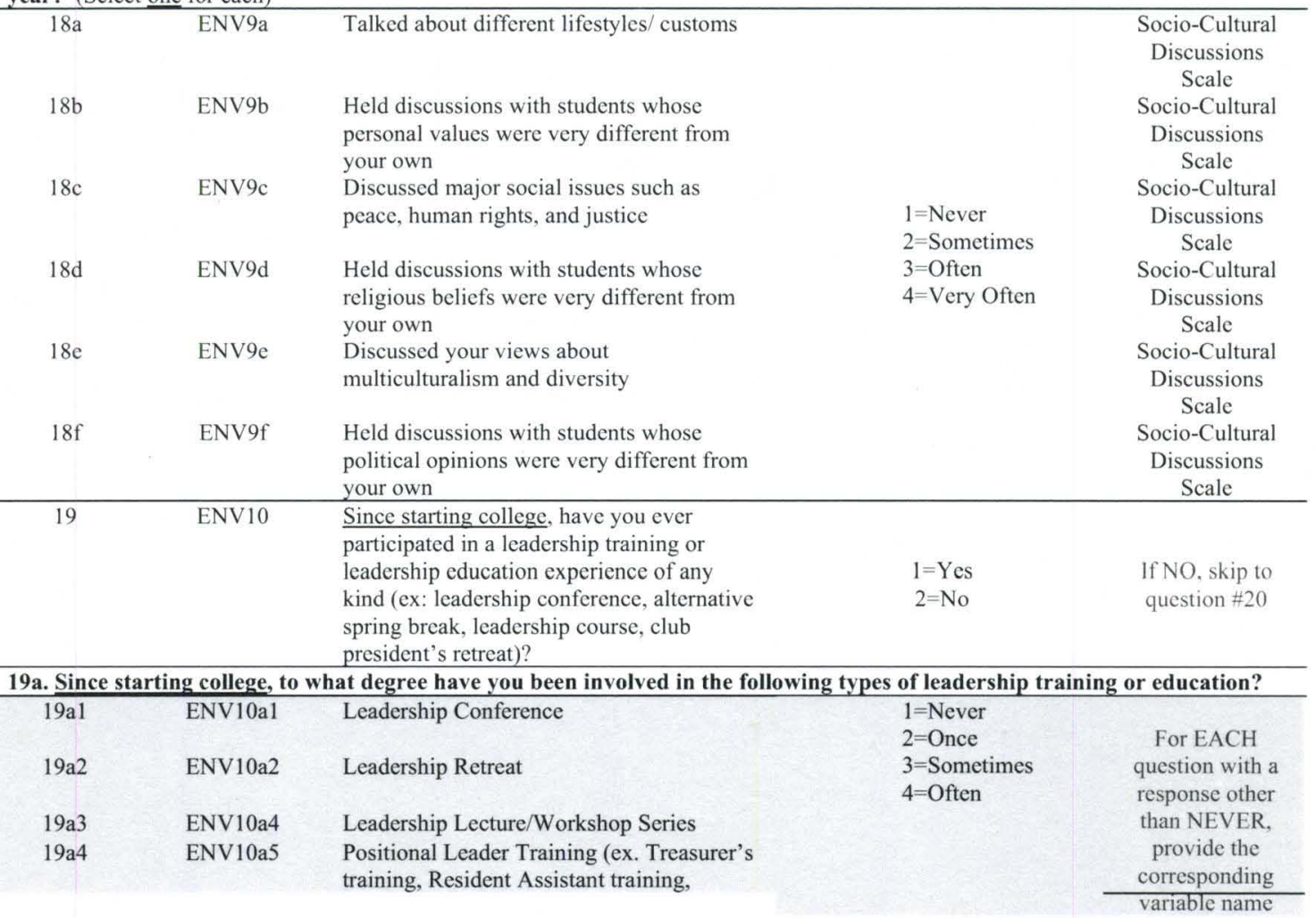




\begin{tabular}{|c|c|c|c|c|}
\hline & & & & \multirow{9}{*}{$\begin{array}{l}\text { from question } \\
\# 19 \text { c. }\end{array}$} \\
\hline $\begin{array}{l}19 \mathrm{a} 4 \\
19 \mathrm{a} 5\end{array}$ & $\begin{array}{l}\text { ENV10a5 } \\
\text { ENV10a7 }\end{array}$ & $\begin{array}{l}\text { Student Government training) } \\
\text { Leadership Course }\end{array}$ & & \\
\hline $19 \mathrm{a} 6$ & ENV10a10 & $\begin{array}{l}\text { Short-Term Service Immersion (ex. } \\
\text { alternative spring break, January term } \\
\text { service project) }\end{array}$ & & \\
\hline $19 \mathrm{a} 7$ & ENV10a11 & Emerging or New Leaders Program & & \\
\hline $19 \mathrm{a} 8$ & ENV10a12 & Living-Learning Leadership Program & & \\
\hline $19 \mathrm{a} 9$ & ENV10a13 & Peer Leadership Educator Team & & \\
\hline $19 \mathrm{a} 10$ & ENV10a14 & Outdoor Leadership Program & & \\
\hline 19a11 & ENV10a15 & Women's Leadership Program & & \\
\hline $19 \mathrm{a} 12$ & ENV10a16 & Multicultural Leadership Program & & \\
\hline \multicolumn{5}{|c|}{ 19b. Since starting college, have you been involved in the following types of leadership training or education? } \\
\hline $19 \mathrm{~b} 1$ & ENV10a3 & Leadership Certificate Program & \multirow{4}{*}{$\begin{array}{l}1=\text { Yes } \\
2=\text { No }\end{array}$} & \multirow{4}{*}{$\begin{array}{c}\text { For EACH Yes } \\
\text { response, } \\
\text { provide the } \\
\text { corresponding } \\
\text { variable name } \\
\text { from question } \\
\quad \# 19 c .\end{array}$} \\
\hline $19 \mathrm{~b} 2$ & ENV10a6 & Leadership Capstone Experience & & \\
\hline $19 \mathrm{~b} 3$ & ENV10a8 & Leadership Minor & & \\
\hline $19 \mathrm{~b} 4$ & ENV10a9 & Leadership Major & & \\
\hline \multicolumn{5}{|c|}{$\begin{array}{l}\text { 19c. Since starting college, to what extent has participation in the following types of training or education assisted in the } \\
\text { development of your leadership ability? }\end{array}$} \\
\hline $19 \mathrm{c} 1$ & ENV10b1 & Leadership Conference & \multirow{16}{*}{$\begin{array}{l}1=\text { Not At All } \\
2=\text { Minimally } \\
3=\text { Moderately } \\
4=\text { A Great Deal }\end{array}$} & \\
\hline $19 \mathrm{c} 2$ & ENV10b2 & Leadership Retreat & & \\
\hline $19 \mathrm{c} 3$ & ENV10b3 & Leadership Certificate Program & & \\
\hline $19 \mathrm{c} 4$ & ENV10b4 & Leadership Lecture/Workshop Series & & \\
\hline $19 \mathrm{c} 5$ & ENV10b5 & $\begin{array}{l}\text { Positional Leader Training (ex. Treasurer's } \\
\text { training, Resident Assistant training, } \\
\text { Student Government training) }\end{array}$ & & \\
\hline $19 \mathrm{c} 6$ & ENV10b6 & Leadership Capstone Experience & & \\
\hline $19 \mathrm{c} 7$ & ENV10b7 & Leadership Course & & \\
\hline $19 \mathrm{c} 8$ & ENV10b8 & Leadership Minor & & \\
\hline $19 \mathrm{c} 9$ & ENV10b9 & Leadership Major & & \\
\hline $19 \mathrm{cl} 0$ & ENV10b10 & $\begin{array}{l}\text { Short-Term Service Immersion (ex. } \\
\text { alternative spring break, January term } \\
\text { service project) }\end{array}$ & & \\
\hline $19 \mathrm{cll}$ & ENV10b11 & Emerging or New Leaders Program & & \\
\hline $19 \mathrm{cl} 2$ & ENV10b12 & Living-Learning Leadership Program & & \\
\hline $19 \mathrm{c} 13$ & ENV10b13 & Peer Leadership Educator Team & & \\
\hline $19 \mathrm{cl} 4$ & ENV10b14 & Outdoor Leadership Program & & \\
\hline $19 \mathrm{cl} 5$ & ENV10b15 & Women's Leadership Program & & \\
\hline $19 \mathrm{cl} 6$ & ENV10b16 & Multicultural Leadership Program & & \\
\hline & & ASSESSING YOUR GF & & \\
\hline
\end{tabular}

For the statements that refer to a group, think of the most effective, functional group of which you have been a part. This might be a formal organization or an informal study group. For consistency, use the same group in all your responses.

$\begin{array}{llll}\text { 20a SRLS1 } & \text { I am open to others' ideas } & 1=\text { Strongly } & \begin{array}{c}\text { Controversy with } \\ \text { Civility Scale }\end{array}\end{array}$


Hearing differences in opinions enriches my thinking

SRLS6 I have low self esteem

SRLS7 I struggle when group members have ideas

that are different from mine

SRLS8 Transition makes me uncomfortable

SRLS9 I am usually self confident

SRLS10 I am seen as someone who works well with others

SRLS11 Greater harmony can come out of disagreement

SRLS12 I am comfortable initiating new ways of

looking at things

SRLS13 My behaviors are congruent with my beliefs

SRLS14 I am committed to a collective purpose in those groups to which I belong

SRLS15 It is important to develop a common direction in a group in order to get anything done

SRLS16 I respect opinions other than my own

SRLS19

Change brings new life to an organization The things about which I feel passionate have priority in my life

I contribute to the goals of the group

SRLS20

There is energy in doing something a new way

SRLS21 I an uncomfortable when someone

disagrees with me

SRLS22 I know myself pretty well

SRLS23 I am willing to devote the time and energy to things that are important to me

SRLS24 I stick with others through difficult times

SRLS25 When there is a confliet between two

people. one will win and the other will lose

SRLS26

SRLS27

Change makes me uncomfortable

It is important to me to act on my beliefs

SRLS28 I am focused on my responsibilities

SRLS29

SRLS30

I can make a difference when I work with others on a task

SRLS31 I think it is important to know other people's priorities

SRLS32 My actions are consistent with my values

SRLS33

I believe I have responsibilities to my community

SRLS34

I could describe my personality

SRLS35

I have helped to shape the mission of the group

Common values drive an organization

Controversy with

Civility Scale

Controversy with

Civility Scale

Consciousness of Self Scale

Controversy with

Civility Scale

Consciousness of Self Scale

Controversy with

Civility Scale

Change Scale

Consciousness of Self Scale

Collaboration Scale

Controversy with

Civility Scale

Change Scale

\section{Congruence \\ Scale \\ Common \\ Purpose Scale \\ Common \\ Purpose Scale}

Controversy with

Civility Scale

Change Scale

Consciousness of Self Scale

Common

Purpose Scale

Change Scale

Controversy with

Civility Scale

Consciousness of Self Scale

Commitment Scale

Commitment Scale

Controversy with

Civility Scale

Change Scale

Congruence Scale

Commitment Scale

Collaboration Scale

Collaboration Scale

Common

Purpose Scale

Congruence Scale

Citizenship Scale

Consciousness of

Self Scale

Common

Purpose Scale

Change Scale

Common

Purpose Scale

Citizenship Scale 


\begin{tabular}{|c|c|c|c|c|}
\hline & & someone else & & \\
\hline $20 \mathrm{~mm}$ & SRLS39 & I work well in changing environments & & Change Scale \\
\hline $20 \mathrm{nn}$ & SRLS40 & $\begin{array}{l}\text { I work with others to make my } \\
\text { communities better places }\end{array}$ & & Citizenship Scale \\
\hline 2000 & SRLS41 & $\begin{array}{l}\text { I can describe how I am similar to other } \\
\text { people }\end{array}$ & & $\begin{array}{l}\text { Consciousness of } \\
\text { Self Scale }\end{array}$ \\
\hline $20 \mathrm{pp}$ & SRLS42 & $\begin{array}{l}\text { I enjoy working with others toward } \\
\text { common goals }\end{array}$ & & $\begin{array}{l}\text { Collaboration } \\
\text { Scale }\end{array}$ \\
\hline $20 \mathrm{qq}$ & SRLS43 & I am open to new ideas & & Change Scale \\
\hline $20 \mathrm{rr}$ & SRLS44 & $\begin{array}{l}\text { I have the power to make a difference in } \\
\text { my community }\end{array}$ & & Citizenship Scale \\
\hline $20 \mathrm{ss}$ & SRLS45 & I look for new ways to do something & & Change Scale \\
\hline $20 \mathrm{tt}$ & SRLS46 & I am willing to act for the rights of others & & Citizenship Scale \\
\hline $20 \mathrm{uu}$ & SRLS47 & $\begin{array}{l}\text { I participate in activities that contribute to } \\
\text { the common good }\end{array}$ & & Citizenship Scale \\
\hline $20 \mathrm{vv}$ & SRLS48 & $\begin{array}{l}\text { Others would describe me as a cooperative } \\
\text { group member }\end{array}$ & & $\begin{array}{l}\text { Collaboration } \\
\text { Scale }\end{array}$ \\
\hline $20 w w$ & SRLS49 & I am comfortable with conflict & & $\begin{array}{l}\text { Controversy with } \\
\text { Civility Scale }\end{array}$ \\
\hline $20 x x$ & SRLS50 & $\begin{array}{l}\text { I can identify the differences between } \\
\text { positive and negative change }\end{array}$ & & Change Scale \\
\hline $20 y y$ & SRLS51 & I can be counted on to do my part & & $\begin{array}{l}\text { Commitment } \\
\text { Scale }\end{array}$ \\
\hline $20 \mathrm{zz}$ & SRLS52 & $\begin{array}{l}\text { Being seen as a person of integrity is } \\
\text { important to me }\end{array}$ & & $\begin{array}{l}\text { Congruence } \\
\text { Scale }\end{array}$ \\
\hline 20aaa & SRLS53 & I follow through on my promises & & $\begin{array}{l}\text { Commitment } \\
\text { Scale }\end{array}$ \\
\hline $20 \mathrm{bbb}$ & SRLS54 & $\begin{array}{l}\text { I hold myself accountable for } \\
\text { responsibilities I agree to }\end{array}$ & & $\begin{array}{l}\text { Commitment } \\
\text { Scale }\end{array}$ \\
\hline $20 \mathrm{ccc}$ & SRLS55 & $\begin{array}{l}\text { I believe I have a civic responsibility to the } \\
\text { greater public }\end{array}$ & & Citizenship Scale \\
\hline 20ddd & SRLS56 & Self-reflection is difficult for the & & $\begin{array}{l}\text { Consciousness of } \\
\text { Self Scale }\end{array}$ \\
\hline 20eee & SRLS57 & Collaboration produces better results & & $\begin{array}{l}\text { Collaboration } \\
\text { Scale }\end{array}$ \\
\hline $20 \mathrm{fff}$ & SRLS58 & $\begin{array}{l}\text { I know the purpose of the groups to which I } \\
\text { belong }\end{array}$ & & $\begin{array}{c}\text { Common } \\
\text { Purpose Scale }\end{array}$ \\
\hline $20 \mathrm{ggg}$ & SRLS59 & I am comfortable expressing myself & & $\begin{array}{l}\text { Consciousness of } \\
\text { Self Scale }\end{array}$ \\
\hline $20 \mathrm{hhh}$ & SRLS60 & $\begin{array}{l}\text { My contributions are recognized by others } \\
\text { in the groups I belong to }\end{array}$ & & $\begin{array}{l}\text { Collaboration } \\
\text { Scale }\end{array}$ \\
\hline $20 \mathrm{iii}$ & SRLS61 & $\begin{array}{l}\text { I work well when I know the collective } \\
\text { values of a group }\end{array}$ & & $\begin{array}{c}\text { Common } \\
\text { Purpose Scale }\end{array}$ \\
\hline $20 \mathrm{jjj}$ & SRLS62 & I share my ideas with others & & $\begin{array}{l}\text { Controversy with } \\
\text { Civility Scale }\end{array}$ \\
\hline $20 \mathrm{kkk}$ & SRLS63 & My behaviors reflect my beliefs & & $\begin{array}{l}\text { Congruence } \\
\text { Scale }\end{array}$ \\
\hline 20111 & SRLS64 & I am genuine & & $\begin{array}{l}\text { Congruence } \\
\text { Scale }\end{array}$ \\
\hline $20 \mathrm{mmm}$ & SRLS65 & $\begin{array}{l}\text { I am able to trust the people with whom I } \\
\text { work }\end{array}$ & & $\begin{array}{l}\text { Collaboration } \\
\text { Scale }\end{array}$ \\
\hline $20 \mathrm{nnn}$ & SRLS66 & $\begin{array}{l}\text { I value opportunities that allow me to } \\
\text { contribute to my community }\end{array}$ & & Citizenship Scale \\
\hline 20000 & SRLS67 & $\begin{array}{l}\text { I support what the group is trying to } \\
\text { accomplish }\end{array}$ & & $\begin{array}{c}\text { Common } \\
\text { Purpose Scale }\end{array}$ \\
\hline 20ppp & SRLS68 & It is easy for me to be truthful & & $\begin{array}{l}\text { Congruence } \\
\text { Scale }\end{array}$ \\
\hline $20 \mathrm{qqq}$ & SRLS69 & $\begin{array}{l}\text { It is important to me that I play an active } \\
\text { role in my communities }\end{array}$ & & Citizenship Scale \\
\hline $20 \mathrm{rrr}$ & SRLS70 & I volunteer my time to the community & & Citizenship Scale \\
\hline 20 sss & SRLS71 & $\begin{array}{l}\text { I believe my work has a greater purpose for } \\
\text { the larger community }\end{array}$ & & Citizenship Scale \\
\hline \multicolumn{5}{|c|}{ THINKING MORE ABOUT YOURSELF } \\
\hline 21 & DEM4 & $\begin{array}{l}\text { How would you characterize your political } \\
\text { views? (Choose One) }\end{array}$ & $\begin{array}{l}\text { 1=Very liberal } \\
2=\text { Liberal } \\
3=\text { Moderate } \\
4=\text { Conservative } \\
5=\text { Very } \\
\text { conservative }\end{array}$ & \\
\hline
\end{tabular}




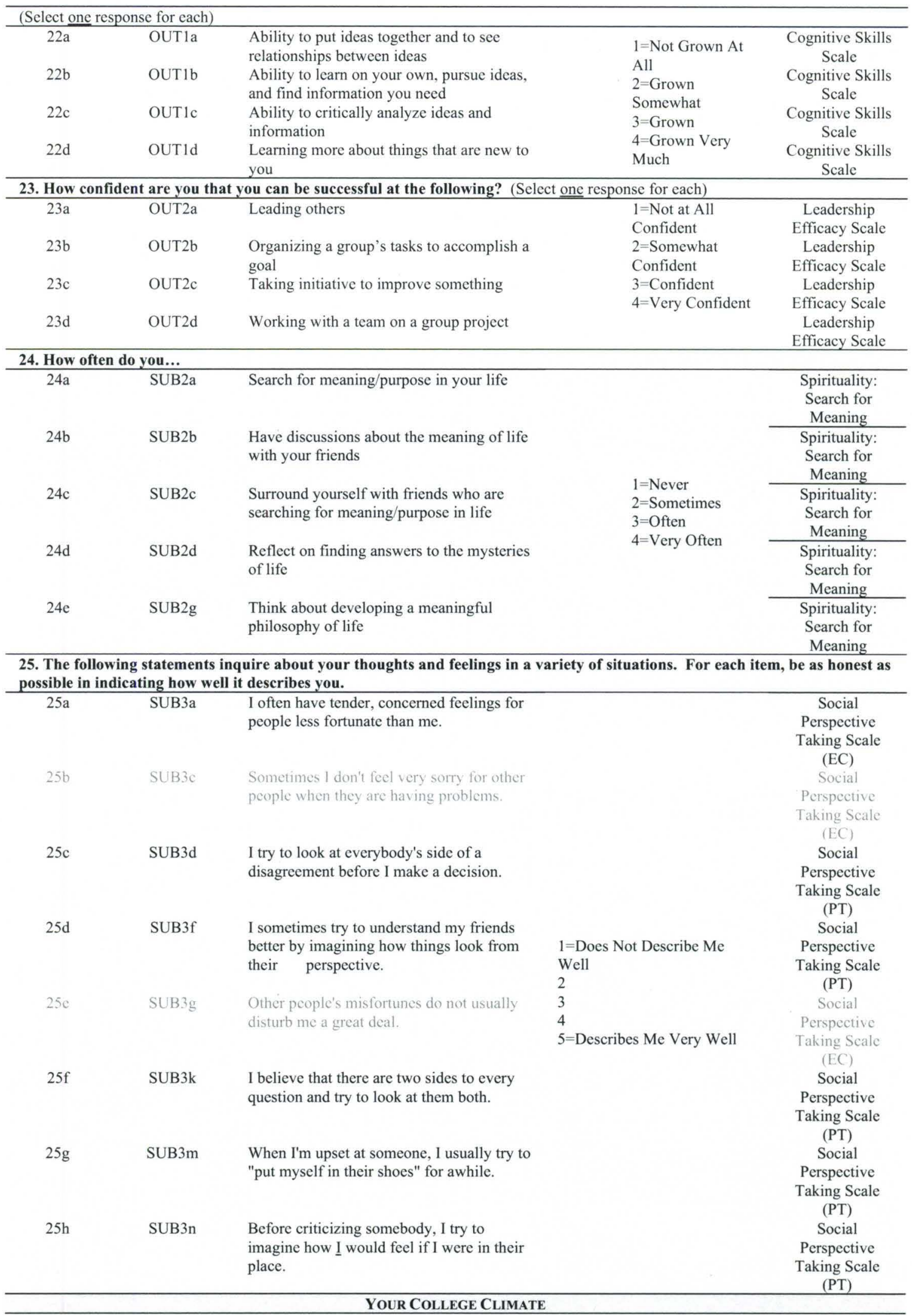




\begin{tabular}{|c|c|c|c|c|}
\hline \multicolumn{5}{|c|}{ 26. Indicate your level of agreement with the following statements about your experience on your current campus } \\
\hline $26 a$ & ENV11a_1 & I feel valued as a person at this school & $\begin{array}{l}1=\text { Strongly } \\
\text { Disagree }\end{array}$ & $\begin{array}{l}\text { Belonging } \\
\text { Climate }\end{array}$ \\
\hline $26 b$ & ENV11a_2 & $\begin{array}{l}\text { I feel accepted as a part of the campus } \\
\text { community }\end{array}$ & $\begin{array}{l}2=\text { Disagree } \\
3=\text { Neutral } \\
4=\text { Agree } \\
5=\text { Strongly Agree }\end{array}$ & $\begin{array}{l}\text { Belonging } \\
\text { Climate }\end{array}$ \\
\hline $26 \mathrm{c}$ & ENVIIa 4 & $\begin{array}{l}\text { I have observed discriminatory words, } \\
\text { behaviors or gestures directed at people like } \\
\text { me }\end{array}$ & Discrim & ory Climate \\
\hline $26 \mathrm{~d}$ & ENV11a_5 & I feel I belong on this campus & & $\begin{array}{l}\text { Belonging } \\
\text { Climate }\end{array}$ \\
\hline $26 \mathrm{c}$ & ENV11a_11 & $\begin{array}{l}\text { I have encountered diserimination while } \\
\text { attending this institution }\end{array}$ & & $\begin{array}{l}\text { Discriminatory } \\
\text { Climate }\end{array}$ \\
\hline $26 f$ & ENVI1a_12 & $\begin{array}{l}\text { I feel there is a general atmosphere of } \\
\text { prejudice among students }\end{array}$ & & $\begin{array}{l}\text { Discriminatory } \\
\text { Climate }\end{array}$ \\
\hline $26 g$ & ENV11a_15 & $\frac{\text { Faculty has c discriminated against people liki }}{\text { me }}$ & & $\begin{array}{l}\text { Discriminatory } \\
\text { Climate }\end{array}$ \\
\hline $26 h$ & ENVIIa_16 & $\begin{array}{l}\text { Staff members have discriminated against } \\
\text { people like me }\end{array}$ & & $\begin{array}{c}\text { Discriminatory } \\
\text { Climate }\end{array}$ \\
\hline \multicolumn{5}{|c|}{ BACKGROUND INFORMATION } \\
\hline 27 & DEM5 & $\begin{array}{l}\text { Which of the following best describes your } \\
\text { primary major? (Select the category that } \\
\text { best represents your field of study) }\end{array}$ & $\begin{array}{l}\text { 1=Agriculture } \\
2=\text { Architecture/ Urban } \\
\text { planning } \\
3=\text { Biological/ Life Sciences } \\
\text { (ex. biology, biochemistry, } \\
\text { botany, zoology) } \\
\text { 4=Business (ex. accounting, } \\
\text { business administration, } \\
\text { marketing, management) } \\
\text { 5=Communication (speech, } \\
\text { journalism, television/radio) } \\
6=\text { Computer and Information } \\
\text { Sciences } \\
7=\text { Education } \\
8=\text { Engineering } \\
9=\text { Ethnic, Cultural Studies, } \\
\text { and Area Studies } \\
10=\text { Foreign Languages and } \\
\text { Literature (ex. French, } \\
\text { Spanish) } \\
11=\text { Health-Related Fields (ex. } \\
\text { nursing, physical therapy, } \\
\text { health technology) } \\
12=\text { Humanities (ex. English, } \\
\text { Literature, Philosophy, } \\
\text { Religion, History) } \\
13=\text { Liberal/ General Studies } \\
14=\text { Mathematics } \\
15=\text { Multi/ Interdisciplinary } \\
\text { Studies (ex. international } \\
\text { relations, ecology, } \\
\text { environmental studies) } \\
16=\text { Parks, Recreation, Leisure } \\
\text { Studies, Sports Management } \\
17=\text { Physical Sciences (ex. } \\
\text { physics, chemistry, } \\
\text { astronomy, earth science) } \\
18=\text { Pre-Professional (ex. pre- } \\
\text { dental, pre-medical, pre- } \\
\text { veterinary) } \\
\text { 19=Public Administration (ex. } \\
\text { city management, law } \\
\text { enforcement) } \\
20=\text { Social Sciences (ex. } \\
\text { anthropology, economics, } \\
\text { polisual and Performing }\end{array}$ & \\
\hline
\end{tabular}




\begin{tabular}{|c|c|c|c|c|}
\hline & & & $\begin{array}{l}\text { Arts (ex. art, music, theater) } \\
22=\text { Undecided } \\
99=\text { Asked but not answered }\end{array}$ & \\
\hline & Dem5.1 & Agriculture & $1=$ Yes & \\
\hline & Dem5.2 & Architecture/ Urban planning & $2=\mathrm{No}$ & \\
\hline & Dem5.3 & $\begin{array}{l}\text { Biological/ Life Sciences (ex. biology, } \\
\text { biochemistry, botany, zoology) }\end{array}$ & & \\
\hline & Dem5.4 & $\begin{array}{l}\text { Business (ex. accounting, business } \\
\text { administration, marketing, management) }\end{array}$ & & \\
\hline & Dem5.5 & $\begin{array}{l}\text { Communication (speech, journalism, } \\
\text { television/radio) }\end{array}$ & & \\
\hline & Dem5.6 & Computer and Information Sciences & & \\
\hline & Dem5.7 & Education & & \\
\hline & Dem5.8 & Engineering & & \\
\hline & Dem5.9 & Ethnic, Cultural Studies, and Area Studies & & \\
\hline & Dem5.10 & $\begin{array}{l}\text { Foreign Languages and Literature (ex. } \\
\text { French, Spanish) }\end{array}$ & & \\
\hline & Dem5.11 & $\begin{array}{l}\text { Health-Related Fields (ex. nursing, } \\
\text { physical therapy, health technology) }\end{array}$ & & \\
\hline & Dem5.12 & $\begin{array}{l}\text { Humanities (ex. English, Literature, } \\
\text { Philosophy, Religion, History) }\end{array}$ & & \\
\hline & Dem5.13 & Liberal/ General Studies & & \\
\hline & Dem5.14 & Mathematics & & \\
\hline & Dem5.15 & $\begin{array}{l}\text { Multi/ Interdisciplinary Studies (ex. } \\
\text { international relations, ecology, } \\
\text { environmental studies) }\end{array}$ & & \\
\hline & Dem5.16 & $\begin{array}{l}\text { Parks, Recreation, Leisure Studies, Sports } \\
\text { Management }\end{array}$ & & \\
\hline & Dem5.17 & $\begin{array}{l}\text { Physical Sciences (ex. physics, chemistry, } \\
\text { astronomy, earth science) }\end{array}$ & & \\
\hline & Dem5.18 & $\begin{array}{l}\text { Pre-Professional (ex. pre-dental, pre- } \\
\text { medical, pre-veterinary) }\end{array}$ & & \\
\hline & Dem5.19 & $\begin{array}{l}\text { Public Administration (ex. city } \\
\text { management, law enforcement) }\end{array}$ & & \\
\hline & Dem5.20 & $\begin{array}{l}\text { Social Sciences (ex. anthropology, } \\
\text { economics, political science, psychology, } \\
\text { sociology) }\end{array}$ & & \\
\hline & Dem5.21 & $\begin{array}{l}\text { Visual and Performing Arts (ex. art, music, } \\
\text { theater) }\end{array}$ & & \\
\hline & Dem5.22 & Undecided & & \\
\hline 28 & PRE6 & $\begin{array}{l}\text { Did your high school require community } \\
\text { service for graduation? }\end{array}$ & \multicolumn{2}{|l|}{$\begin{array}{l}1=\text { Yes } \\
2=\text { No }\end{array}$} \\
\hline 29 & DEM6 & What is your age? & Open Response & \\
\hline \multirow[t]{2}{*}{$30 \mathrm{a}$} & DEM7 & What is your gender? & $\begin{array}{l}1=\text { Female } \\
2=\text { Male } \\
3=\text { Transgender }\end{array}$ & $\begin{array}{l}\text { If } 1 \text { or } 2 \text {, skip to } \\
\text { question } \# 31\end{array}$ \\
\hline & DEM7.1 & Gender (with transgender as missing) & $\begin{array}{l}1=\text { Female } \\
2=\text { Male }\end{array}$ & \\
\hline $30 \mathrm{~b}$ & DEM $7 b$ & $\begin{array}{l}\text { Please indicate which of the following best } \\
\text { describe you? }\end{array}$ & $\begin{array}{l}1=\text { Female to male } \\
2=\text { Male to female } \\
3=\text { Intersexed } \\
4=\text { Rather not say }\end{array}$ & \\
\hline \multirow[t]{2}{*}{31} & DEM8 & What is your sexual orientation? & $\begin{array}{l}1=\text { Heterosexual } \\
2=\text { Bisexual } \\
3=\text { Gay/Lesbian } \\
4=\text { Questioning } \\
5=\text { Rather not say }\end{array}$ & \\
\hline & DEM8.1 & Sexual Orientation (collapsed) & $\begin{array}{l}\text { 1=Heterosexual } \\
\text { 2=Bisexual, Gay/Lesbian, } \\
\text { Questioning } \\
\text { 3=Rather not say }\end{array}$ & \\
\hline
\end{tabular}




\begin{tabular}{|c|c|c|c|c|}
\hline 32 & DEM9 & $\begin{array}{l}\text { Indicate your citizenship and/ or generation } \\
\text { status: (Choose One) }\end{array}$ & $\begin{array}{l}1=\text { Your grandparents, parents, } \\
\text { and you were born in the U.S. } \\
2=\text { Both of your parents AND } \\
\text { you were born in the U.S. } \\
3=\text { You were born in the U.S., } \\
\text { but at least one of your } \\
\text { parents was not } \\
4=\text { You are a foreign born, } \\
\text { naturalized citizen } \\
5=\text { You are a foreign born, } \\
\text { resident alien/ permanent } \\
\text { resident } \\
6=\text { International student }\end{array}$ & \\
\hline \multirow[t]{4}{*}{$33 a$} & DEM10a & $\begin{array}{l}\text { Please indicate your broad racial group } \\
\text { membership: (Mark all that apply) }\end{array}$ & $\begin{array}{l}\text { 1=White/ Caucasian } \\
\text { 2=Middle Eastern } \\
\text { 3=African American/ Black } \\
\text { 4=American Indian/ Alaska } \\
\text { Native } \\
\text { 5=Asian American/ Asian } \\
6=\text { Latino/ Hispanic } \\
7=\text { Multiracial } \\
\text { 8=Race/ Ethnicity not } \\
\text { included above }\end{array}$ & DEM10 \\
\hline & $\begin{array}{l}\text { DEM10A.1 } \\
\text { DEM10A.2 } \\
\text { DEM10A.3 } \\
\text { DEM10A.4 } \\
\text { DEM10A.5 } \\
\text { DEM 10A.6 } \\
\text { DEM10A.7 } \\
\text { DEM10A.8 }\end{array}$ & $\begin{array}{c}\text { White/ Caucasian } \\
\text { Middle Eastern } \\
\text { African American/ Black } \\
\text { American Indian/ Alaska Native } \\
\text { Asian American/ Asian } \\
\text { Latino/ Hispanic } \\
\text { Multiracial } \\
\text { Race/ Ethnicity not included above }\end{array}$ & & $\begin{array}{l}\text { Note these } \\
\text { variables are } \\
\text { permutations of } \\
\text { the above } \\
\text { question that } \\
\text { allow for the } \\
\text { identification of } \\
\text { cach unique } \\
\text { racial group } \\
\text { identified above. }\end{array}$ \\
\hline & DEM10C & Racial Groups & $\begin{array}{l}\text { 1=White/ Caucasian } \\
\text { 2=Middle Eastern } \\
\text { 3=African American/ Black } \\
\text { 4=American Indian/Alaska } \\
\text { Native } \\
\text { 5=Asian American/Asian } \\
\text { 6=Latino/ Hispanic } \\
\text { 7=Multiracial } \\
\text { 8=Race/ Ethnicity not } \\
\text { included above }\end{array}$ & $\begin{array}{l}\text { Each person falls } \\
\text { into only one } \\
\text { category and } \\
\text { students that are } \\
\text { multiracial, but } \\
\text { did not select } \\
\text { that group are } \\
\text { forced into the } \\
\text { category }\end{array}$ \\
\hline & DEM10D & Racial Groups & $\begin{array}{l}\text { 1= Latino/ Hispanic } \\
2=\text { American Indian/ Alaska } \\
\text { Native } \\
3=\text { Asian American/ Asian } \\
\text { 4= African American/ Black } \\
\text { 5=Native Hawaiian or Other } \\
\text { Pacific Islander } \\
\text { 6=White } \\
7=\text { Two or More Races } \\
8=\text { Race or Ethnicity Unknown } \\
9=\text { Non-Resident Alien }\end{array}$ & $\begin{array}{l}\text { Conforms to } \\
\text { Department of } \\
\text { Education } \\
\text { requirements } \\
\text { with students } \\
\text { that are } \\
\text { multiracial, but } \\
\text { did not select } \\
\text { that group are } \\
\text { forced into the } \\
\text { category. Note } \\
\text { that Middle } \\
\text { Eastern students } \\
\text { are placed in the } \\
\text { Caucasian group. }\end{array}$ \\
\hline $33 \mathrm{~b}$ & DEM10b & $\begin{array}{l}\text { Please indicate your ethnic group } \\
\text { memberships (Mark all that apply). }\end{array}$ & $\begin{array}{c}\text { African American/ Black } \\
\text { 1=Black American } \\
\text { 2=African } \\
3=\text { West Indian } \\
\text { 4=Brazilian }\end{array}$ & $\begin{array}{l}\text { Note that: } \\
\text { 1) This question } \\
\text { only pertains to }\end{array}$ \\
\hline
\end{tabular}




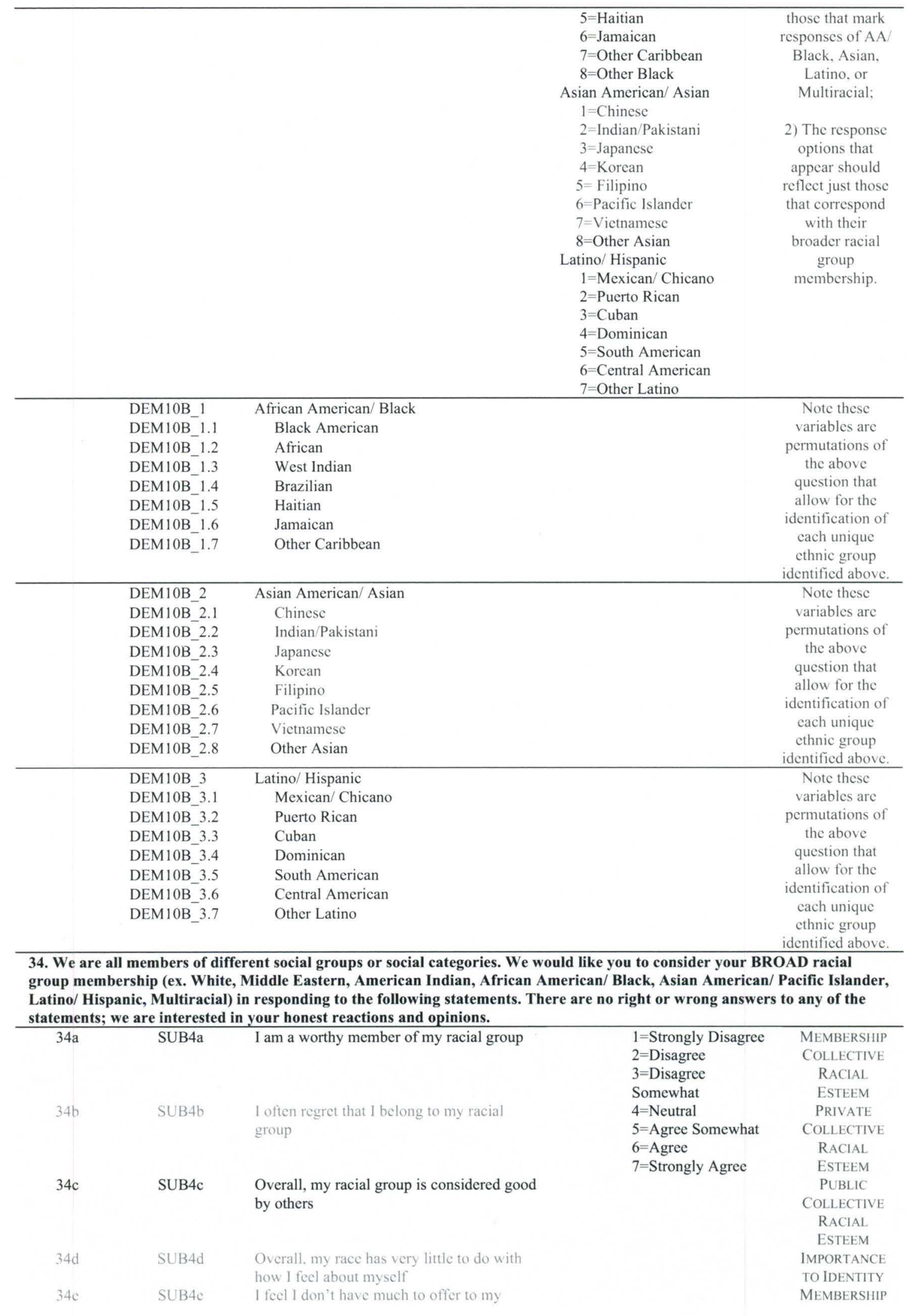


In general, I'm glad to be a member of my racial group

PRIVATE

COllective

RACIAL

ESTEEM

PUBLIC

$34 \mathrm{~g}$ SUB4g $\quad \begin{aligned} & \text { Most people consider my racial group, on } \\ & \text { the average, to be more ineffective than }\end{aligned}$

other groups

The racial group I belong to is an important reflection of who I am

I am a cooperative participant in the activities of my racial group

$34 \mathrm{j} S U B 4 \mathrm{j} \quad \begin{aligned} & \text { Overall, } 1 \text { often feel that my racial group is } \\ & \text { not worthwhile }\end{aligned}$

In general, others respect my race

\begin{tabular}{|c|c|c|}
\hline 341 & SUB4I & $\begin{array}{l}\text { My race is unimportant to my sense of } \\
\text { what kind of a person } 1 \text { am }\end{array}$ \\
\hline $4 \mathrm{~m}$ & SUB $4 m$ & $\begin{array}{l}\text { I often feel I am a useless member of my } \\
\text { racial group }\end{array}$ \\
\hline
\end{tabular}

MEMBERSHIP

COLLECTIVE

RACIAL

ESTEEM

PRIVATE

COLLeCTIVE

RACIAL

ESTEEM

PUBLIC

COLleCtIVE

RACIAL

ESTEEM

IMPORTANCE

TO IDENTITY

MEMBERSHIP

COLLECTIVE

RACIAL

ESTEEM

PRIVATE

Collective

RACIAL

ESTEEM

PUBLIC

340 SUB4o In general, others think that my racial

group is unworthy

COLleCtIVH

RACIAL

ESTEEM

IMPORTANCE

\begin{tabular}{|c|c|c|c|c|}
\hline $34 p$ & SUB4p & $\begin{array}{l}\text { In general, belonging to my racial group is } \\
\text { an important part of my self image }\end{array}$ & & $\begin{array}{l}\text { IMPORTANCE } \\
\text { TO IDENTITY }\end{array}$ \\
\hline $35 \mathrm{a}$ & DEM11a & $\begin{array}{l}\text { Do you have any of the following } \\
\text { conditions: } \\
\text { a. Blindness, deafness, or a severe } \\
\text { vision or hearing impairment; } \\
\text { b. A psychological, mental, or } \\
\text { emotional condition lasting } 6 \\
\text { months or more; } \\
\text { c. A condition that substantially } \\
\text { limits one or more basic physical } \\
\text { activities such as walking, } \\
\text { climbing stairs, reaching, lifting, } \\
\text { or carrying; } \\
\text { d. A condition that affects your } \\
\text { learning or concentration; or } \\
\text { e. A permanent medical condition } \\
\text { such as diabetes, severe asthma, } \\
\text { etc.? }\end{array}$ & $\begin{array}{l}1=\mathrm{Yes} \\
2=\mathrm{No}\end{array}$ & $\begin{array}{l}\text { If NO, skip to } \\
\text { question } \# 36\end{array}$ \\
\hline $35 b$ & DEM11b & Please indicate the conditions you have: & $\begin{array}{l}\text { 1=Deaf/Hard of Hearing } \\
2=\text { Blind/Visual Impairment } \\
\text { 3=Speech/Language Condition } \\
\text { 4=Learning Disability } \\
\text { 5=Physical or Musculoskeletal } \\
\text { (ex. multiple sclerosis) } \\
\text { 6=Attention Deficit Disorder/ } \\
\text { Attention Deficit Hyperactivity } \\
\text { Disorder } \\
\text { 7=Psychiatric/Psychological } \\
\text { Condition (ex. anxiety disorder, } \\
\text { major depression) }\end{array}$ & \\
\hline
\end{tabular}




\begin{tabular}{|c|c|c|c|}
\hline & & & $\begin{array}{l}8=\text { Neurological Condition (ex. } \\
\text { brain injury, stroke) } \\
9=\text { Medical (ex. diabetes, severe } \\
\text { asthma) } \\
10=\text { Other }\end{array}$ \\
\hline 36 & DEM12 & $\begin{array}{l}\text { What is your current religious preference? } \\
\text { (Please Select One) }\end{array}$ & $\begin{array}{l}1=\text { Agnostic } \\
2=\text { Atheist } \\
3=\text { Baptist } \\
4=\text { Buddhist } \\
5=\text { Catholic } \\
6=\text { Church of Christ } \\
7=\text { Eastern Orthodox } \\
8=\text { Episcopalian } \\
9=\text { Hindu } \\
10=\text { Islamic } \\
11=\text { Jewish } \\
12=\text { LDS (Mormon) } \\
13=\text { Lutheran } \\
14=\text { Methodist } \\
15=\text { Presbyterian } \\
16=\text { Quaker } \\
17=\text { Seventh Day Adventist } \\
18=\text { Unitarian/Universalist } \\
19=\text { UCC/Congregational } \\
20=\text { Other Christian } \\
21=\text { Other Religion } \\
22=\text { None }\end{array}$ \\
\hline 37 & DEM13 & $\begin{array}{l}\text { What is your best estimate of your grades } \\
\text { so far in college? [Assume } 4.00=\mathrm{A} \text { ] } \\
\text { (Choose One) }\end{array}$ & $\begin{array}{l}1=3.50-4.00 \\
2=3.00-3.49 \\
3=2.50-2.99 \\
4=2.00-2.49 \\
5=1.99 \text { or less } \\
6=\text { No college GPA }\end{array}$ \\
\hline \multirow[t]{2}{*}{38} & DEM14 & $\begin{array}{l}\text { What is the HIGHEST level of formal } \\
\text { education obtained by any of your parent(s) } \\
\text { or guardian(s)? (Choose one) }\end{array}$ & $\begin{array}{l}\text { 1=Less than high school } \\
\text { diploma or less than a GED } \\
2=\text { High school diploma or a } \\
\text { GED } \\
3=\text { Some college } \\
\text { 4=Associates degree } \\
5=\text { Bachelors degree } \\
6=\text { Masters degree } \\
7=\text { Doctorate or professional } \\
\text { degree (ex. JD, MD, PhD) } \\
8=\text { Don't know }\end{array}$ \\
\hline & DEM14.1 & First Generation College Student & $\begin{array}{l}1=\text { First Generation } \\
2=\text { Non-First Generation }\end{array}$ \\
\hline 39 & DEM15 & $\begin{array}{l}\text { What is your best estimate of your parent(s) } \\
\text { or guardian(s) combined total income from } \\
\text { last year? If you are independent from } \\
\text { your parent(s) or guardian(s), indicate your } \\
\text { income. (Choose one) }\end{array}$ & $\begin{array}{l}1=\text { Less than } \$ 12,500 \\
2=\$ 12,500-\$ 24,999 \\
3=\$ 25,000-\$ 39,999 \\
4=\$ 40,000-\$ 54,999 \\
5=\$ 55,000-\$ 74,999 \\
6=\$ 75,000-\$ 99,999 \\
7=\$ 100,000-\$ 149,999 \\
8=\$ 150,000-\$ 199,999 \\
9=\$ 200,000 \text { and over } \\
10=\text { Don't know } \\
11=\text { Rather not say }\end{array}$ \\
\hline \multirow[t]{2}{*}{40} & ENV12 & $\begin{array}{l}\text { Which of the following best describes } \\
\text { where are you currently living while } \\
\text { attending college? (Choose one) }\end{array}$ & $\begin{array}{l}1=\text { Parent/guardian or other } \\
\text { relative home } \\
2=\text { Other off-campus home, } \\
\text { apartment, or room } \\
3=\text { College/university residence } \\
\text { hall } \\
4=\text { Fraternity or sorority house } \\
5=\text { Other on-campus student } \\
\text { housing } \\
6=\text { Other }\end{array}$ \\
\hline & ENV12.1 & On-campus vs. Off-campus Housing & $\begin{array}{l}1=\text { On-campus } \\
2=\text { Off-campus }\end{array}$ \\
\hline
\end{tabular}




\begin{tabular}{|c|c|c|c|c|}
\hline 41 & DEF & $\begin{array}{l}\text { Please provide a brief definition of what the } \\
\text { term leadership means to you. }\end{array}$ & Open response & Comment box \\
\hline & PRECOG & Cognitive Skills Pretest & $\begin{array}{c}1=\text { Not at all } \\
\text { confident } \\
2=\text { Somewhat } \\
\text { confident } \\
3=\text { Confident } \\
4=\text { Very Confident }\end{array}$ & \\
\hline & PREEFF & Leadership Efficacy Pretest & $\begin{array}{c}1=\text { Not at all } \\
\text { confident } \\
2=\text { Somewhat } \\
\text { confident } \\
3=\text { Confident } \\
4=\text { Very Confident }\end{array}$ & \\
\hline & PRESPIR & Spirituality Pretest & $\begin{aligned} & 1=\text { Never } \\
& 2=\text { Sometimes } \\
& 3=\text { Often } \\
& 4=\text { Very Often }\end{aligned}$ & \\
\hline & PRESPT & Social Perspective Taking Pretest & $\begin{array}{l}1=\text { Does Not Describe Me Well } \\
2 \\
3 \\
4 \\
5=\text { Describes Me Very Well }\end{array}$ & \\
\hline & PREOMNI & Omnibus SRLS Pretest & $\begin{aligned} 1 & =\text { Strongly Disagree } \\
2 & =\text { Disagree } \\
3 & =\text { Neutral } \\
4 & =\text { Agree } \\
5= & \text { Strongly Agree }\end{aligned}$ & \\
\hline & PRECRE & Collective Racial Efficacy Pretest & $\begin{aligned} & 1=\text { Strongly Disagree } \\
& 2=\text { Disagree } \\
& 3=\text { Disagree } \\
& \text { Somewhat } \\
& 4=\text { Neutral } \\
& 5=\text { Agree Somewhat } \\
& 6=\text { Agree } \\
& 7=\text { Strongly Agree }\end{aligned}$ & \\
\hline & OUTSCB & Social Change Behaviors Scale & $\begin{aligned} 1= & \text { Never } \\
2 & =\text { Once } \\
3 & =\text { Sometimes } \\
4= & \text { Often }\end{aligned}$ & \\
\hline & MENOUTLE & $\begin{array}{l}\text { Mentoring Outcomes: Leadership } \\
\text { Empowerment Scale }\end{array}$ & \multirow[t]{2}{*}{$1=$ Strongly Disagree } & \\
\hline & MENOUTPD & $\begin{array}{l}\text { Mentoring Outcomes: Personal } \\
\text { Development Scale }\end{array}$ & & \\
\hline & SOCCUL & Socio-Cultural Discussions Scale & $\begin{aligned} & 1=\text { Never } \\
& 2=\text { Sometimes } \\
& 3=\text { Often } \\
& 4=\text { Very Often }\end{aligned}$ & \\
\hline & SELF & Consciousness of Self Scale & \multirow{9}{*}{$\begin{array}{l}1=\text { Strongly Disagr } \\
2=\text { Disagree } \\
3=\text { Neutral } \\
4=\text { Agree } \\
5=\text { Strongly Agree }\end{array}$} & \\
\hline & CONGRU & Congruence Scale & & \\
\hline & COMMIT & Commitment Scale & & \\
\hline & COLLAB & Collaboration Scale & & \\
\hline & COMMON & Common Purpose Scale & & \\
\hline & CIVIL & Controversy with Civility Scale & & \\
\hline & CITZEN & Citizenship Scale & & \\
\hline & CHANGE & Change Scale & & \\
\hline & OMNIBUS & Omnibus SRLS & & \\
\hline & OUTCOG & Cognitive Skills Scale & $\begin{array}{l}1=\text { Not Grown At All } \\
2=\text { Grown Somewhat } \\
3=\text { Grown } \\
4=\text { Grown Very Much }\end{array}$ & \\
\hline & OUTEFF & Leadership Efficacy Scale & $\begin{array}{l}\text { 1=Not at All } \\
\text { Confident } \\
2=\text { Somewhat } \\
\text { Confident } \\
3=\text { Confident } \\
4=\text { Very Confident }\end{array}$ & \\
\hline & OUTSPIR & Spirituality: Search for Meaning Scale & $1=$ Never & \\
\hline
\end{tabular}


$2=$ Sometimes

$3=$ Often

4=Very Often

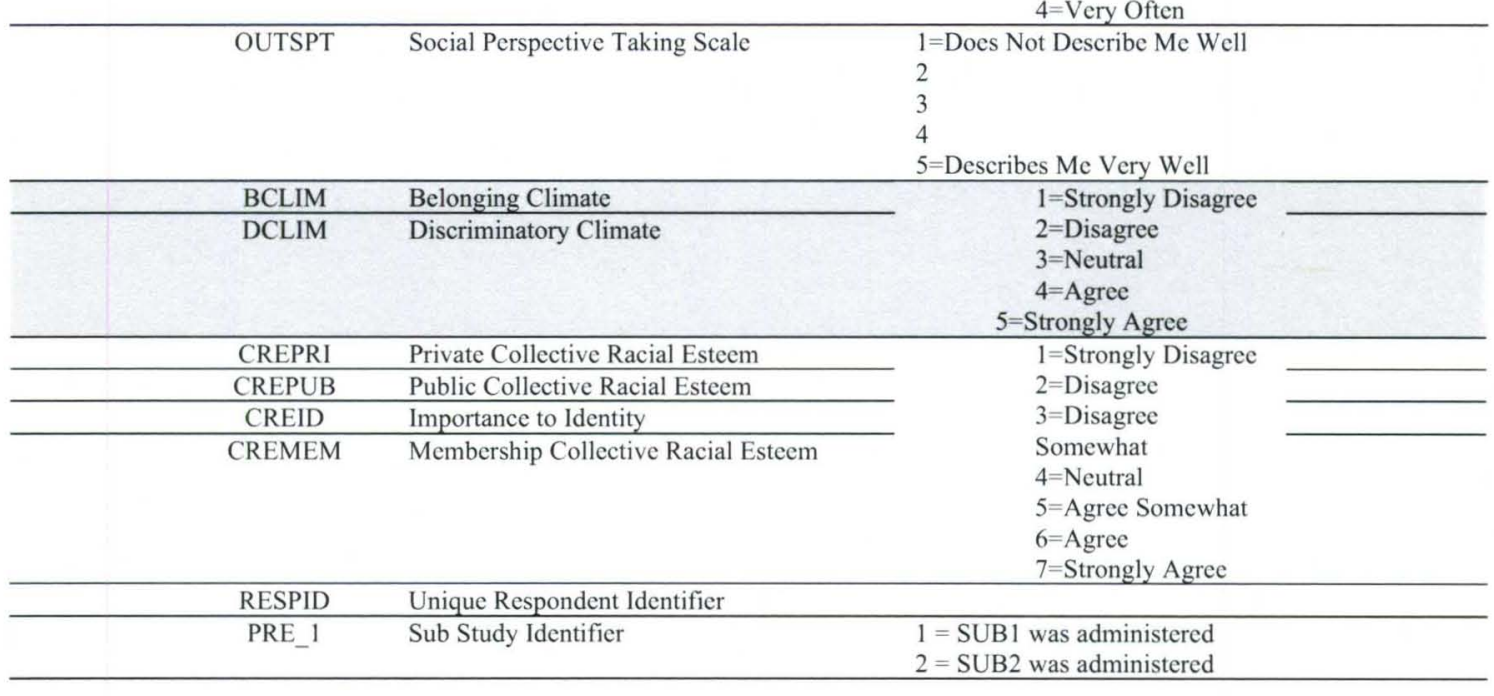




\begin{tabular}{|c|c|c|c|}
\hline PRE_4 & Sample Type & $\begin{array}{l}1=\text { Random } \\
\text { Sample } \\
2= \\
\text { Comparative } \\
\text { Sample } \\
3=\text { In both } \\
\text { samples }\end{array}$ & \\
\hline PRE_5 & Class (From Sample) & $\begin{array}{l}1=\text { First }- \\
\text { Year } \\
2= \\
\text { Sophomore } \\
3=\text { Junior } \\
4=\text { Senior } \\
5=\text { Other } \\
9=\text { Missing }\end{array}$ & $\begin{array}{c}\text { This } \\
\text { variable } \\
\text { reflects } \\
\text { data } \\
\text { provided } \\
\text { along with } \\
\text { student } \\
\text { contact } \\
\text { information } \\
\text { and was } \\
\text { not } \\
\text { reported by } \\
\text { the actual } \\
\text { students } \\
\end{array}$ \\
\hline GENDER & Gender(From Sample) & $\begin{array}{l}1=\text { Male } \\
2=\text { Female }\end{array}$ & $\begin{array}{c}\text { This } \\
\text { variable } \\
\text { reflects } \\
\text { data } \\
\text { provided } \\
\text { along with } \\
\text { student } \\
\text { contact } \\
\text { information } \\
\text { and was } \\
\text { not } \\
\text { reported by } \\
\text { the actual } \\
\text { students }\end{array}$ \\
\hline HISPANIC & $\begin{array}{l}\text { Hispanic(From } \\
\text { Sample) }\end{array}$ & $\begin{array}{l}0= \\
\text { Respondent } \\
\text { is not race } \\
1= \\
\text { Respondent } \\
\text { is race } \\
9=\text { Missing }\end{array}$ & $\begin{array}{c}\text { This } \\
\text { variable } \\
\text { reflects } \\
\text { data } \\
\text { provided } \\
\text { along with } \\
\text { student } \\
\text { contact } \\
\text { information } \\
\text { and was } \\
\end{array}$ \\
\hline
\end{tabular}




\begin{tabular}{|c|c|c|c|}
\hline & & & $\begin{array}{c}\text { not } \\
\text { reported by } \\
\text { the actual } \\
\text { students }\end{array}$ \\
\hline INDIAN & $\begin{array}{l}\text { American Indian(From } \\
\text { Sample) }\end{array}$ & $\begin{array}{l}0= \\
\text { Respondent } \\
\text { is not race } \\
1= \\
\text { Respondent } \\
\text { is race } \\
9=\text { Missing }\end{array}$ & $\begin{array}{c}\text { This } \\
\text { variable } \\
\text { reflects } \\
\text { data } \\
\text { provided } \\
\text { along with } \\
\text { student } \\
\text { contact } \\
\text { information } \\
\text { and was } \\
\text { not } \\
\text { reported by } \\
\text { the actual } \\
\text { students }\end{array}$ \\
\hline ASIAN & $\begin{array}{l}\text { Asian American(From } \\
\text { Sample) }\end{array}$ & $\begin{array}{l}0= \\
\text { Respondent } \\
\text { is not race } \\
1= \\
\text { Respondent } \\
\text { is race } \\
9=\text { Missing }\end{array}$ & $\begin{array}{c}\text { This } \\
\text { variable } \\
\text { reflects } \\
\text { data } \\
\text { provided } \\
\text { along with } \\
\text { student } \\
\text { contact } \\
\text { information } \\
\text { and was } \\
\text { not } \\
\text { reported by } \\
\text { the actual } \\
\text { students }\end{array}$ \\
\hline BLACK & $\begin{array}{l}\text { African } \\
\text { American/Black(From } \\
\text { Sample) }\end{array}$ & $\begin{array}{l}0= \\
\text { Respondent } \\
\text { is not race } \\
1= \\
\text { Respondent } \\
\text { is race } \\
9=\text { Missing }\end{array}$ & $\begin{array}{c}\text { This } \\
\text { variable } \\
\text { reflects } \\
\text { data } \\
\text { provided } \\
\text { along with } \\
\text { student } \\
\text { contact } \\
\text { information } \\
\text { and was } \\
\text { not } \\
\text { reported by } \\
\text { the actual } \\
\text { students } \\
\end{array}$ \\
\hline
\end{tabular}




\begin{tabular}{|c|c|c|c|}
\hline PACIFIC & $\begin{array}{l}\text { Hawaiian/ Pacific } \\
\text { Islander(From Sample) }\end{array}$ & $\begin{array}{l}0= \\
\text { Respondent } \\
\text { is not race } \\
1= \\
\text { Respondent } \\
\text { is race } \\
9=\text { Missing }\end{array}$ & $\begin{array}{c}\text { This } \\
\text { variable } \\
\text { reflects } \\
\text { data } \\
\text { provided } \\
\text { along with } \\
\text { student } \\
\text { contact } \\
\text { information } \\
\text { and was } \\
\text { not } \\
\text { reported by } \\
\text { the actual } \\
\text { students }\end{array}$ \\
\hline WHITE & $\begin{array}{l}\text { Caucasian/White(From } \\
\text { Sample) }\end{array}$ & $\begin{array}{l}0= \\
\text { Respondent } \\
\text { is not race } \\
1= \\
\text { Respondent } \\
\text { is race } \\
9=\text { Missing }\end{array}$ & $\begin{array}{c}\text { This } \\
\text { variable } \\
\text { reflects } \\
\text { data } \\
\text { provided } \\
\text { along with } \\
\text { student } \\
\text { contact } \\
\text { information } \\
\text { and was } \\
\text { not } \\
\text { reported by } \\
\text { the actual } \\
\text { students } \\
\end{array}$ \\
\hline DISP_MAIN & Respondent Disposition & $\begin{array}{l}1= \\
\text { Complete } \\
2=\text { Partial }\end{array}$ & \\
\hline STARTTIME & $\begin{array}{l}\text { STARTTIME: The date } \\
\text { and time this } \\
\text { participant/user began } \\
\text { entering data. }\end{array}$ & & \\
\hline ENDTIME & $\begin{array}{l}\text { ENDTIME: The date } \\
\text { and time this } \\
\text { participant/user } \\
\text { finished entering data. }\end{array}$ & & \\
\hline ELAPSEDTIME & $\begin{array}{l}\text { ELAPSEDTIME: The } \\
\text { total number of minutes } \\
\text { it took this } \\
\text { participant/user to } \\
\text { finish entering data. }\end{array}$ & & \\
\hline PCTCOMPLETE & $\begin{array}{l}\text { PCTCOMPLETE: The } \\
\text { percent of the survey }\end{array}$ & & \\
\hline
\end{tabular}




\begin{tabular}{|c|c|c|}
\hline & completed. & \\
\hline LOGINTIME & $\begin{array}{l}\text { LOGINTIME: The date } \\
\text { and time when this } \\
\text { participant last logged } \\
\text { in. }\end{array}$ & \\
\hline NUMPRESENTED & $\begin{array}{l}\text { NUMPRESENTED: } \\
\text { Number of questions } \\
\text { presented to the } \\
\text { participant. }\end{array}$ & \\
\hline NUMANSWERED & $\begin{array}{l}\text { NUMANSWERED: } \\
\text { Number of questions } \\
\text { answered by this } \\
\text { participant. }\end{array}$ & \\
\hline NUMUNANSWERED & $\begin{array}{l}\text { NUMUNANSWERED: } \\
\text { Number of questions } \\
\text { unanswered by this } \\
\text { participant. }\end{array}$ & \\
\hline PCTUNANSWERED & $\begin{array}{l}\text { PCTUNANSWERED: } \\
\text { Percentage of questions } \\
\text { unanswered by this } \\
\text { participant. }\end{array}$ & \\
\hline INCOMP & $\begin{array}{l}\text { INCOMP: Last } \\
\text { answered question }\end{array}$ & \\
\hline SRLS_90 & $\begin{array}{l}\text { Did respondent answer } \\
90 \% \text { of the SRLS } \\
\text { items? }\end{array}$ & $\begin{array}{l}1= \\
\text { Yes } \\
0= \\
\text { No }\end{array}$ \\
\hline CORE_90 & $\begin{array}{l}\text { Did respondent answer } \\
90 \% \text { of the CORE } \\
\text { Outcome measures? } \\
\text { (Only 'Yes' } \\
\text { respondents used in } \\
\text { reporting) }\end{array}$ & $\begin{array}{l}1= \\
\text { Yes } \\
0= \\
\text { No }\end{array}$ \\
\hline
\end{tabular}


CURRICULUM VITAE

\section{Personal data}

Michael D. Anthony, Ph.D.

Home: 3030 Plantation Dr.

Sellersburg, IN 47172

Phone: (812) 748-5004

Work: Cultural Center

120. E. Brandeis Ave.

University of Louisville

Louisville, KY 40292

Phone: (502) 852-0229

Email: michael.anthony@louisville.edu

\section{Summary of Qualifications}

- Highly inclusive, motivational, and results-driven management and supervision style

- Detail-oriented professional with a talent for arranging and maximizing resources, and a passion for student development and engagement

- Proven ability to lead, counsel, and communicate in various roles including supervisor, liaison, facilitator, advocate and mentor to a variety of constituents

\section{EDUCATION}

Doctor of Philosophy - Educational Leadership and Organizational

Development

University of Louisville, Louisville, KY

Master of Arts in Higher Education

University of Louisville, Louisville, KY

Bachelor of Science in Business Management, concentration in Marketing North Carolina State University, Raleigh, NC

\section{WORK EXPERIENCE}

\section{Interim Director - Cultural Center \\ August 2008 - present}

University of Louisville

- Create a welcoming, supportive, and nurturing environment for underrepresented students by understanding and articulating issues of 
- multiculturalism, cross-cultural interactions, racism, sexism, heterosexism, homophobia, classism, ageism, religious and/or military oppression, etc.

- Develop, promote and collaborate with other departments to present a variety of cross-cultural programs that assist with the recruitment, retention and cultural enrichment of African American students, faculty, staff and other under-represented groups as well as programs and services that educate the campus community

- Provide administrative oversight of academic and cultural programs including the Black Diamond Choir, Society of Porter Scholars, the National Black Family Conference, cultural history months, culturally-focused graduation celebrations and the diversity training and education of campus constituents

- Serve as primary advisor to the Association of Black Students, the American International Relations Club, and the Student African American Brotherhood (SAAB)

- Manage and supervise Center's staff and administer budget of over $\$ 500,000$, along with providing oversight of multicultural student organizations' budgets, ensuring that university policies and procedures are being followed

- Provide student and leadership development, conflict resolution and organizational development for multicultural students and student organizations

- Undergird student retention by referring students to university services (i.c. Financial Aid, Academic Support, Peer Mentoring, Student Health and Counseling Center)

- Engage in fundraising and grant writing opportunities to expand programs and funding for the Center

\section{Coordinator - Office of Civic Engagement, Leadership and Service} University of Louisville May 2007 - July 2008

- Oversee the Student Leadership and Service Learning programs, including selection, training, development and supervision of staff, budget oversight, program implementation and assessment

- Develop programs and activities working in collaboration with various academic units and student organizations to enhance the campus community and student engagement

- Serve as an active member of the Dean of Students leadership team and assist with Student Affairs and campus-wide programs and initiatives

- Assist student groups by providing services that support their academic success and retention

- Participate in Student Orientation and Welcome Week activities

- Serve as advisor for the Student Government Association with the Dean of Students

- Prepare reports and participate in assessment activities as requested by the Dean of Students and Vice President for Student Affairs

\section{Lead Facilitator - The LeaderShape ${ }^{\circledR}$ Institute Champaign-Urbana, IL \\ May 2006 - present}

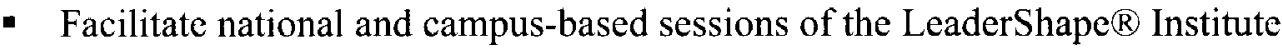


- Train cluster facilitator and on-site coordinators at national and campus-based sessions

- Mentor incoming Lead Facilitators before, during, and after annual training

- Advise the President on curriculum and logistical matters of the institute

\section{National Speaker - American Student Government Association \\ Gainesville, FL \\ October 2006 - present}

- Design and implement leadership development workshops for Student Government leaders at regional and national conferences

- Facilitate roundtable discussions amongst student government leaders

- Advise the Executive Director on conference content, location, and logistics

Coordinator for Student Leadership Programs

University of Louisville

May 2005 - April 2007

- Develop and articulate vision and mission of the Office of Student Leadership Development

- Manage the programs, resources, and services of the Office of Student Leadership Development

- Assist the Vice President for Student Affairs with special projects and division initiatives

- Promote achievement of Student Affairs and Department of Campus Life strategic goals

- Advise the Student Government Association

- Advise the Student African American Brotherhood

- Coordinate the U of L Leadership Conference

- Collaborate with various departments/units to create, promote, and coordinate leadership opportunities for students

- Coordinate and accompany students to local, regional, and/or national conferences

- Develop and manage the leadership resource area and facilitate the development of a co-curricular transcript

- Advise the Freshmen L.E.A.D. program

- Supervise graduate and undergraduate staff

Resident Director, Office of Housing \& Residence Life August 2003 - April 2005 University of Louisville

- Assisted with RD and RA selection, training, and evaluation

- Responded to crisis and conflict situations within the residence hall

- Enforced H\&RL policies and procedures

- Adjudicated disciplinary hearings and sanctioned students accordingly

- Advocated for and oversaw several major rehabilitation projects for the residence hall

- Supervised staff of 5 Resident Assistants and 10-15 Desk Assistants

- Advised and counseled the hall council

- Maintained budget of Community Development funds

- Facilitated program-planning process effectively each semester with RA staff

- Conducted performance appraisals of RAs at least once per semester. 
- Secured RA staff files and kept progress reports updated

- Maintained integrity of building key system

\section{Conference Director, Office of Housing \& Residence Life}

\section{University of Louisville}

May 2004 - August 2004

- Maintained key and building security throughout the summer

- Interviewed and trained conference staff

- Supervised staff of 2 Conference Assistants and 6 Desk Assistants

- Conducted group leader meetings with conference guests

- Enforced conference policies and procedures while guests were on-site

- Scheduled building coverage and on-call schedule for multiple halls

- Facilitated team building and motivation activities

- Completed billing summaries and inventory checks once groups left campus

- Responded to crisis and emergency situations across campus

\section{TEACHING EXPERIENCE}

Instructor, ECPY 355 - Campus Developmental Leadership 2005 - present University of Louisville - Louisville, $K Y$

Guest Lecturer, ECPY 661 - Introduction to College Student Personnel University of Louisville - Louisville, $K Y \quad 2010$

Guest Lecturer, ELFH 682 - Organization and Administration of Higher

Education

$$
\text { University of Louisville - Louisville, } K Y
$$

Guest Lecturer, ELFH 682 - Organization and Administration of Higher Education

University of Louisville - Louisville, $K Y$

2008

Instructor, HON 341 - Learning to Lead, Leading Through Service University of Louisville - Louisville, $K Y$

Spring 2007

Adjunct Faculty, GE 101 - Strategies for Academic Success Jefferson Community and Technical College - Louisville, KY Fall 2006

\section{UNIVERSITY APPOINTMENTS}

Intramural Advisory Board

Leadership Development Planning Team, Chair

Orientation Advisory Committee

Welcome Weekend Committee (Chair, 2006)

Honors Council

International Service Learning Program Task Force

Carnegie Community Engagement Work Group

QEP / Student Affairs Collaborative Learning Community 2007 - 2008

Professional Development Committee

Substance Abuse Prevention Coalition

Student Affairs Think Tank

Ideas to Action Quality Enhancement Plan Task Group

Parking Advisory Committee

Bias Incident Response Team

President's Community Service Honor Roll

$$
\begin{aligned}
& 2004-\text { present } \\
& 2005-2006 \\
& 2005-2007 \\
& 2005-\text { present } \\
& 2006-\text { present } \\
& 2007-2009 \\
& 2007-2008 \\
& 2007-2008 \\
& 2007-2008 \\
& 2007-2008 \\
& 2007-\text { present } \\
& 2008-\text { present } \\
& 2007-2008 \\
& 2009-\text { present } \\
& 2009-\text { present }
\end{aligned}
$$


Commission on Diversity and Racial Equality

2008 - present

Black Faculty and Staff Association

2010 - present

\section{RELATED EXPERIENCE}

Founder \& Owner - Anthony Creative Solutions, LLC December 2008 - present Leadership and diversity education and consulting company serving education, non-profit and corporate organizations.

External CAS Reviewer - Bellarmine University June 2010

Offices of Multicultural Affairs, Women Center Programs, Service Learning, and LGBT Services

External Reviewer - East Carolina University $\quad$ February 2009

Office of Intercultural Student Affairs and Center for Student Leadership \& Civic Engagement

International Service Learning Program

August 2004 - April 2005

- Conducted service learning projects in Belize, Central America in 2004 and 2005

- Instructed the EDAP 596 International Leadership course

- Recruited and processed program participants

- Served as liaison between the program administration, participating faculty, the Board of Directors, and the Vice President for Student Affairs

- Established the first ISLP Alumni Association

- Created constitution and by-laws to govern the alumni association

- Conducted a Phonathon to raise funds for the program's endowment

- Managed pre-departure seminars weekly during the spring semester

Office of the Vice President for Student Affairs

January 2004 - May 2004

- Presented at parent orientation sessions during new student orientation

- Attended planning meetings with Orientation officials to discuss Parents Orientation

- Worked with Orientation intern to create and distribute Parents Orientation booklet and resources

- Revised policies and procedures in Parents Helpline binder

- Responded to phone calls and emails received by the Parents Helpline

- Met with Housing and Residence Life officials in order to plan a NSSE survey disbursement and to develop a marketing plan

- Attended various staff meetings and functions of the Student Affairs Division and office staff 


\section{LEADERSHIP}

ACPA Presidential Intern for the President of ACPA 2008-2010

Assistant to the Director, NASPA Kentucky $\quad 2008-2010$

Past-President, College Personnel Association of Kentucky $2008-2009$

President, College Personnel Association of Kentucky $\quad 2007-2008$

Vice Chair for Research, ACPA Commission on Student Involvement $2007-2008$

President-elect, College Personnel Association of Kentucky2006 - 2007

Membership Coordinator, College Personnel Association of Kentucky $2005-2006$

Gen. Hugh Shelton Leadership Center Board of Advisors 2002 - present North Carolina State University

Alpha Phi Alpha Fraternity, Inc. 1999 - present Louisville, $K Y$

Coach, Mentor, Trainer - General Hugh Shelton Leadership Challenge

Raleigh, NC

Summer 2005

Cluster Facilitator, The LeaderShape $\mathbb{B}$ Institute 2004

North Carolina State University

Graduate Student Coordinator, College Personnel Association of Kentucky $2004-2005$

Chair, South Atlantic Affiliate of College and University Residence Halls Conference $2004-2005$

University of Louisville

\section{SELECTED PRESENTATIONS}

Anthony, M.D. (October 2010). A Legacy of Leadership \& Service: The Fundamental Tradition. KY Private and Independent Colleges SGA Conference Bellarmine University, Louisville, KY.

Anthony, M.D. \& Curtis, P. N. (February 2010). How Students Become Better Critical Thinkers Through Out-Of-Classroom Engagement. Celebration of Teaching and Learning - University of Louisville, Louisville, KY. 
Anthony, M.D. \& LaRue, S. (May 2009). Infusing Critical Thinking into Campus Programs to Build Community. Ideas 2 Action Institute - University of Louisville, Louisville, KY.

Anthony, M.D. \& Johnson, J.L. (March 2009). Responding to Incidents of Bias on Campus. American College Personnel Association National Convention, Washington, DC.

Atkins, J., Anthony, M.D. \& Bergman, M.J. (November 2008). Going Back to School: Implications for Adult Learners. Southern Association of College Student Affairs Regional Conference, Hilton Head, SC.

Anthony, M.D. \& Curtis, P.N. (March 2008). Making Connections: Professional Development in Student Affairs. College Personnel Association of Kentucky State Conference, Louisville, KY.

Anthony, M.D. Recognized Student Organization Trainings (2007). University of Louisville, Louisville, KY.

Anthony, M.D., Woods, E., \& Curtis, P.N. (December 2006). ECPY 355 Campus Developmental Leadership. Leadership Educators Institute, Tempe, AZ.

Anthony, M.D. (September 2006). Leadership within SGA. University of Kentucky SGA Retreat, Southern Seminary, Louisville, KY.

Anthony, M.D. (August 2006). All eyes on me. African Christian Fellowship Midwestern Convention, Southern Seminary, Louisville, KY.

Anthony, M.D. (December 2005). There is always a choice... and the choice is yours. GEAR UP! Kentucky campus visit program, Louisville, KY.

Anthony, M.D. (October 2005). Building community in the residence halls CARDSS as a model. Leadership U, University of Louisville, Louisville, KY.

Anthony, M.D. \& Todd, Jr., D.D. (September 2005). Five steps in effective leadership. Bellarmine Student Leadership Conference, Bellarmine University, Louisville, KY.

Anthony, M.D. (August 2005). The relational leadership model. University of Louisville Marching Band, Louisville, KY.

Anthony, M.D. (August 2005). It's all Greek to me! Greek Leadership Retreat, Murray State University, Murray, KY.

Anthony, M.D. (May 2005). Making the connection. Kentucky Leadership Academy, Corbin, KY. 
Anthony, M.D. \& Cuyjet, M.J. (March 2004). So you want to advise the SGA president... What were you thinking!?!? College Personnel Association of Kentucky, State Conference, Lexington, KY.

Anthony, M.D. (February 2003). Raise up and get it done: How to effectively communicate with administrators. LEAD Conference, North Carolina State University, Raleigh, NC.

\section{CASE STUDIES \& GRANTS}

- Anthony, M.D. \& Hirschy, A.S. (2005, March). The Bourbon Street Blues. Case study created for College Personnel Association of Kentucky. Lou., KY.

- Success, Engagement and Satisfaction (SES) Grant, \$20,000 to fund a new collaboration between the University of Louisville and the Leadership Louisville Center.

\section{SPECIALIZED TRAINING}

- National Coalition Building Institute Leadership Training - August 2010

- ACPA e-Learning Course: "Assessment as a Primer" - October 2005

- The Blueprint Workshop: Building a Leadership Program - November 2005

- California Coalition Against Sexual Assault Training Institute - October 2005

\section{PROFESSIONAL\& COMMUNITY INVOLVEMENT}

- Alpha Lambda Chapter of Alpha Phi Alpha Fraternity, Inc.

- American Association of Colleges \& Universities (AACU)

- American College Personnel Association, College Student Educators International (ACPA)

- Big Brothers/Big Sisters of Kentucky

- Celebration of Teaching and Learning, University of Louisville

- College Personnel Association of Kentucky (CPAK)

- Community Empowerment Center Fatherhood Initiative Board of Advisors

- International Leadership Association (ILA)

- Leadership Louisville Center

- National Association of Student Personnel Administrators (NASPA)

- National Clearinghouse for Leadership Programs (NCLP)

- New Professionals Institute (NPI)

- Regional Entry Level Institute

- Southern Association of College Student Affairs (SACSA) 


\section{HONORS \& AWARDS}

- Golden Key International Honor Society - October 2006

- National Society of Collegiate Scholars, Distinguished Member - September 2006

- SEAHO Graduate Student of the Year Nomination - February 2005

- Kentucky Association of Housing Officers Graduate Student of the Year October 2004

- Kentucky Association of Housing Officers SEAHO Scholarship - October 2004

- Kentucky Graduate Institute, Graduate - October 2003

- Outstanding Graduate, School of Education - May 2005

- The LeaderShape ${ }^{\circledR}$ Institute, Graduate - Summer 2002

- National Residence Hall Honorary

- SEAHO PPP certificate

- Sigma Alpha Lambda National Leadership and Honor Organization

\section{TECHNOLOGY EXPERIENCE}

- Adobe Acrobat

- Blackboard(C Academic Suite

- Microsoft Office: Excel, PowerPoint, Publisher, Word

- Plone Web Design

- Statistical Package for the Social Sciences (SPSS) 


\section{REFERENCES}

Mordean Taylor-Archer, Ph.D.

Vice Provost for Diversity

University of Louisville

209 Grawemeyer Hall

Louisville, KY 40292

(502) 852-8357

m()raylol a louisville.edu

Michael J. Cuyjet, Ed.D.

Professor - Educational \& Counseling Psychology

College of Education and Human Development

University of Louisville

Louisville, KY 40292

(502) 852-2364

cuyjeta. louisville.edu

Tom Jackson, Jr., Ed.D.

Vice President for Student Affairs and President of ACPA - College Student

Educators, International

University of Louisville

Student Activities Center - W302

Louisville, KY 40292

(502) 852-6933

tom.jackson a louisville.edu

J. Michael Mardis, Ph.D.

Associate Vice President for Student Affairs and Dean of Students

University of Louisville

Student Activities Center - W301

Louisville, KY 40292

(502) $852-5787$

mjmard01 a louisville.edu

Pam Nessle Curtis, M.Ed.

Director

Office of Civic Engagement, Leadership and Service

University of Louisville

Student Activities Center - W301

Louisville, KY 40292

(502) 852-0242

pncurt() la louisville.edu 